NASA/TM-2000-209891, Vol. 208

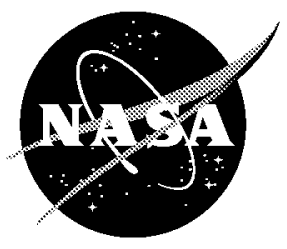

Technical Report Series on the Boreal Ecosystem-Atmosphere Study (BOREAS)

Forrest G. Hall and K. Huemmrich, Editors

Volume 208

BOREAS TF-10 NSA-YJP Tower Flux, Meteorological, and Porometry Data

J. Harry McCaughey and Laura Liblik

Queen's University, Kingston, Ontario

National Aeronautics and

Space Administration

Goddard Space Flight Center

Greenbelt, Maryland 20771 
The NASA STI Program Office ... in Profile

Since its founding, NASA has been dedicated to the advancement of aeronautics and space science. The NASA Scientific and Technical Information (STI) Program Office plays a key part in helping NASA maintain this important role.

The NASA STI Program Office is operated by Langley Research Center, the lead center for NASA's scientific and technical information. The NASA STI Program Office provides access to the NASA STI Database, the largest collection of aeronautical and space science STI in the world. The Program Office is also NASA's institutional mechanism for disseminating the results of its research and development activities. These results are published by NASA in the NASA STI Report Series, which includes the following report types:

- TECHNICAL PUBLICATION. Reports of completed research or a major significant phase of research that present the results of NASA programs and include extensive data or theoretical analysis. Includes compilations of significant scientific and technical data and information deemed to be of continuing reference value. NASA's counterpart of peer-reviewed formal professional papers but has less stringent limitations on manuscript length and extent of graphic presentations.

- TECHNICAL MEMORANDUM. Scientific and technical findings that are preliminary or of specialized interest, e.g., quick release reports, working papers, and bibliographies that contain minimal annotation. Does not contain extensive analysis.

- CONTRACTOR REPORT. Scientific and technical findings by NASA-sponsored contractors and grantees.
- CONFERENCE PUBLICATION. Collected papers from scientific and technical conferences, symposia, seminars, or other meetings sponsored or cosponsored by NASA.

- SPECIAL PUBLICATION. Scientific, technical, or historical information from NASA programs, projects, and mission, often concerned with subjects having substantial public interest.

- TECHNICAL TRANSLATION. English-language translations of foreign scientific and technical material pertinent to NASA's mission.

Specialized services that complement the STI Program Office's diverse offerings include creating custom thesauri, building customized databases, organizing and publishing research results ... even providing videos.

For more information about the NASA STI Program Office, see the following:

- Access the NASA STI Program Home Page at http://www.sti.nasa.gov/STI-homepage.html

- E-mail your question via the Internet to help@sti.nasa.gov

- Fax your question to the NASA Access Help Desk at (301) 621-0134

- Telephone the NASA Access Help Desk at (301) 621-0390

- Write to:

NASA Access Help Desk

NASA Center for AeroSpace Information 7121 Standard Drive Hanover, MD 21076-1320 
NASA/TM-2000-209891, Vol. 208

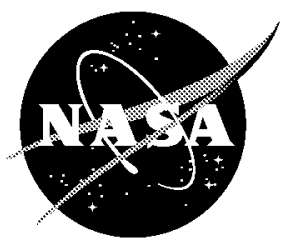

Technical Report Series on the Boreal Ecosystem-Atmosphere Study (BOREAS)

Forrest G. Hall and K. Huemmrich, Editors

Volume 208

BOREAS TF-10 NSA-YJP Tower Flux, Meteorological, and Porometry Data

J. Harry McCaughey and Laura Liblik

Queen's University, Kingston, Ontario

National Aeronautics and

Space Administration

Goddard Space Flight Center

Greenbelt, Maryland 20771 


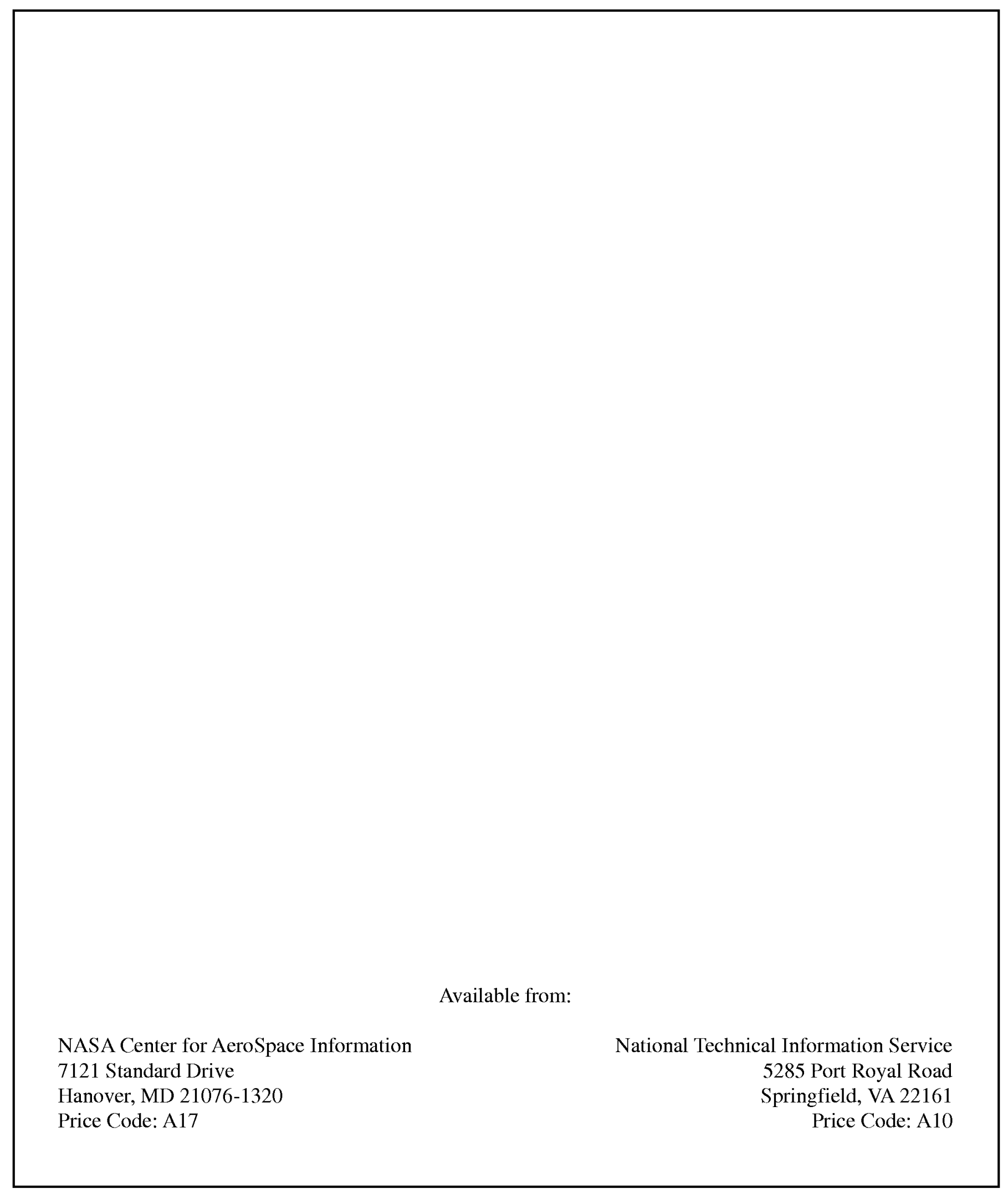




\title{
BOREAS TF-10 NSA-YJP Tower Flux, Meteorological, and Porometry Data
}

\author{
J. Harry McCaughey, Laura Liblik
}

\section{Summary}

The BOREAS TF-10 team collected tower flux and meteorological data at two sites, a fen and a young jack pine forest, near Thompson, Manitoba, Canada, as part of BOREAS. A preliminary data set was assembled in August 1993 while field testing the instrument packages, and at both sites data were collected from 15-Aug to 31-Aug. The main experimental period was in 1994, when continuous data were collected from the young jack pine site from 23-May to 20-Sep. Upon examination of the 1994 data set, it became clear that the behavior of the heat, water, and carbon dioxide fluxes throughout the whole growing season was an important scientific question, and that the 1994 data record was not sufficiently long to capture the character of the seasonal behavior of the fluxes. Thus, the young jack pine site was operated from 08-May to 07-Nov in 1996 in order to collect data from spring melt to autumn freeze-up. All variables are presented as 30-minute averages. Supporting data were also collected to describe the surface's state and to provide the information, in association with the flux data, to build SVAT models. For the young jack pine site, these supporting data included stomatal conductance measurements. The data are stored in tabular ASCII files.

\section{Table of Contents}

1) Data Set Overview

2) Investigator(s)

3) Theory of Measurements

4) Equipment

5) Data Acquisition Methods

6) Observations

7) Data Description

8) Data Organization

9) Data Manipulations

10) Errors

11) Notes

12) Application of the Data Set

13) Future Modifications and Plans

14) Software

15) Data Access

16) Output Products and Availability

17) References

18) Glossary of Terms

19) List of Acronyms

20) Document Information 


\title{
1. Data Set Overview
}

\author{
1.1 Data Set Identification \\ BOREAS TF-10 NSA-OJP Tower Flux, Meteorological, and Porometry Data
}

\subsection{Data Set Introduction}

The meteorological data collected from the fen and Young Jack Pine (YJP) towers represent, in some sense, polar opposites of the range of surface climate conditions expected in the boreal forest. The fen is normally characterized by abundant water close to, or located at, the surface, whereas the YJP site can be one of the driest surfaces in the boreal forest. Jack pine generally inhabit well-drained, sandy soils where, in the absence of regular precipitation, a significant water deficit can develop. The data presented here bear out the contrast in the surface climate conditions experienced by the two sites. For example, in the driest periods in the summer of 1994 it was common to measure mid-afternoon Bowen ratios in the range of 10 to 15 , leading to the characterization of the site as a "Green Desert"; at the same time, the typical Bowen ratio at the fen seldom exceeded 1.0, and was usually closer to 0.8 .

The YJP site can be fairly described as a fast response surface in that there were major and rapid changes in flux behavior, especially in evaporation, as the site was wetted or when it dried down. No such behavior could be ascribed to the fen because of the steadier supply of surface water.

\subsection{Objective/Purpose}

This project is concerned with the spatial heterogeneity of surface energy fluxes in the northern boreal forest. The study was designed to compare surface radiation, energy, water, $\mathrm{CO}_{2}$ fluxes, and their biophysical controls at both wetland and upland forest sites within the northern boreal forest. Specific objectives of the study were as follows:

- To quantify the differences between surface-atmosphere interactions between the sites.

- To compare hydrological estimates of basin evaporation to modeled water loss values (computed from knowledge of the vegetational composition of homogeneous landscape units and their ecotones, and the functional response of these units to climatic forcing.

- To provide continuous tower fluxes of water, sensible heat, and $\mathrm{CO}_{2}$ in support of the development of Soil-Vegetation-Atmosphere-Transfer (SVAT) models at the stand and regional scales.

Data for this study were collected at two sites in the BOReal Ecosystem-Atmosphere Study (BOREAS) Northern Study Area (NSA) at Thompson, Manitoba: a young jack pine forest (YJP), and a fen wetland.

\subsection{Summary of Parameters}

The following micrometeorological variables were measured at the YJP site: net radiation, incoming and reflected solar radiation, incoming and outgoing longwave radiation, incoming and reflected photosynthetic photon flux density (PPFD), wind speed, wind direction, wet- and dry-bulb temperature, biomass temperature, soil temperature, soil heat flux, sensible heat flux, latent heat flux, $\mathrm{CO}_{2}$ flux, rainfall, and soil moisture.

In addition, the following biophysical variables were measured: stomatal conductance, leaf temperature, leaf area index (LAI), tree height $(\mathrm{h})$, diameter at breast height (dbh), and tree stem density. 


\subsection{Discussion}

Data collected for this study can be divided into two primary groups: micrometeorological measurements and biophysical measurements.

Micrometeorological Measurements:

The primary objective of this project was to develop a full suite of radiation, energy, and $\mathrm{CO}_{2}$ flux measurements for the two flux tower sites. At both towers, identical instrumentation was used for data collection. The measurement systems used can be briefly summarized as follows:

- $\quad$ Radiation balance fluxes, including PPFD, were monitored using standard instrumentation mounted near the top of the flux towers.

- Soil heat flux $(\mathrm{G})$ was measured using soil heat flux plates combined with calorimetric calculations of heat storage (see Sections 4.1 and 9.1).

- Convective fluxes of latent (LE) and sensible (H) heat were measured directly via the eddy covariance technique.

- $\quad$ Net $\mathrm{CO}_{2}$ flux ( $\left.\mathrm{Fe}_{\mathrm{CO} 2}\right)$ was measured using an eddy covariance system; this system consisted of a single-axis sonic anemometer and a fast-response infrared $\mathrm{CO}_{2}$ gas analyzer. The air intake was located at the same level as the sonic anemometer, and air was drawn down to the gas analyzer at the base of the tower. Lag times between the gas analyzer signal and the sonic anemometer signal were included in the online processing of the flux; offline processing included heat flux density corrections (Webb et al., 1980) and $\mathrm{CO}_{2}$ storage in the air layer between the intake and the surface.

Flux data were supported with accompanying meteorological measurements. At each site, profiles of wind speed, temperature, and humidity were measured in the lower boundary layer. In addition, soil and biomass temperatures, wind direction, and rainfall were monitored.

Tower data at both sites were collected from 15-Aug to 31-Aug-1993. In 1994, the YJP tower was operational almost continuously from 23-May to 30-Sep, and the fen tower was operational from 08-Apr to 23-Sep. Before 01-Jun, only convective energy fluxes and the supporting profile data were measured at the fen to support an associated hydrological study of snowmelt in an adjoining basin during the Focused Field Campaign (FFC) from 12-Apr to 02-May. $\mathrm{CO}_{2}$ flux data came online at the fen by 01-Jun-1994. In 1995, only the fen was operational to support the continuation of the hydrological experiment; data were collected from the tower from 15-Apr to 10-Jun. In 1996, the measurement period at the YJP extended from 08-May to 07-Nov; at the fen data were collected from 29-Apr to 05-Nov.

\section{Biophysical Measurements}

The micrometeorological data at YJP were supplemented with biophysical data collected from areas surrounding the tower. These measurements included (h), (dbh), (LAI), and stomatal conductance of the coniferous overstory. The measurements, combined with the tower data, represent the basis for intersite comparisons of surface-atmosphere interactions.

\subsection{Related Data Sets}

BOREAS AFM-07 SRC Surface Meteorological Data

BOREAS HYD-01 Volumetric Soil Moisture Data

BOREAS TF-10 NSA-Fen Tower Flux and Meteorological Data

BOREAS TF-04 SSA-YJP Tower Flux and Meteorological Data 


\section{Investigator(s)}

\subsection{Investigator(s) Name and Title}

Dr. J. Harry McCaughey (Principal Investigator (PI) at YJP)

Department of Geography

Queen's University

Dr. Dennis E. Jelinski (PI at Fen)

Department of Geography

Queen's University

Two PIs were associated with the Tower Flux (TF)-10 group: Harry McCaughey and Dennis Jelinski. Harry McCaughey oversaw the tower fluxes at both the YJP and the fen, and Dennis Jelinski was responsible for the vegetation work at the fen. Peter Lafleur shared responsibility for measurements at both sites. In addition, a large group of very competent graduate students, field assistants, and technicians contributed to the overall success of the work. Special mention goes to David Joiner and Paul Bartlett (Queen's University). David developed and built the $\mathrm{CO}_{2}$ measurement system. Paul started work as a technician in the group and later stayed at Queen's as a doctoral student. He made many contributions, but special mention must go to his work on assembling and organizing the deployment of equipment in 1993 and to his porometry work at the YJP site in 1994 and 1996. Andrew Costello, Queen's, helped in the field setup in 1993 and did most of the initial stand measurements on the YJP canopy. He was assisted by Blair Mantha from Trent. Bob Metcalfe, Queen's and Trent, worked on an associated hydrology project focused upon the feeder basin north of the fen. He was supervised jointly by Jim Buttle, Trent University, and Harry McCaughey. Mike Skarupa and Greg Bryant, Trent, assisted in the data collection efforts at both sites. Kristan Boudreau was an outstanding field assistant, and she performed excellent work in 1994 in all facets of the experiments at both sites. Bruce Robertson and Derek Mueller were able field assistants in 1996. Finally, a special thanks to Laura Liblik, who did the majority of the work associated with the preparation of the data set before its submission to the BOREAS Information System (BORIS). Her attention to detail, her writing, and her editorial skills are much appreciated.

\subsection{Title of Investigation}

Surface Energy and Water Balances of Forest and Wetland Subsystems in the Boreal Forest Surface Atmosphere Links and Ecological Controls

\subsection{Contact Information}

\section{Contact 1:}

Dr. J. Harry McCaughey

Dept. of Geography

Queen's University

Kingston, ON

CANADA

K7L 3N6

(613) 545-6035

(613) 545-6122 (fax)

mccaughe@post.queensu.ca 
Contact 2:

Dr. Peter M. Lafleur

Dept. of Geography

Trent University

Peterborough, ON

CANADA

K9J 7B8

(705) 748-1487

(705) 748-1205 (fax)

plafleur@trentu.ca

\section{Contact 3:}

Dr. Dennis Jelinski

School of Environmental Studies

Queen's University

Kingston, Ontario

CANADA

K7L 3N6

(613) 545-6875

(613) 545-6617 (fax)

dj4@qsilver.queensu.ca

\section{Contact 4:}

K. Fred Huemmrich

University of Maryland

Code 923

NASA GSFC

Greenbelt, MD 20771

(301) 286-4862

(301) 286-0239 (fax)

Karl.Huemmrich@gsfc.nasa.gov

\section{Theory of Measurements}

Many of the individual measurements made during the study involved routinely collected data obtained with a single instrument (e.g., incoming solar radiation and temperature measurement with thermocouples). Such measurements represent standard data collection techniques, and specific, detailed elaboration is not provided in this report. However, there is discussion of some limited aspects of these routine measurements where such detail is required for a complete understanding. Readers are referred to the manufacturers' specifications for details on the theory of measurement and operation of individual instruments.

The following section describes only the measurement method used for the fluxes.

Sensible (H) and latent (LE) heat fluxes and the net flux of $\mathrm{CO}_{2}\left(\mathrm{Fe}_{\mathrm{CO} 2}\right)$ (net ecosystem exchange, NEE) were found using the eddy covariance technique (Campbell and Unsworth, 1979; Tanner et al., 1993). Fluxes are computed as the time-averaged product of the fluctuations of vertical wind velocity $\left(w^{\prime}\right)$ and fluctuations of the appropriate scalar (the covariance). For example, fluctuations of temperatures $\left(\mathrm{T}^{\prime}\right)$ for $\mathrm{H}$, water vapor density $\left(\mathrm{q}^{\prime}\right)$ for $\mathrm{LE}$, and $\mathrm{CO}_{2}$ concentration $\left(\mathrm{C}^{\prime}\right)$ for $\mathrm{Fe}_{\mathrm{CO}}$, give:

$$
\begin{aligned}
& \mathrm{LE}=\mathrm{L}<\mathrm{w}^{\prime} \mathrm{q}^{\prime}> \\
& \mathrm{H}=\text { rho } \mathrm{Cp}<\mathrm{w}^{\prime} \mathrm{T}^{\prime}
\end{aligned}
$$




$$
\mathrm{FeCO}_{2}=\operatorname{rho}(\mathrm{c})<\mathrm{w}^{\prime} \mathrm{C}^{\prime}
$$

where $\mathrm{L}$ is the latent heat of vaporization of water $(\mathrm{J} / \mathrm{kg})$, rho is the density of air $\left(\mathrm{kg} / \mathrm{m}^{3}\right), \mathrm{Cp}$ is the specific heat of air at constant pressure $\left(\mathrm{J} / \mathrm{kg} /{ }^{\circ} \mathrm{C}\right)$, rho(c) is the density of $\mathrm{CO}_{2}\left(\mathrm{~kg} / \mathrm{m}^{3}\right)$, and the $<>$ symbol represents a time-averaged product or covariance.

In practical terms, the eddy covariance technique is very sensitive to site conditions and instrument response. For one-dimensional measurements, the site is assumed to be perfectly flat. This eliminates net positive or negative horizontal advection. Ideally, the response time of the instrument should be fast enough to monitor the complete spectrum of frequencies occurring in the turbulent flow. However, the total response is determined by the response time of the individual sensor, the instrument size and orientation, and the capacity to monitor the signal. Where two sensors are required, one to monitor $\mathrm{w}^{\prime}$ and the other to monitor the appropriate scalar variable ( $\mathrm{T}^{\prime}, \mathrm{q}^{\prime}$, or $\left.\mathrm{C}^{\prime}\right)$, then separation of the instruments in horizontal space introduces a possible error of mismatched frequencies sensed by the two systems. It is desirable to have the instruments as close together as possible; however, this can result in distortion of the wind field of one instrument by the presence of the other. A compromise is needed to overcome these two opposing problems, and sensors are typically placed $0.30 \mathrm{~m}$ to $0.40 \mathrm{~m}$ apart. Given the current status of data logging capacity, eddy covariance instruments are usually sampled at a rate of $10 \mathrm{~Hz}$ or greater.

\section{Equipment}

\subsection{Sensor/Instrument Description}

\section{Micrometeorological Instruments}

Meteorological and flux data at both sites were collected with similar instrumentation. Instruments were mounted on towers as described in Section 4.1.2. A listing of instrumentation follows.

- $\quad$ Net radiation was measured with a net pyrradiometer (model CN-1 Middleton, Carter-Scott Design, Victoria, Australia) aspirated with dry nitrogen gas.

- Incoming and outgoing solar radiation were measured with pyranometers (model 8-48, Eppley Laboratories, Inc., Newport, RI, USA).

- $\quad$ Outgoing longwave radiation was measured with a pyrgeometer (model PIR, Eppley Laboratories, Inc., Newport, RI, USA).

- Incoming and outgoing PPFD were measured with quantum sensors (model LI-Q190SA, LI-COR, Inc., Lincoln, NE, USA).

- Absolute wet- and dry-bulb temperatures were measured with psychrometers constructed from PVC tubing covered with reflective tape. Ventilation was supplied by a 12 -volt DC fan that gave an air flow between 4-6 m/s across the sensor. The sensors were single-junction 24 a.w.g. copper-constantan thermocouples sealed with epoxy in stainless steel tubing $(250 \mathrm{~mm}$ in length, $3.5 \mathrm{~mm}$ in diameter). The wet-bulbs were covered with cotton wicking to a length of $150 \mathrm{~mm}$.

- Wind speeds were measured with 3-cup anemometers (model 12102, R.M. Young Co., Traverse City, MI, USA). The anemometers contain a DC generator that produces an analog signal proportional to wind speed.

- Wind direction was measured with a vane (model 12302, R.M. Young Co., Traverse City, MI, USA) containing a potentiometer that designates direction as proportional to the voltage output.

- $\quad$ Rainfall was measured with tipping bucket gauges (YJP: model P501, Weathermeasure Corporation, Sacramento, CA, USA; Fen: model TE252M, Campbell Scientific, Inc., Logan, UT, USA).

- Soil temperatures were measured with single-junction copper-constantan thermocouples (24 a.w.g.) fixed into a 3.18-cm-diameter wooden dowel inserted into the soil. Two soil temperature rods were installed at each site in order to sample soil temperatures below different cover types. 
At YJP, one rod was placed $14 \mathrm{~m}$ from the tower at $323^{\circ}$ among young jack pine trees 1.5 $\mathrm{m}$ in height. In 1993, temperatures only from 1-, 5-, and 10-cm depths are available from the north site. Temperatures from 1-, 5-, 10-, 25-, 50-, and 75-cm depths are available from this site in 1994 . The second rod was placed $6.7 \mathrm{~m}$ to the west of the tower $\left(253^{\circ}\right)$ among trees 2-3 $\mathrm{m}$ in height. Temperatures at the west site were recorded at depths of $1,5,10,25,50,75$, and $100 \mathrm{~cm}$ in both years.

- $\quad$ Soil heat flux was measured at each site with two soil heat flux plates (model HFT-3, Radiation Energy Balance Systems, Inc. (REBS), Seattle, WA, USA). Values from these instruments, combined with the soil temperature profiles, were used to calculate soil heat flux at each site as follows. At YJP, measurements were obtained at a depth of $10 \mathrm{~cm}$ below the soil surface. Heat storage in the soil layer above the heat flux plates was calculated using temperatures measured at the 1-cm, 5-cm and 10-cm levels (see Section 9.1).

- All tower variables (except eddy covariance) were recorded on data loggers (model CR7X, Campbell Scientific, Inc., Logan, UT, USA). The eddy covariance signals were recorded on data loggers (model 21X, Campbell Scientific, Inc., Logan, UT, USA).

- $\quad \mathrm{CO}_{2}$ concentration and flux densities were measured with a system designed at Queen's University by D. Joiner. It consisted of a single-axis sonic anemometer (mentioned above) and a fast response infrared gas analyzer (IRGA) (model LI-6252, LI-COR, Inc., Lincoln, NE, USA).

Air is drawn by an AC pump from the intake of a tube (1/4" i.d. Bev-a-line IV) situated on the sonic anemometer arm to the IRGA at the base of the tower. The flow is split before reaching the IRGA, and the line to the IRGA passes through a fine particle filter. Air from the IRGA passes a pressure transducer (model PX142, Omega Engineering, Stamford, CT, USA) and a mass flow sensor (model 5860E, Brooks Instruments Division, Hatfield, PA, USA).

Cross-correlation analysis was used to determine the travel time of the air from the tube inlet to the gas analyzer. The flux density of carbon dioxide was then determined with the eddy covariance technique by finding the covariance of the $10-\mathrm{Hz}$ direct output from the gas analyzer with time-lagged vertical wind velocity measured with a one-dimensional sonic anemometer (model CA-27, Campbell Scientific, Inc., Logan, UT, USA).

The direct output from the IRGA was calibrated once a day using calibration gases flowing through the gas analyzer at the same pressure as that of the air down the tower. These field calibrations, linear over the range of ambient carbon dioxide concentrations and unchanging with temperature, were constantly corrected for pressure changes recorded with the gauge pressure transducer.

Data processing and storage were done on data loggers (model 21X, Campbell Scientific, Inc., Logan, UT, USA), using the covariance at $10 \mathrm{~Hz}$ data and a 15-minute averaging subinterval. The $\mathrm{CO}_{2}$ flux data were corrected for fluctuations of temperature and water vapor density during postseasonal analysis (Webb et al., 1980).

Absolute concentrations of $\mathrm{CO}_{2}$ were calculated using the factory calibration equation supplied with the LI-6252 and were corrected for air pressure fluctuations. Station values for air pressure were obtained from the Thompson airport and entered daily as a constant into the data loggers. Daily field calibration of the IRGA showed that the absolute concentration may exhibit a drift of up to 3 ppmv over a 24-hour period.

Final $\mathrm{CO}_{2}$ flux density values combine the contributions from both the eddy flux and the changes in $\mathrm{CO}_{2}$ storage for the volume of air beneath the eddy covariance instruments. 


\section{Biophysical Instruments}

- Biomass temperatures at YJP were measured with copper-constantan parallel thermocouples (30 a.w.g.) embedded directly into the boles. Thermojunctions were placed at the approximate center of the biomass volume (1/3 of the way up the tree and 1/3 of the radius into the boles) (McCaughey and Saxton, 1988; Saxton and McCaughey, 1988). Four parallel thermocouples, each one consisting of three thermojunctions wired in parallel, were used. One set was placed in three large trees $(\sim 5.0 \mathrm{~m}$ in height $) 12.6 \mathrm{~m}$ from the tower at $185^{\circ}$, the second set was placed in three medium trees $(\sim 2.5 \mathrm{~m}$ in height $) 9.6 \mathrm{~m}$ from the tower at $218^{\circ}$, the third set was placed in three small trees $\left(\sim 1.5 \mathrm{~m}\right.$ in height) $14 \mathrm{~m}$ from the tower at $230^{\circ}$, and the fourth set was placed in three small trees $(\sim 1.5 \mathrm{~m}$ in height) near the northern soil heat flux plate at $323^{\circ}$.

- Leaf stomatal conductance was measured with a steady state diffusion porometer (model LI-1600, LI-COR, Inc., Lincoln, NE, USA). Measurements on jack pine shoots required that the sensing head was fitted with a cylindrical chamber (model LI-1600-07, LI-COR, Inc., Lincoln, NE, USA).

- $\quad$ Projected LAI was measured with an optical Plant Canopy Analyzer (model LAI-2000, LI-COR, Inc., Lincoln, NE, USA).

\subsubsection{Collection Environment}

The instruments were operated mainly under summer conditions with maximum temperatures around $35^{\circ} \mathrm{C}$. Data were collected over the growing season of 1994 and the spring through fall/winter of 1996. In the spring and fall/winter seasons, more extreme low temperatures were experienced. During these periods, the environment was more severe, and freezing temperatures were common; the lowest temperatures experienced were around $-30^{\circ} \mathrm{C}$.

\subsubsection{Source/Platform}

The towers erected at YJP and fen were 12-meter-tall triangular communications type, guyed on three sides, and anchored into the mineral soil. At both sites, all sensors were mounted on the towers with fixed aluminum ( $3.18 \mathrm{~cm}$ diameter) extension arms, with the exception of the eddy covariance equipment, which was mounted on a swivel system allowing for orientation of the instruments into the wind. Sensor height above the surface, distance from the tower, and orientation (degrees from magnetic north) are given for the YJP in Table 1.

Biomass temperatures were measured at two sites in the vicinity of the flux tower at YJP. One site, directly west of the tower, was named the "west site," and the other, located north of the tower, was named the "north site." Biomass temperature sensors consisted of three-junction parallel thermocouples, and one thermojunction was inserted into three separate trees in three chosen height categories (small, medium, and large) at the west site. At the north site, only small trees existed. Each thermojunction was inserted into the bole to a depth of one-third the radius depth at a height of one-third the height of the tree (see Section 4.1). Table 2 shows the height and dbh for all trees sampled at the two measurement sites. 
Table 1. Sensor heights on the flux tower at the YJP in 1993, 1994, and 1996. The orientation of the arm holding the sensor is given in degrees measured from magnetic north, and the distance $(\mathrm{m})$ from the tower is given. The symbol n/a, indicating "not applicable," means that no measurements were taken. The orientation of the arm holding the sonic anemometer and the krypton hygrometer was variable on a swivel mount that could be set anywhere from $120^{\circ}$ from magnetic north through $360^{\circ}$ to $25^{\circ}$ from magnetic north.

Table 1. Sensor heights on the flux tower at the YJP in 1993, 1994, and 1996.

\begin{tabular}{|c|c|c|c|c|c|}
\hline \multirow[t]{2}{*}{ Variable [Sensor] } & \multicolumn{3}{|c|}{ Height (m) } & \multirow{2}{*}{$\begin{array}{c}\text { Distance } \\
\text { (m) }\end{array}$} & \multirow{2}{*}{$\begin{array}{l}\text { Orientation } \\
\text { (degrees) }\end{array}$} \\
\hline & 1993 & 1994 & 1996 & & \\
\hline Incoming Solar Radiation [pyranometer] & 11.82 & 11.82 & 11.82 & 1.5 & 143 \\
\hline Outgoing Solar Radiation [pyranometer] & 11.58 & 11.58 & 11.58 & 1.5 & 143 \\
\hline Outgoing Longwave Radiation [pyranometer] & 11.38 & 11.38 & 11.38 & 1.5 & 203 \\
\hline Net Radiation [net pyrradiometer] & 11.70 & 11.70 & 11.70 & 2.3 & 133 \\
\hline Incoming PPFD [quantum sensor] & 11.54 & 11.54 & 11.54 & 1.5 & 213 \\
\hline Outgoing PPFD [quantum sensor] & 11.36 & 11.36 & 11.36 & 1.5 & 213 \\
\hline \multicolumn{6}{|l|}{ Wet- and Dry-bulb Temperatures [thermocouples] } \\
\hline $\begin{array}{l}\text { Canopy } \\
\text { Level } 1 \\
\text { Level } 2 \\
\text { Level } 3 \\
\text { Level } 4 \\
\text { Level } 5\end{array}$ & $\begin{array}{l}1.60 \\
5.10 \\
6.10 \\
7.10 \\
9.10 \\
11.10\end{array}$ & $\begin{array}{l}1.60 \\
5.17 \\
6.10 \\
7.15 \\
7.70 \\
10.30\end{array}$ & $\begin{array}{l}\mathrm{n} / \mathrm{a} \\
5.17 \\
\mathrm{n} / \mathrm{a} \\
\mathrm{n} / \mathrm{a} \\
7.70 \\
10.30\end{array}$ & $\begin{array}{l}1.5 \\
0.8 \\
0.8 \\
0.8 \\
0.8 \\
0.8\end{array}$ & $\begin{array}{l}233 \\
233 \\
233 \\
233 \\
233 \\
233\end{array}$ \\
\hline Wind Direction [vane] & 11.10 & 10.30 & 10.30 & 1.8 & 323 \\
\hline \multicolumn{6}{|l|}{ Wind Speed [cup anemometer] } \\
\hline $\begin{array}{l}\text { Level } 1 \\
\text { Level } 2 \\
\text { Level } 3 \\
\text { Level } 4 \\
\text { Level } 5\end{array}$ & $\begin{array}{l}5.10 \\
6.10 \\
7.10 \\
9.10 \\
11.10\end{array}$ & $\begin{array}{l}5.17 \\
6.10 \\
7.15 \\
7.70 \\
10.30\end{array}$ & $\begin{array}{l}5.17 \\
\text { n/a } \\
\text { n/a } \\
7.70 \\
10.30\end{array}$ & $\begin{array}{l}1.5 \\
1.5 \\
1.5 \\
1.5 \\
1.5\end{array}$ & $\begin{array}{l}323 \\
323 \\
323 \\
323 \\
323\end{array}$ \\
\hline $\begin{array}{l}\text { Vertical Wind Speed } \\
\text { [sonic anemometer] }\end{array}$ & 9.35 & 9.00 & 9.00 & 1.0 & $120-360-25$ \\
\hline Vapor Density [krypton hygrometer] & 9.35 & 9.00 & 9.00 & 1.0 & $120-360-25$ \\
\hline Relative Humidity [T/RH sensor] & $\mathrm{n} / \mathrm{a}$ & $\mathrm{n} / \mathrm{a}$ & 10.30 & 0.2 & 232 \\
\hline
\end{tabular}


Table 2. Location of biomass temperature sensors at the west and north measurement sites at YJP. The same locations were used in all three experimental years: 1993, 1994, and 1996. $\mathrm{h}$ is tree height (m) and $\mathrm{dbh}(\mathrm{m})$ is the diameter at breast height. At the west site, three sizes of trees were sampled: small, medium, and large. Three trees in each size range were sampled with three-junction parallel thermocouples, and one thermojunction was located in each tree.

Table 2. Location of biomass temperature sensors at the west and north measurement sites at YJP.

\begin{tabular}{||c|l|l||}
\hline \hline \multirow{3}{*}{ West site: } & $\mathbf{h}(\mathbf{m})$ & $\mathbf{d b h}(\mathbf{m})$ \\
\hline \multirow{3}{*}{ small trees } & & \\
\hline \multirow{3}{*}{ medium trees } & 1.45 & 0.0045 \\
\cline { 2 - 4 } & 1.20 & $<0.0030$ \\
\cline { 2 - 4 } & 1.75 & 0.0070 \\
\hline \multirow{3}{*}{ large trees } & 2.70 & 0.0210 \\
\cline { 2 - 4 } & 2.35 & 0.0160 \\
\cline { 2 - 3 } & 2.90 & 0.0190 \\
\hline \multirow{2}{*}{ North site: } & 5.80 & 0.0600 \\
\hline \multirow{2}{*}{ small trees } & 4.20 & 0.0420 \\
\cline { 2 - 4 } & 4.30 & 0.0430 \\
\hline
\end{tabular}

\subsubsection{Source/Platform Mission Objectives}

The primary objective of the team was to collect and analyze the micrometeorological data from the two flux towers on a continuous basis during all of the experiments. In addition, data were assembled to characterize the surface's state in terms of LAI, type, distribution, height, and density of the vegetation, and stomatal conductance at the YJP only. Subsidiary experiments in 1996 at the YJP measured soil evaporation, throughfall, and rainfall interception of the canopy.

\subsubsection{Key Variables}

The key meteorological variables are incoming and reflected solar radiation, PPFD, outgoing terrestrial radiation, net radiation, wet- and dry-bulb temperatures, wind speed, wind direction, latent and sensible heat fluxes, net $\mathrm{CO}_{2}$ flux, soil temperature, biomass temperature, rainfall, and water level. The key biophysical variables are LAI, leaf stomatal conductance, $h$, stem density, and dbh. 


\subsubsection{Principles of Operation}

\section{Sonic Anemometer}

The sonic anemometer system (model CA27, Campbell Scientific ,Inc., Logan, UT, USA) obtains the velocity fluctuations of vertical wind speed from the measured Doppler shift induced by the wind velocity on an ultrasonic frequency pulse broadcast across a $10-\mathrm{cm}$ path. The effect of temperature on sound velocity is eliminated by determining the Doppler frequency from the difference between forward and reverse path observations. Electronic processing of the signals from the ultrasonic transducers produces a real-time analog output voltage in the range $\pm 4.0 \mathrm{~V} \mathrm{DC}$.

Air temperature fluctuations for the Campbell Scientific eddy covariance system are measured with a fine-wire thermocouple mounted about $4 \mathrm{~cm}$ from the anemometer sound path. The thermocouple output is amplified to a $\pm 4.0 \mathrm{~V} \mathrm{DC}$ signal. The thermocouple temperature is referenced to the instrument case, which is thermally lagged and responds slowly to temperature changes.

\section{Absorption Hygrometer}

The absorption hygrometer (model KH20, Campbell Scientific, Inc., Logan, UT, USA) measures the ultraviolet light transmission across a nominal $1-\mathrm{cm}$ path in a water vapor absorption band corresponding to a krypton emission line (Campbell and Tanner, 1985). Instrument response is at least sufficient to resolve fluctuations of $80 \mathrm{~Hz}$. The instrument output is a voltage in the range 0 to $4 \mathrm{~V} \mathrm{DC}$. The signal strength may be subject to gradual diminution as a result of scale accumulation on the optical surfaces.

\section{Longwave Radiation Measurement}

The sensing surface of a pyrgeometer (model PIR, Eppley Laboratories, Inc., Newport, RI, USA) consists of a differential thermopile that measures net longwave radiation fluxes between itself and the sky or ground (depending on orientation). The dome of the pyrgeometer is composed of silicon with a vacuum-deposited interference filter on its inner surface. The composite dome transmission shows an abrupt transition between approximately 3 and 4 micrometers from complete opaqueness to maximum transparency.

The outgoing longwave radiation from the instrument is calculated using the temperature of its blackbody cavity and the Stefan-Boltzmann equation. This flux is added to the thermopile signal to get the total incoming flux. The temperature of the blackbody radiator can be measured using a thermistor.

The thermopile output signal is measured as a single-ended voltage in the Campbell Scientific CR7X data logger. The case thermistor is not polarized, and is connected between an analog input channel and ground. A 1000-ohm resistor is connected between the analog input channel and a switched analog output channel (725 card). The thermistor is excited with $1350 \mathrm{mV}$ across the 1000 -ohm resistor, and the thermistor (pyrgeometer) temperature is calculated as a function of the thermistor voltage (a function of its resistance). This method corresponds to the protocol for using the Eppley pyrgeometer proposed by the National Atmospheric Radiation Center (NARC). This method does not use the pyrgeometer's battery-powered temperature compensation circuit, and no battery should be installed when using the pyrgeometer in this manner.

\section{Plant Canopy Analyzer}

The plant canopy analyzer (model LAI-2000, LI-COR, Inc., Lincoln, NE, USA) is composed of a LAI-2070 control unit and a LAI-2050 sensor head. The sensor head projects the image of its nearly hemispheric view onto five detectors arranged in concentric rings (approximately 0-13, 16-28, 32-43, 47-58, and 61-74 degrees of zenith angle). Radiation above $490 \mathrm{~nm}$ is rejected. Data are stored and processed in the control unit. LAI is calculated by the reduction in light intensity measured between an above-canopy reading and a below-canopy reading. Normally, simultaneous measurements of these two quantities can be achieved with two sensors connected to the same control unit. Where this is not possible, two sensors and separate control units can be used and the data later integrated, or a single sensor and control unit is used for above- and below-canopy measurements. The LAI value obtained from the LAI-2000 relates directly to projected leaf area; corrections can be applied for clumping within the canopy or conversion to total surface area. For further information, consult the LAI-2000 plant canopy analyzer instruction manual. 


\section{Diffusion Porometer}

Leaf stomatal conductance was measured with a steady state porometer (model LI-1600, LI-COR, Inc., Lincoln, NE, USA). Leaf samples are placed in contact with a cuvette by clamping a portion of the leaf over an aperture in the cuvette wall. The relative humidity in the cuvette is held constant by flowing dry air directly into the cuvette at an appropriate rate.

Diffusive resistance/conductance is determined by measuring the flow required to obtain a balance between the flux of water transpired from the leaf and the flow of moist air out of the cuvette at a set humidity (usually ambient). The instrument also measures leaf temperature, cuvette temperature, and transpiration rate. For measurements of coniferous needles, the LI-1600-07 cylindrical chamber is used. This allows a small portion of a branch containing needles to be inserted into the cuvette. The LI-1600 is also outfitted with a quantum sensor for instantaneous measurement of PPFD.

\subsubsection{Sensor/Instrument Measurement Geometry}

See Table 2 in Section 4.1.2.

\subsubsection{Manufacturer of Sensor/Instrument}

Mass flow sensor and control unit for eddy covariance system:

Brooks Instruments Division

Emmerson Electric Co.

407 W. Vine St.

Hatfield, PA 19440

USA

(215) 362-3500

Sonic anemometer; krypton hygrometer; fine-wire thermocouple; CR7X and 21X data loggers; rain gauge (fen):

Campbell Scientific, Inc.

P.O. Box 551

Logan, UT 84321

USA

(519) 354-7356

Pyranometer; pyrgeometer:

Eppley Laboratories, Inc.

P.O. Box 419

Newport, RI 02840

USA

(401) 847-1020

LAI-2000 Plant canopy analyzer; diffusion porometer; quantum sensor; CO2 IRGA:

LI-COR, Inc.

4421 Superior Street

P.O. Box 4425

Lincoln, NE 68504

USA

(402) 467-3576

Net pyrradiometer:

Carter-Scott Design

22 Ailsa Street

Box Hill

Victoria, 3128

AUSTRALIA

+61-3-9899-4277 
Pressure transducer; thermocouple wire:

Omega Engineering

One Omega Drive

P.O. Box 4047

Stamford, CT 06907

USA

(203) 359-1660

Soil heat flux plate:

REBS

P.O. Box 15512

Seattle, WA 98115-0512

USA

(206) 624-7221

Cup anemometer; wind vane:

R.M. Young Co.

2801 Aero Park Drive

Traverse City, MI 49648

USA

(616) 946-3980

Rain gauge (YJP):

Weathermeasure Corporation

P.O. Box 41257

Sacramento, CA 95841

USA

(916) 481-7565

\subsection{Calibration}

Pyranometers, pyrgeometers, and net pyrradiometers used at both sites were calibrated at NARC, Atmospheric Environment Service (AES), Downsview, Ontario. Following the intersite calibration on net pyrradiometers performed in the field in 1994 with the roving REBS 6-net pyrradiometer (Hodges and Smith, 1997; Smith et al., 1997), a corrected set of net radiation data was calculated for the 1994, 1995, and 1996 experimental periods for both the fen and YJP. The corrected net radiation data will potentially facilitate the intercomparison of flux behavior between the tower flux sites.

$\mathrm{CO}_{2}$ concentrations for high- and low-span calibration gases were determined at the Carbon Cycle Research Section, AES, Downsview, Ontario, Canada.

Factory calibrations were used for several instruments, and the recalibration details for individual sensors are given below.

The details of the recalibration performed on the porometers (LI-COR, Inc., Lincoln, NE, USA) used in the experiments are given in Section 4.2.2.

Following the 1993 field experiment, each individual calibration for the group of cup anemometers and wind vane (R.M. Young Co., Traverse City, MI, USA) was checked using the wind tunnel at Trent University, and no changes were needed to the original factory calibrations. Because the potentiometers on the two wind vanes were set in the field each time the instruments were deployed, both can be considered to have had regular field calibration checks.

For the soil heat flux plates (REBS, Seattle, WA, USA), the factory calibrations were accepted for all four transducers, two at each site.

Routine calibration checks were done on all rain gauges (Campbell Scientific, Inc., Logan, UT, USA, and Weathermeasure Corporation, Sacramento, CA, USA) by pouring a known amount of water into the gauge and noting the response. In all cases, the gauges were within the manufacturer's specification.

The sonic anemometers and krypton hygrometers (Campbell Scientific, Inc., Logan, UT, USA) at both the fen and YJP sites were recalibrated in March 1994 following the 1993 experiment and before 
redeployment for the 1994 experiment. Minor changes resulted, but they were not large enough to require correction to the 1993 data.

For all thermocouples, the appropriate calibration equation available in the data loggers (Campbell Scientific, Inc., Logan, UT, USA) was used.

\subsubsection{Specifications}

Whenever a new calibration was determined for an instrument, the new calibration was applied from the time of the recalibration. There was no attempt to blend the calibrations before and after the recalibration. Any step-up or step-down in the data values as a result of recalibration was accepted. For all instruments, the calibration changes were minor, and there were no instances where a blending of the calibrations was necessary.

\subsubsection{Tolerance}

The precision of the measured meteorological variables and the corresponding transducers are summarized below. In the following list, micromole is abbreviated to umol.

\begin{tabular}{||l|l|l||}
\hline \hline Variable & Transducer & Precision \\
\hline solar radiation & Eppley pyranometer & $1 \mathrm{~W} / \mathrm{m}^{2}$ \\
\hline longwave radiation & Eppley pyrgeometer & $1 \mathrm{~W} / \mathrm{m}^{2}$ \\
\hline net radiation & Middleton net pyrradiometer & $1 \mathrm{~W} / \mathrm{m}^{2}$ \\
\hline PPFD & LI-COR quantum sensor & $1 \mu \mathrm{mol} / \mathrm{m}^{2} / \mathrm{s}$ \\
\hline soil heat flux & LI-COR IRGA & $1 \mathrm{ppmv}$ \\
\hline air, soil, and biomass & REBS heat flux plate & $1 \mathrm{~W} / \mathrm{m}^{2}$ \\
\hline temperature & $\begin{array}{l}\text { Copper/constantan } \\
\text { horizontal wind speed }\end{array}$ & $0.1{ }^{\circ} \mathrm{C}$ \\
\hline wind direction & R.M. Young cup anemometer & $0.1 \mathrm{~m} / \mathrm{s}$ \\
\hline relative humidity & R.M. Young wind vane & $1^{\circ}$ \\
\hline vertical wind speed & R.M. Young T/RH sensor & $1 \%$ \\
\hline rainfall & $\begin{array}{l}\text { Campbell Scientific sonic } \\
\text { anemometer }\end{array}$ & $0.1 \mathrm{~m} / \mathrm{s}$ \\
\hline rainfall & $\begin{array}{l}\text { Campbell Scientific tipping } \\
\text { bucket }\end{array}$ & $0.1 \mathrm{~mm}$ \\
\hline \hline
\end{tabular}

\subsubsection{Frequency of Calibration}

All radiometers used in the study were on a regular, 2-year calibration cycle. This calibration frequency was increased during BOREAS, and each radiometer was calibrated before each major field experiment. Full calibrations were done in April 1994, October 1994, and March 1996.

One sonic anemometer (model CA27, Campbell Scientific, Inc., Logan, UT, USA) was recalibrated by the manufacturer in May 1995 following water damage to the instrument in September 1994 at the fen. 
Two porometers (model 1600, LI-COR, Inc., Lincoln, NE, USA) were used in the study. Each one was calibrated by the manufacturer prior to the 1993 field experiment; they were also intercalibrated. The single one that continued to be used in 1996 at the YJP was recalibrated by the manufacturer in April 1995.

The krypton hygrometers from the YJP and fen were calibrated in 1993 before deployment in the field and were recalibrated in March 1994.

Calibrations were determined on all $\mathrm{CO}_{2}$ reference gas tanks prior to both major field seasons in March 1994 and March 1996.

Routine calibration checks were made on the rain gauges, following the protocol suggested by the manufacturers, prior to their deployment in all field experiments. No calibration change was necessary to either gauge.

\subsubsection{Other Calibration Information}

A summary follows of the instruments used at each site along with their calibration histories.

Solar radiation was measured using Eppley pyranometers. The instruments, identified by serial number, used at both sites for each experiment are given in Table 3.

Table 3. Eppley pyranometers used at the YJP and Fen in all experimental years. Each pyranometer is identified by its serial number.

Table 3. Eppley pyranometers used at the Y.JP

\begin{tabular}{||l|l|l|l|l||}
\hline \hline Variable & Year & $\mathbf{1 9 9 4}$ & $\mathbf{1 9 9 5}$ & $\mathbf{1 9 9 6}$ \\
\hline Kd & $\mathbf{1 9 9 3}$ & 15889 & ----- & 15889 \\
\hline Ku & 13762 & 14713 & ----- & 14713 \\
\hline \hline
\end{tabular}

The calibration histories of the pyranometers are shown in Table 4. All calibrations remained stable through the BOREAS field periods, and the largest change in any calibration was $-0.57 \%$.

Table 4. Calibration history of the Eppley pyranometers used in all experimental years. The change in calibration is given as a percentage from the previous value. The units of calibration are microvolts $/ \mathrm{W} / \mathrm{m}^{2}$.

Table 4. Calibration history of the Eppley pyranometers

\begin{tabular}{||l|l|l|l||}
\hline \hline Serial number & Year & Calibration & $\begin{array}{l}\text { \%change in } \\
\text { calibration }\end{array}$ \\
\hline \multirow{3}{*}{13762} & 1992 & 12.21 & -1.12 \\
\cline { 2 - 5 } & 1994 & 12.14 & -0.57 \\
\cline { 2 - 5 } & 1996 & 12.20 & 0.49 \\
\hline \multirow{3}{*}{13855} & 1992 & 10.92 & -0.55 \\
\cline { 2 - 5 } & 1994 & 10.89 & -0.27 \\
\cline { 2 - 5 } & 1996 & 10.92 & 0.28 \\
\hline
\end{tabular}




\begin{tabular}{||l|l|l|l||}
\hline 14713 & 1992 & 11.17 & -0.62 \\
\cline { 2 - 4 } & 1994 & 11.14 & -0.27 \\
\cline { 2 - 4 } & 1996 & 11.14 & 0.00 \\
\hline 15889 & 1992 & 11.09 & -1.10 \\
\cline { 2 - 4 } & 1994 & 11.05 & -0.36 \\
\cline { 2 - 4 } & 1996 & 11.06 & 0.09 \\
\hline
\end{tabular}

Longwave radiation was measured using Eppley pyrgeometers. Instrument 20837F3 was used at YJP in 1993, 1994, and 1996, and instrument 29583F3 was used at Fen from 1993 to 1996. The calibration history of each instrument is given in Table 5. The first calibration of instrument $29583 \mathrm{~F} 3$ in 1994 proved to be wrong because of a malfunctioning reference temperature bath NARC. This was corrected by a recalibration of the instrument the same year, and all of the data were corrected in postprocessing.

Table 5. Calibration history of the Eppley pyrgeometers used in all experimental years. The change in calibration is given as a percentage from the previous value. The units of calibration are microvolts $/ \mathrm{W} / \mathrm{m}^{2}$.

Table 5. Calibration history of the Eppley pyrgeometers

\begin{tabular}{||l|l|l|l||}
\hline \hline Serial number & Year & Calibration & \% change in calibration \\
\hline \multirow{3}{*}{$20837 \mathrm{F3}$} & 1992 & 3.96 & -2.22 \\
\cline { 2 - 4 } & 1994 & 3.88 & -2.02 \\
\cline { 2 - 4 } & 1996 & 3.86 & - \\
\hline & 1993 & 3.97 & - \\
\cline { 2 - 4 } & 1994 & 3.62 & -8.82 (calibration is suspect) \\
\cline { 2 - 4 } & 1994 & 3.83 & -3.53 (recalibration for 1994) \\
\cline { 2 - 4 } & 1996 & 3.83 & 0.00 \\
\hline
\end{tabular}

Net radiation was measured using Middleton net pyrradiometers. The instruments used are listed in Table 6.

Table 6. Middleton net pyrradiometers used in the field experiments. Each instrument is identified by serial number. 
Table 6. Middleton net pyrradiometers

\begin{tabular}{||l|l||}
\hline \hline Serial number & Site \\
\hline 1330 & Fen in 1993, and from DOY 97-145 in 1996 \\
\hline 1333 & Fen in 1994, and 1995, and from DOY 146 in 1996 \\
\hline 1408 & YJP in 1993, 1994, and 1996 \\
\hline
\end{tabular}

The calibration histories of the net pyrradiometers are given in Table 7. For all net pyrradiometers, the calibration values are given separately for shortwave (SW), longwave (LW), and combined - the arithmetic average of SW and LW. The combined value was used for all times of the day, including the nighttime, when only longwave radiation is present. All instruments had two calibrations in 1994. The first calibration proved to be wrong because of a malfunctioning reference temperature bath at NARC. This was corrected by a recalibration of the instrument the same year, and all of the data were corrected in postprocessing. With the exception of the aberrant first calibration in 1994, all instruments remained stable for the duration of the experiments; the largest change was less than $4 \%$ and was normally less than $1 \%$.

Table 7. Calibration history of the Middleton net pyrradiometers used in all experimental years. The change in calibration is given as a percentage from the previous value. The units of calibration are microvolts $/ \mathrm{W} / \mathrm{m}^{2}$. Separate calibrations are given for shortwave (SW), longwave (LW), and combined - the arithmetic average of the SW and LW values. The calibration constant (cal. constant) is the ratio of the SW to LW calibration.

Table 7. Calibration history of the Middleton net pyrradiometers

\begin{tabular}{||l|l|l|l|l|l|l|l|l||}
\hline \hline $\begin{array}{l}\text { Serial } \\
\text { number }\end{array}$ & Year & SW & $\begin{array}{l}\text { \% } \\
\text { SWange }\end{array}$ & LW & $\begin{array}{l}\text { \% } \\
\text { LWange }\end{array}$ & $\begin{array}{l}\text { \% } \\
\text { change } \\
\text { com- } \\
\text { bined }\end{array}$ & $\begin{array}{l}\text { cal. } \\
\text { con- } \\
\text { stant } \\
\text { bined }\end{array}$ \\
\hline \multirow{3}{*}{1330} & 1992 & 37.52 & -0.87 & 35.18 & -3.98 & 36.35 & -2.42 & 1.07 \\
\cline { 2 - 10 } & 1994 & 38.16 & 1.17 & 32.40 & -7.90 & 35.28 & -2.94 & 1.18 \\
\cline { 2 - 10 } & 1994 & 37.55 & 0.08 & 34.82 & -1.02 & 36.19 & -0.44 & 1.08 \\
\cline { 2 - 10 } & 1996 & 35.54 & -5.35 & 34.13 & -1.98 & 34.84 & -3.73 & 1.04 \\
\hline \multirow{3}{*}{1333} & 1992 & 37.74 & -2.15 & 34.90 & -6.46 & 36.32 & -4.27 & 1.08 \\
\cline { 2 - 10 } & 1994 & 38.41 & 1.78 & 32.85 & -5.87 & 35.63 & -1.90 & 1.17 \\
\cline { 2 - 10 } & 1994 & 38.17 & 1.14 & 34.62 & -0.80 & 36.39 & 0.22 & 1.10 \\
\cline { 2 - 10 } & 1996 & 38.12 & -0.13 & 35.17 & 1.59 & 36.64 & 0.69 & 1.08 \\
\hline \multirow{3}{*}{1408} & 1992 & 38.58 & -1.36 & 35.99 & -5.01 & 37.28 & -3.14 & 1.07 \\
\cline { 2 - 9 } & 1994 & 38.53 & -0.13 & 35.83 & -0.44 & 37.18 & -0.29 & 1.08 \\
\cline { 2 - 9 } & 1996 & 38.17 & -0.93 & 35.36 & -1.30 & 36.77 & -1.10 & 1.08 \\
\hline \hline
\end{tabular}


PPFD was measured using LI-COR, Inc., quantum sensors. Table 8 shows the instruments used at each site in each experimental year, and Table 9 gives the calibration constants.

Table 8. Quantum sensors used at the experimental sites and the variables measured: PPFDd is incoming PPFD, and PPFDu is reflected PPFD. Instruments are identified by serial number.

Table 8. Quantum sensors used

\begin{tabular}{||l|l|l||}
\hline \hline Serial number & Site & Variable \\
\hline Q17605 & Fen 1993 to 1996 & PPFDd \\
\hline Q16754 & Fen 1993 to 1996 & PPFDu \\
\hline Q17614 & YJP 1993, 1994, 1996 & PPFDd \\
\hline Q17613 & YJP 1993, 1994, 1996 & PPFDu \\
\hline
\end{tabular}

Table 9. Calibration constants in units of $\mu$ mole $/ \mathrm{s} / \mathrm{m}^{2} / \mathrm{mv}$ for the quantum sensors used in the experiments. The instruments are identified by serial number.

Table 9. Calibration constants

\begin{tabular}{||l|l||}
\hline Serial & Calibration \\
\hline Q17613 & 295.12 \\
\hline Q17614 & 307.74 \\
\hline Q17605 & 293.25 \\
\hline Q16754 & 355.87 \\
\hline
\end{tabular}

$\mathrm{CO}_{2}$ concentration and $\mathrm{CO}_{2}$ flux density were measured using an IRGA (model LI-6252, LI-COR, Inc., Lincoln, NE, USA) and a sonic anemometer (model CA27, Campbell Scientific, Inc., Logan, UT, USA). Table 10 lists the IRGAs and the sonic anemometers used at both sites. Sonic 1353 was damaged by water seeping into the lower arm at the conclusion of the 1994 experiment. This instrument was repaired and recalibrated before being deployed again in 1996.

Table 10. The sonic anemometers and IRGAs used at the fen and YJP. The instruments are identified by serial number. There was no $\mathrm{CO}_{2}$ flux measured at the fen in 1995; the sonic measured the convective fluxes only.

Table 10. The sonic anemometers and IRGAs

\begin{tabular}{||l|l|l||}
\hline \hline \multirow{3}{*}{ Sonic anemometer } & Serial number & Site \\
\hline \multirow{2}{*}{ IRGA } & 1201 & Fen in 1995, YJP in 1993, 1994, and 1996 \\
\cline { 2 - 4 } & 1353 & Fen in 1993, 1994, and 1996 \\
\hline & IRG2-208 & Fen in 1993, 1994, and 1996 \\
\cline { 2 - 3 } & IRG2-209 & YJP in 1993, 1994, and 1996 \\
\hline
\end{tabular}


Soil heat flux was measured using REBS soil heat flux plates. The calibrations of the plates and the sites where they were deployed are given in Table 11.

Table 11. Calibrations for the soil heat flux plates, in units of $\mathrm{W} / \mathrm{m}^{2} / \mathrm{mV}$, and the sites where they were deployed. Individual plates are identified by serial number.

Table 11. Calibrations for the soil heat flux plates

\begin{tabular}{||l|l|l||}
\hline \hline Serial number & Calibration & Site \\
\hline 933060 & 40.0 & Fen in 1993, 1994, 1995, and 1996 \\
\hline 933061 & 38.7 & Fen in 1993, 1994, 1995, and 1996 \\
\hline 933062 & 39.0 & YJP in 1993, 1994, and 1996 \\
\hline 933063 & 40.7 & YJP in 1993, 1994, and 1996 \\
\hline
\end{tabular}

Horizontal wind speed was measured using 3 cup anemometers (model 12102, R.M. Young Co., Traverse City, MI, USA). These instruments have calibrations in units of $\mathrm{mv}$ at $1800 \mathrm{rpm}$, and this is combined with a second general calibration equation to convert $\mathrm{rpm}$ to $\mathrm{m} / \mathrm{s}$. The calibrations of the anemometers are given in Table 12.

Table 12. Calibration of the 3-cup anemometers used at each site for horizontal wind speed measurement at the levels identified, e.g., U1 is the anemometer at level 1. The units of the calibration are $\mathrm{mv}$ at $1800 \mathrm{rpm}$.

Table 12. Calibration of the 3 -cup anemometers

Site: YJP

\begin{tabular}{||l|l|l|l|l||}
\hline \hline Level & $\mathbf{1 9 9 3}$ & $\mathbf{1 9 9 4}$ & $\mathbf{1 9 9 5}$ & $\mathbf{1 9 9 6}$ \\
\hline U1 & 2400 & 2400 & - & 2400 \\
\hline U2 & 2398 & 2398 & - & ---- \\
\hline U3 & 2404 & 2404 & - & ---- \\
\hline U4 & 2404 & 2404 & - & 2404 \\
\hline U5 & 2402 & 2402 & - & 2402 \\
\hline \hline
\end{tabular}

Site: Fen

\begin{tabular}{||l|l|l|l|l||}
\hline \hline Level & $\mathbf{1 9 9 3}$ & $\mathbf{1 9 9 4}$ & $\mathbf{1 9 9 5}$ & $\mathbf{1 9 9 6}$ \\
\hline U1 & 2400 & 2400 & 2400 & ----- \\
\hline U2 & 2397 & 2397 & 2397 & 2397 \\
\hline U3 & 2396 & 2396 & 2401 & 2395 \\
\hline U4 & 2401 & 2401 & 2401 & ---- \\
\hline U5 & 2399 & 2399 & 2399 & 2401 \\
\hline \hline
\end{tabular}


Relative humidity was measured using a combination temperature/relative humidity probe (model 41372VC, R.M. Young Co., Traverse City, MI, USA) at each site in 1996 (Table 13). The temperature is measured with an RTD sensor, and the relative humidity is measured with a capacitance element. This probe was ventilated naturally and shielded by a 12-level plate shield. Each probe has the same calibration and specifications (Table 14).

Table 13. Temperature/relative humidity sensors used at the sites in 1996.

\begin{tabular}{||l|l|l||}
\hline \hline Model & Serial number & Site \\
\hline $41372 \mathrm{VC}$ & 1762 & Fen \\
\hline $41372 \mathrm{VC}$ & 1763 & YJP \\
\hline
\end{tabular}

Table 14. Calibration and specifications for the temperature/relative humidity sensor (model 41372VC, R.M. Young Co., Traverse City, MI, USA).

\begin{tabular}{|c|c|}
\hline \multirow[t]{8}{*}{ Relative humidity: } & operating temperature: $-10^{\circ} \mathrm{C}$ to $60^{\circ} \mathrm{C}$ \\
\hline & measuring range: 0 to $100 \%$ \\
\hline & accuracy at $20^{\circ} \mathrm{C}: 2 \%$ from $0-90 \% \mathrm{RH}$ \\
\hline & $3 \%$ from $90-100 \% \mathrm{RH}$ \\
\hline & stability: better than $\pm 2 \% \mathrm{RH}$ for 2 years \\
\hline & response time: $15 \mathrm{sec}$ \\
\hline & sensor element: Vaisala intercap \\
\hline & output signal: $0-1$ volt DC \\
\hline \multirow[t]{3}{*}{ Temperature: } & calibrated measuring range: $-50^{\circ} \mathrm{C}$ to $50^{\circ} \mathrm{C}$ \\
\hline & accuracy at $20^{\circ} \mathrm{C}: \pm 0.3^{\circ} \mathrm{C}$ \\
\hline & output signal: $0-1$ volt DC \\
\hline
\end{tabular}

Rainfall was measured using tipping bucket rain gauges at both sites in all years. At the YJP, the gauge (model P510, Weathermeasure Corporation, Sacramento, CA, USA) was mounted at canopy top, and at the fen, the gauge (model TE525, Texas Instruments, supplied by Campbell Scientific, Inc., Logan, UT, USA) was at a height of 1 meter above the surface. For the Weathermeasure gauge, 1 tip equals 0.01 inches $(0.254 \mathrm{~mm}$ of rain), and for the Texas Instruments gauge, 1 tip equals $1 \mathrm{~mm}$ of rain.

Leaf stomatal conductance was measured using a steady-state diffusion porometer (model LI-1600, serial number SSP1094, LI-COR, Inc., Lincoln, NE, USA). The onboard quantum sensor (serial number Q11174) has a calibration constant of 5.21 microamps/(1000 بmoles $\left./ \mathrm{s} / \mathrm{m}^{2}\right)$. This calibration remained stable from 1993 to the end of the experiment in 1996; there was no change at the 1995 recalibration.

Atmospheric pressure was measured at each site in 1996 using a Vaisala pressure transmitter (model PTB 101B, Vaisala, Oy, Finland, and supplied by Campbell Scientific, Inc., Logan, UT, USA). Each instrument had been calibrated against a working standard in February 1996. The instrument at YJP was S/N R0940044, and that at the fen was S/N R0940004. 


\section{Data Acquisition Methods}

The outputs from all instruments producing voltages were recorded on data loggers. Data from the loggers' memories were downloaded at regular intervals to either cassette tape or electronic storage module, and all data were transferred in the field to microcomputers and backed up on either floppy diskette or 1-GB Jaz drives (Iomega Corporation, Fenton, MO, USA).

Specific details for each major system are given below.

- Tower data (except eddy covariance). All signals were recorded on data loggers (model CR7X, Campbell Scientific, Inc., Logan, UT, USA) at a scan rate of once per 10 seconds. Output was processed every 3,15 , and 30 minutes depending on the variable. Only 30 -minute data are reported in the BORIS data base.

- Eddy covariance. All signals were recorded on data loggers (model 21X, Campbell Scientific, Inc., Logan, UT, USA) at a scan rate of once per 0.1 seconds. Intermediate processing was done every 15 minutes and output data were processed every 30 minutes.

- Leaf conductance. Porometric data from the LI-1600 were recorded on cassette tapes and later downloaded to microcomputers. The measurement frequency was variable. Data were collected on selected days under chosen weather conditions and only when the canopy was dry. Typically, measurements started early in the morning and continued every hour until evening.

- $\quad$ Forest canopy measurements. Canopy parameters (dbh, h, stem density) were recorded manually in field notebooks and later transposed to digital files.

\section{Observations}

\subsection{Data Notes}

\section{Biophysical Measurements}

The micrometeorological data at YJP were supplemented with biophysical data collected from areas surrounding the tower. These measurements included h, dbh, LAI, and stomatal conductance of the coniferous overstory. The measurements, combined with the tower data, represent the basis for intersite comparisons of surface-atmosphere interactions. The sections below include descriptions of the major sampling programs.

\section{Forest Stand Parameters}

Forest stand parameters were measured along transects within the zone designated as the wind aligned blob (WAB), the area of the site, centered on the experimental tower and of radius $500 \mathrm{~m}$, within which the majority of the surface fluxes originate. There was no sampling in the zone from $60^{\circ}$ to $120^{\circ}$. The parameters measured included $\mathrm{h}, \mathrm{dbh}$, and stem density. Five transects were sampled in both 1993 and 1994. In 1993, each transect radiated a distance of $500 \mathrm{~m}$ from the tower to the edge of the WAB at orientations of $10^{\circ}, 130^{\circ}, 190^{\circ}, 250^{\circ}$, and $310^{\circ}$. In 1994 , the transects started at a distance of $125 \mathrm{~m}$ from the tower and continued out to $500 \mathrm{~m}$ at bearings of $40^{\circ}, 160^{\circ}, 220^{\circ}, 280^{\circ}$, and $340^{\circ}$, which are midday between the orientations of the earlier lines. Two sampling methods were employed. First, in 1993, tree density and height were measured in square, $25 \mathrm{~m}^{2}$ plots every $100 \mathrm{~m}$ along each transect. A total of 20 plots were measured, and these data were designated as quadrat data. Tree height was measured with a survey stadia rod or tape, and dbh for trees with $\mathrm{h}$ greater than $1.3 \mathrm{~m}$ was measured with calipers. Using a subsample of 312 trees, a relationship was found between dbh and $h$. This relationship was then used to calculate tree heights for all trees sampled subsequently along the transects. The results of the quadrat survey indicated significant variation in stand parameters between transects and within a single transect. For example, stem density varied from 8,000 to 11,000 trees/ha within the 20 sample plots. To investigate smaller-scale spatial variation, a denser sampling was conducted by measuring dbh and stem density every $10 \mathrm{~m}$ along all transects using the Point Center Quarter Method (PCQM) (Mueller-Dombois and Ellenberg, 1974). Trees with $\mathrm{h}>1.3 \mathrm{~m}$ and trees with 
$\mathrm{h}<1.3 \mathrm{~m}$ were sampled separately. A summary of the 1993 PCQM transect data is shown in Table 15. Aggregating these data revealed that the greatest stem density occurred within $200 \mathrm{~m}$ of the tower at a value of 20,000 trees/ha, and a decrease out to the edge of the WAB where the value dropped to around 10,000 trees/ha. The variation in stem density was associated with three vegetation patterns: dense cover of short trees, sparse cover of tall trees, and a mixture of short and long trees. The average tree height on the site was $2.27 \mathrm{~m}$. Destructive sampling of nine trees yielded a value for the total green biomass of the canopy of $2.24 \mathrm{~kg} / \mathrm{m}^{2}$ using the model developed by Alemdag (1983).

Table 15. Average canopy parameters for the YJP site developed from PCQM data from five transects sampled in 1993. Each transect ran from the tower to the edge of the WAB, and samples were taken every $10 \mathrm{~m}$. The orientation of the transects is from magnetic north. Units of measurement are as follows: dbh in $\mathrm{cm}$, height in $\mathrm{m}$, and stem density in trees/ha. Source: Costello (1995).

Table 15. Average canopy parameters for the Y.JP site

\begin{tabular}{||l|l|l|l|l|l||}
\hline \hline & \multicolumn{5}{|c||}{ Transect Orientation (degrees) } \\
\hline Variable & $\mathbf{1 0}$ & $\mathbf{1 3 0}$ & $\mathbf{1 9 0}$ & $\mathbf{2 5 0}$ & $\mathbf{3 1 0}$ \\
\hline dbh & 1.39 & 1.77 & 1.51 & 2.05 & 1.60 \\
\hline Tree height & 2.08 & 2.35 & 2.17 & 2.55 & 2.23 \\
\hline $\begin{array}{l}\text { Stem density } \\
\text { Number of } \\
\text { samples }\end{array}$ & 16800 & 14400 & 7000 & 13200 & 10000 \\
\hline \hline
\end{tabular}

\section{Stomotal Conductance}

Stomatal conductance was measured with a steady-state diffusion porometer (model LI-1600, LI-COR, Inc., Lincoln, NE, USA) fitted with a cylindrical chamber aperture. Shoot samples were prepared at least 24 hours prior to the first measurements. Preparation involved isolating a clump of needles that would fit completely into the porometer's sample chamber. To achieve this, some needles were removed from the twig on either side of the sample clump. The bare twig, thus exposed, allowed the soft foam of the sample chamber to close around it and provided an air-tight seal around the sample clump.

After the needles were removed, the shoots were given 24 hours for sap to close over the scars. The sample needle clump was tagged for identification. Following several measurement sessions (generally over a few weeks), the tagged needles were collected, counted, and bagged for later determination of needle areas.

The true leaf surface area of each needle was calculated using the volume displacement technique described by Brand (1987). The true sample area was then used to correct the porometer conductance values as described in the porometer's manual.

\section{Experiment}

Sampling in 1993 was designed to investigate the variability of stomatal conductance in the YJP forest within the tower WAB. Measurements were stratified according to needle age, position in the tree, and location in the forest. These subcanopies were selected to be representative of the range of canopy morphologies (tree height and spacing) within the WAB as determined from the analysis of tree size distribution (described above). The mean values of the three canopy parameters are summarized for each subcanopy below, where n/a means "not applicable": 


\begin{tabular}{||l|l|l|l||}
\hline \hline Sub canopy & dbh $(\mathbf{c m})$ & $\mathbf{h}(\mathbf{m})$ & $\begin{array}{l}\text { stem density } \\
\text { (trees/ha) }\end{array}$ \\
\hline 1 & n/a & 1.2 & 63000 \\
\hline 2 & 3.65 & 3.7 & 8000 \\
\hline 3 & 2.02 & 2.5 & 18000 \\
\hline 4 & n/a & 1.2 & 78000 \\
\hline 5 & 3.39 & 3.5 & 7000 \\
\hline 6 & 1.96 & 2.5 & 15000 \\
\hline
\end{tabular}

Three canopy parameters are encoded in the variable CANOPY_ID, a three-digit number. The first (left-most) digit of CANOPY_ID represents location in the forest. This single digit ranges from 1 to 6 , representing six different locations or subcanopies within the WAB. The second digit represents needle age classification. A 0 represents current year needles, and a 1 represents all needles aged 1 year and greater. Finally, the third (right-most) digit represents position on the tree. This digit ranges from 0 to 3 . A 0 represents breast height measurements regardless of subcanopy location. Digits of 1,2, and 3 represent other height positions that are dependent upon subcanopy. For the small tree height canopies (locations 1 and 4), breast height was effectively the top of the trees. Thus, a position indicator of 1 represents a measurement of approximately $2 / 3$ of the tree height down from the top of the canopy. In the taller canopies (locations 2, 3,5, and 6), breast height represented the lowest position in the tree that was sampled. A position indicator of 2 represents approximately $1 / 2$ to $2 / 3$ the height of the tree from the ground. A position indicator of 3 indicates a measurement near the top of the canopy.

All porometry data are presented as the means from each porometry session. Sessions lasted between 15 and 30 minutes, and one to five sessions occurred on a given day.

\section{Experiment} 1994.

At the conclusion of the experiment in 1993, the porometer was recalibrated and used again in

Examination of the 1993 conductance data set revealed no significant differences between the numerous categories. Therefore, it was decided that the measurement strategy should be simplified for 1994. Two areas were selected for sampling. The first, roughly $20 \mathrm{~m} \times 20 \mathrm{~m}$ in size, was located 150 $\mathrm{m}$ from the flux tower at a bearing of $56^{\circ}$; it was considered to be representative of the majority of the site that was characterized by the presence of well-drained, sandy soil. A similar sized area was chosen $300 \mathrm{~m}$ from the flux tower at a bearing of $61^{\circ}$ to represent the wetter eastern border zone of the site. In order to correspond with LAI measurements, conductance samples were stratified into two height classes: tall and short. A tall tree was $>1.3 \mathrm{~m}$ and a short tree was $<1.3 \mathrm{~m}$ in height. Samples were also classified as being above or below breast height. During a 30-minute sampling period, samples were collected from one or both sites, depending on the time required to establish an equilibrium condition in the sample chamber. For each site, in each sample period, 15 needle clumps were sampled: 5 clumps from short trees (below breast height), 5 clumps from tall trees above breast height, and 5 clumps from tall trees below breast height.

After several measurement sessions (generally over a few weeks), the tagged sample needle clumps were collected. The needles were removed from each sample and counted. Their projected area was determined by placing them on a light table and capturing their area and associated statistics (mean size and shape) with an AgVision imaging system (Decagon Devices, Pullman, WA, USA). The actual needle area was found by multiplying the projected area by 2.57 , a species-specific correction factor. The correction factor was determined as the ratio of actual to projected needle area. Actual leaf area was found by volume displacement. 
For each sample, the measured conductance represents a relative value that must be corrected for the actual needle area of each clump. This was accomplished by multiplying the relative conductance by the ratio of the aperture setting on the porometer (i.e., the needle area used by the porometer for its conductance measurement) to the actual needle area. It was assumed that needles which fell from the sample during measurements were of average area. The area of each sample was corrected for lost needles by adding the assumed area of lost needles (equal to the number of needles lost multiplied by the average needle area) to the area of that sample clump for all measurements taken prior to the loss of needles.

\section{Experiment}

In 1996, the sample area for stomatal conductance was located approximately $30 \mathrm{~m}$ west of the flux tower and $10 \mathrm{~m}$ south of the soil moisture sampling array operated by the Hydrology (HYD)-01 group. The same sampling strategy used in 1994 was employed: each half-hour when data were collected, 15 trees were sampled, with 5 samples taken on needle clumps from tall trees above $1.3 \mathrm{~m}$, 5 samples from tall trees below $1.3 \mathrm{~m}$ and 5 samples were located on small trees, each one being $<1.3$ $\mathrm{m}$. The needle clumps were harvested at the same frequency as in 1994, and the same methodology was employed to find the actual leaf area of the sample.

\section{LAI Measurements}

LAI measurements were taken using two plant canopy analyzers (model LAI-2000, LI-COR, Inc., Lincoln, NE, USA). One unit, the rover, was positioned close to the ground to detect below-canopy readings at chosen sample points along the transects. The other unit was positioned permanently on top of the instrument hut, mounted on a tripod at a height approximately $4.75 \mathrm{~m}$ from the ground, and was operated in remote mode. This position provided an unobstructed view of the sky from well above the mean canopy height (approximately 2 to 3 meters). Above-canopy readings were recorded automatically every 15 seconds. The start and stop times for data collection were programmed by the operator.

Below-canopy measurements were taken near ground level, at a height of approximately $0.05 \mathrm{~m}$, and at breast height $(1.3 \mathrm{~m})$ every $25 \mathrm{~m}$ along the 10 transects radial to the tower. To avoid underestimation of LAI from illuminated foliage in direct sunlight, measurements were taken just before sunrise and just after sunset. Sky conditions at these times were generally clear. Both sensors were fitted with a lens cap that restricted the field of view to $270^{\circ}$.

To ensure that the two LAI-2000 sensors were measuring the same light intensities, the units were intercalibrated. For calibration purposes, the sensors were placed side-by-side on the rooftop tripod, leveled, and exposed to the same ambient light conditions. The output of one of the sensors was then adjusted to ensure agreement between the light intensities measured by both sensors. In addition, the clocks on both units were synchronized to within $<1 \mathrm{~s}$ of each other.

Each below-canopy measurement was stored as a separate data file. A single data file was created for the above-canopy readings. The data files from the two units were merged using LI-COR software (2000-90 Instrument Support Software v. 2.15, LI-COR, Inc., Lincoln, NE, USA), which matched each below-canopy reading with the above-canopy reading that was recorded at the closest time interval.

Since the LAI-2000 measures only projected leaf area, it was necessary to compute a correction factor to obtain the true LAI. Determination of the conifer correction factor ( $\left.\mathrm{R}^{\prime}\right)$ followed the methods of Gower and Norman (1991). Projected shoot area and total needle area were determined using a computer scanning and imaging system (AgVision, Decagon Devices, Pullman, WA, USA). Intact shoots were placed on the light table of the AgVision system. After determining the projected area, the shoot was turned $180^{\circ}$ and the projected area was recalculated. The shoot projected area $(\mathrm{PA}(\mathrm{S}))$ was then determined by averaging these two values. The needles from the shoot were removed and measured to determine the total projected needle area (PA). R' was calculated from:

$$
\mathrm{R}^{\prime}=\mathrm{PA} / \mathrm{PA}(\mathrm{S})
$$


$\mathrm{R}^{\prime}$ varied with height on the tree as well as with tree size. Average values found were $2.17,1.74$, and 1.74 for 3-, 2-, and 1-m-tall trees. We also examined the shoot clumping factor (SCF) (Chen and Black, 1992; and Smith et al., 1993) and found an average value of 1.47 for the site.

A simple conversion factor was derived to convert the projected needle area (PA) measured by the AgVision imaging system to the actual needle area (based on the assumption that the geometry of jack pine (Pinus banksiana, Lamb.) is best represented by a half cylinder. The relationship is expressed as

$$
\mathrm{AT}=\mathrm{PA}(1+\mathrm{pi} / 2) * 2.57 \mathrm{PA}
$$

where pi is 3.14 , and AT is total needle area $\left(\mathrm{cm}^{2}\right)$.

The LAI found from destructive sampling of nine trees and expressed as one half the needle surface area per unit area was 1.50. Mean values of apparent LAI for all of the sample points on the 10 transects gave an overall site value of 0.79 ( \pm 0.27 s.d.). Using the site's SCF, the calculated actual LAI (one half-side only) is 1.16, which compares reasonably well with the measured LAI of 1.50.

\subsection{Field Notes}

\section{Special Notes: 1993}

All data were averaged over thirty minutes, starting on the hour and half-hour, and ending thirty minutes later. Sampling was continuous, and each day's data is from 0600 UTC to 0600 UTC the next day.

- $\quad$ LONGWAVE_IN_1138CM was calculated as a residual.

- Small nighttime values for SOLAR_RAD_IN_1182CM, SOLAR_RAD_OUT_1158CM,

- $\quad$ PPFD_IN_1154CM, and PPFD_OUT_1136CM were set to zero to account for very slight zero depressions and elevations in the radiometers.

- $\quad$ BIO_TEMP_SMALL_TREES is an average value calculated from the temperatures of the small trees at both the north and west sites.

- HEAT_STORAGE_TOTAL_AVERAGE is an average value calculated from the total heat storage calculated at both the north and west sites.

- $\quad$ HEAT_STORAGE_BIO_AVERAGE is an average value calculated from the biomass heat storage calculated at both the north and west sites.

- Data collection began on DAY 227 at 2330.

\section{Special Notes: 1994}

All data were averaged over thirty minutes, starting on the hour and half-hour, and ending thirty minutes later. Sampling was continuous and each day's data is from 0600 UTC to 0600 UTC the next day.

- $\quad$ LONGWAVE_IN_1138CM was calculated as a residual.

- Small nighttime values for SOLAR_RAD_IN_1182CM, SOLAR_RAD_OUT_1158CM, PPFD_IN_1154CM, and PPFD_OUTT_1136CM were set to zero to account for very slight zero depressions and elevations in the radiometers.

- $\quad$ BIO_TEMP_SMALL_TREES is an average value found from the temperatures of the small trees at both the north and west sites.

- $\quad$ R_NET_1170CM_CORRECTED is calculated from day and night time equations taken from Hodges and Smith (1997) (see documentation for details).

- When SOLAR_RAD_IN_1182CM is greater than zero,CO2_TOTAL_FLUX_900CM is the sum of CO2_EDDY_FLUX_900CM and CO2_STORAGE_FLUX_900CM. If CO2_STORAGE_FLUX_900CM is missing, then CO2_EDDY_FLUX_900CM is used for CO2_TOTAL_FLUX_900CM.

- When SOLAR_RAD_IN_1182CM is equal to zero, CO2_TOTAL_FLUX_900CM is the sum of CO2_FLUX_NIGHT_MODEL_900CM and CO2_STORAGE_FLUX_900CM. If CO2_STORAGE_FLUX_900CM is missing, then CO2_FLUX_NIGHT_MODEL_900CM is used for CO2_TOTAL_FLUX_900CM. 
Data Period: May 24 - June 6/94 (DOY 144-157)

- $\quad$ LONGWAVE_OUT_1138 sensor installed on DOY 148 at 1630

- SOIL_TEMP_NORTH_25CM,SOIL_TEMP_NORTH_50CM and

SOIL_TEMP_NORTH_75CM thermocouples not installed until 179 at 2030.

- $\quad$ LATENT HEAT FLUX 900CM, SENSIBLE HEAT FLUX 900CM, H2O_FLUX_900CM, CO2_TOTAL_FLUX_900CM, CO2_CONC_900CM, SPECIFIC_HUMIDITY_900CM, SPECIFIC_HUMIDITY_STDEV_900CM, W_MEAN_900CM and W_STDEV_900CM values are missing on DOYs 144, 145, 147 from 1830-2230, 148 at 2030 through to 149 at 600 and 149 from 630-1530 due to weather and 153 from $2100-2130$ due to lag tests.

- SOLAR_RAD_IN_1182CM, SOLAR_RAD_OUT_1158CM, NET_SOLAR_RAD_1170CM, LONGWAVE_IN_1138CM, TOTAL_RAD_IN_1160CM, TOTAL_RAD_OUT_1148CM, R_NET_1170CM, R_NET_1170CM_CORRECTED, PPFD_IN_1154CM, PPFD_ŌUT_1136CM, SURFACE_ALBEDO, SOIL_TEMP_NÖRTH_1CM, SOIL_TEMP_NORTH_5CM, SOIL_TEMP_NORTH_10CM, SOIL_TEMP_WEST_25CM,

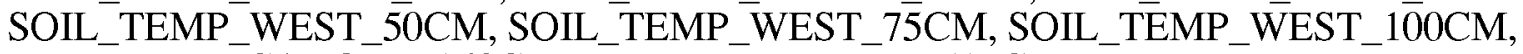
DRY_BULB_CANOPY_160CM,DRY_BULB_TEMP_517CM,

DRY_BULB_TEMP_610CM, DRY_BULB_TEMP_715CM, DRY_BULB_TEMP_770CM, DRY_BULB_TEMP_1030CM, WET_BULB_CANOPY_160CM,

WET_BULB_TEMP_517CM, WET_BULB_TEMP_610CM, WET_BULB_TEMP_715CM, WET_BULB_TEMP_770CM, WET_BULB_TEMP_1030CM, BIO_TEMP_SMALL_TREES, BIO_TEMP_MEDIUM_TREES, BIO_TEMP_LARGE_TREES, VAPOUR_PRESSURE_CANOPY_160CM, VAPOUR_PRESSURE_517CM, VAPOUR_PRESSURE_610CM, VAPOUR_PRESSURE_715CM, VAPOUR_PRESSURE_770CM, VAPOUR_PRESSURE_1030CM, WIND_SPEED_517CM, WIND_SPEED_610CM, WIND_SPEED_715CM, WIND_SPEED_770CM, WIND_SPEED_1030CM, WIND_DIR_1030CM, WIND_DIR_STDEV_1030CM and RAINFALL_250CM values are missing on DOYs 149 from $1530-2300$ and 157 from $1500-1830$.

- SOIL_HEAT_FLUX_NORTH_10CM,SOIL_HEAT_FLUX_WEST_10CM, HEAT_STORAGE_NORTH_TOTAL,HEAT_STORAGE_WEST_TŌTAL, HEAT_STORAGE_NORTH_BIO,HEAT_STORAGE_WEST_BIO, HEAT_STORAGE_SENSIBLE_AIR, HEATT_STORAḠE_LATENT_AIR, HEAT_STORAGE_NORTH_10CM and HEAT_STORAGE_WEST_10CM values are missing on DOYs 149 and 157.

Data Period: June 7 - June 20/94 (DOY 158-171)

- SOIL_TEMP_NORTH_25CM,SOIL_TEMP_NORTH_50CM and SOIL_TEMP_NORTH_75CM thermocouples not installed until 179 at 2030.

- LATENT_HEAT_FLUX_900CM, SENSIBLE_HEAT_FLUX_900CM, H2O_FLUX_900CM, CO2_TOTAL_FLUX_900CM, CO2_CONC_900CM, SPECIFIC_HUMIDITY_900CM, SPECIFIC_HUMIDITY_STDEV_900CM, W_MEAN_900CM and W_STDEV_900CM values are missing on DOY 162 from 1800-600, on 163, on 164 from 630-1500 and on 167 at 1900 through to 168 at 600 due to weather.

- SOLAR_RAD_IN_1182CM, SOLAR_RAD_OUT_1158CM, NET_SOLAR_RAD_1170CM, LONGWAVE_IN_1138CM, TOTAL_RAD_IN_1160CM, TOTAL_RAD_OUT_1 $148 \mathrm{CM}$, R_NET_1170CM, R_NET_1170CM_CORRECTED, PPFD_IN_1154CM, PPFD_OUT_1136CM, SURFACE_ALBEDO, SOIL_TEMP_NORTH_1CM, SOIL_TEMP_NORTH_5CM, SOIL_TEMP_NORTH_10CM, SOIL_TEMP_WEST_25CM, SOIL_TEMP_WEST_50CM, SOIL_TEMP_WEST_75CM, SOIL_TEMP_WEST_100CM, DRY_BULB_CANOPY_160CM, DRY_BULB_TEMP_517CM,

DRY_BULB_TEMP_610 CM, DRY_BULLB_TEMP_715CM, DRY_BULB_TEMP_770CM, DRY_BULB_TEMP_1030CM, WET_BULB_CANOPY_160CM,

WET_BULB_TEMP_517CM, WET_BULB_TEMP_610CM, WET_BULB_TEMP_715CM, 
WET_BULB_TEMP_770CM, WET_BULB_TEMP_1030CM, BIO_TEMP_SMALL_TREES, BIO_TEMP_MEDIUM_TREES,

BIO_TEMP_LARGE_TREES, VAPOUR_PRESSURE_CANOPY_160CM, VAPOUR_PRESSURE_517CM, VAPOUR_PRESSURE_610CM, VAPOUR_PRESSURE 715CM, VAPOUR PRESSURE 770CM, VAPOUR_PRESSURE_1030CM, WIND_SPEED_517CM, WIND_SPEED_610CM, WIND_SPEED_715CM, WIND_SPEED_770CM, WIND_SPEED_1030CM, WIND_DIR_1030CM, WIND_DIR_STDEV_1030CM and RAINFALL_250CM values are missing on 165 at 1500 through 166 at 600 and on 171 at 1900 through 172 at 600 due to weather.

- $\quad$ SOIL_HEAT_FLUX_NORTH_10CM,SOIL_HEAT_FLUX_WEST_10CM, HEAT_STORAGE_NORTH_TOTAL,HEAT_STORAGE_WEST_TOTAL, HEAT_STORAGE_NORTH_BIO,HEAT_STORAGE_WEST_BIO, HEAT_STORAGE_SENSIBLE_AIR, HEATT_STORAḠE_LATENT_AIR, HEAT_STORAGE_NORTH_10CM and HEAT_STORAGE_WEST_10CM values are missing on DOYs 163, 165 and 171.

Data Period: June 21 - July 4/94 (DOY 172-185)

- SOIL_TEMP_NORTH_25CM,SOIL_TEMP_NORTH_50CM and SOIL_TEMP_NORTH_75CM thermocouples not installed until 179 at 2030.

- $\quad$ LATENT_HEAT_FLUX_900CM, SENSIBLE_HEAT_FLUX_900CM, H2O_FLUX_900CM, CO2_TOTAL_FLUX_900CM, CO2_CONC_900CM, SPECIFIC_HUMIDITY_900CM, SPECIFIC_HUMIDITY_STDEV_900CM, W_MEAN_900CM and W_STDEV_900CM values are missing from DOY 184 at 1500 through 189 at 2000 due to generator problems.

- WIND_DIR_1030CM sensor malfunction from DOY 172 through to 190 at 2330. Reinstalled at 2400 on DOY 190. Consequently, no values of WIND_DIR_STDEV_1030CM.

- RAINFALL_250CM gauge malfunction on DOY 185 from 30-1900. Reinstalled at 1930 on DOY 185.

\section{Data Period: July 5 - July 18/94 (DOY 186-199)}

- $\quad$ LATENT_HEAT_FLUX_900CM, SENSIBLE_HEAT_FLUX_900CM, H2O_FLUX_900CM, CO2_TOTAL_FLUX_900CM, $\overline{C O} 2$ CONC_900CM, SPECIFIC_HUMIDITY_900CM, SPECIFIC_HUMIDITY_STDEV_900CM, W_MEAN_900CM and W_STDEV_900CM values are missing from DOY 184 at 1500 through 189 at 2000 due to generator problems. There are no readings on DOYs 191 at 2200 through to 192 at 1730 , on 193 at 1600 through to 195 at 2100 and on 196 from 1500-1730 due to weather.

- $\quad$ SOIL_HEAT_FLUX_NORTH_10CM,SOIL_HEAT_FLUX_WEST_10CM, HEAT_STORAGE_NORTH_TOTAL, HEAT_STORAGE_WEST_TOTAL, HEAT_STORAGE_NORTH_BIO,HEAT_STORAGE_WEST_BIO, HEAT_STORAGE_SENSIBLE_AIR, HEATT_STORAḠE_LATENT_AIR, HEAT_STORAGE_NORTH_10CM and HEAT_STORAGE_WEST_10CM values are missing on DOY 190 .

- WIND_DIR_1030CM sensor malfunction from DOY 172 through to 190 at 2330. Reinstalled at 2400 on DOY 190. Consequently, no values of WIND_DIR_STDEV_1030CM. 
Data Period: July 19 - August 1/94 (DOY 200-213)

- $\quad$ LATENT_HEAT_FLUX_900CM, SENSIBLE_HEAT_FLUX_900CM, H2O_FLUXX_900CM, CO2_TOTAL_FLUX_900CM, $\bar{C} O 2$ 2OCNC_900CM, SPECIFIC_HUMIDITY_900CM, SPECIFIC_HUMIDITY_STDEV_900CM, W_MEAN_900CM and W_STDEV_900CM values are missing on DOYs 200 at 1500 through, 201 at 1730 due to instrument malfunction, on DOY 203 from 1230-1530 due to weather and on DOY 204 from 230-400 due to data inconsistencies. On DOY 206 from 1330-1530 and from 1830-1930 due to data inconsistencies and on DOY 207 at 1300 and on DOY 208 from 230-300 due to data inconsistencies.

\section{Data Period: August 2 - August 15/94 (DOY 214-227)}

- $\quad$ LATENT_HEAT_FLUX_900CM, SENSIBLE_HEAT_FLUX_900CM, H2O_FLUX_900त्CM, CO2_TOTAL_FLUX_900CM, CO2_CONC_900CM, SPECIFIC_HUMIDITY_900CM, SPECIFIC_HUMIDITY_STDEV_900CM, W_MEAN_900CM and W_STDEV_900CM values are missing on DOYs 217 at 2330 through, 218 at 1930, 223 at 2100 through 225 at 1530 due to weather. On DOY 227 at 2400 through 228 at 100 due to data inconsistencies.

\section{Data Period: August 16 - August 29/94 (DOY 228-241)}

- $\quad$ LATENT_HEAT_FLUX_900CM, SENSIBLE_HEAT_FLUX_900CM, H2O_FLUX_900CM, CO2_TOTAL_FLUX_900CM, CO2_CONC_900CM, SPECIFIC_HUMIDITY_900CM, SPECIFIC_HUMIDITY_STDEV_900CM, W_MEAN_900CM and W_STDEV_900CM values are missing on DOYs 234 at 130 through $23 \overline{5}$ at 1600,239 at 1430 through $24 \overline{0}$ at 1430 due to instrument malfunction. On DOYs 241 at 1730 through 242 at 1430 due to weather.

- $\quad$ SOIL_TEMP_WEST_5CM sensor unreliable on DOYs 237 at 2030 through 238 at 230, on DOY 238 from $730-1030$, on DOY 240 from $630-930$, on DOY 241 at 700 through 242 at 600 due to wet conditions.

Data Period: August 30 - September 12/94 (DOY 242-255)

- $\quad$ LATENT_HEAT_FLUX_900CM, SENSIBLE_HEAT_FLUX_900CM, H2O_FLUX_900CM, CO2_TOTAL_FLUX_900CM, CO2_CONC_900CM, SPECIFIC_HUMIDITY_900CM, SPECIFIC_HUMIDITY_STDEV_900CM, W_MEAN_900CM and W_STDEV_900CM values are missing on Jdays 242 from $630-1430,247$ at 1430 through 248 at 1700 due to weather.

- $\quad$ LATENT_HEAT_FLUX_900CM and CO2_TOTAL_FLUX_900CM have missing values on Jdays 253 at 130 through 254 at 600 and on 255 from 630-1500 due to data inconsistency.

- $\quad$ SOIL_TEMP_WEST_5CM sensor unreliable on Jdays 242 from 630-1630, on Jday 248 at 1600 through 249 at 900 , on Jday 249 from 1930-2200, on Jday 250 at 2030 through 251 at 230 , on Jday 251 from 600-1100, on Jday 251 at 1800 through 252 at 1500 , on Jday 252 at 1630 through 253 at 1830, on Jday 255 from 1530-1730, on Jday 255 at 1930 through 256 at 600 due to wet conditions.

\section{Data Period: September 13 - September 20/94 (DOY 256-263)}

- $\quad$ LATENT_HEAT_FLUX_900CM, SENSIBLE_HEAT_FLUX_900CM, H2O_FLŪX_900त्CM, CO2_TOTAL_FLUX_900CM, $\bar{C} O 2 \_C O \overline{O N C} 9900 \mathrm{CM}$, SPECIFIC_HUMIDITY_900CM, SPECIFIC_HUMIDITY_STDEV_900CM, W_MEAN_900CM and W_STDEV_900CM values are missing on DOYs 256 from $16 \overline{3} 0-1700$, and 257 from $1630-1700$ due to weather. On 258 from $730-1500$ and on 259 from 630-1600 due to instrument malfunction. On DOY 263 at 1530 through 264 at 600 due to the end of the 1994 field season.

- SOLAR_RAD_IN_1182CM, SOLAR_RAD_OUT_1158CM, NET_SOLAR_RAD_1170CM, LONGWAVE_IN_1138CM, TOTAL_RAD_IN_1160CM,TOTAL_RAD_OUT_1148CM, R_NET_1170CM, R_NET_1170CM_CORRECTED, PPFD_IN_1154CM, 
PPFD_OUT_1136CM,SURFACE_ALBEDO, SOIL_TEMP_NORTH_1CM,

SOIL_TEMP_NORTH_5CM, SOIL_TEMP_NORTH_10CM, SOIL_TEMP_WEST_25CM, SOIL_TEMP_WEST_50CM, SOIL_TEMP_WEST_75CM,SOIL_TEMP_WEST_100CM, DRY_BULB_CANOPY_160CM,DRY_BULB_TEMP_517CM,

DRY_BULB_TEMP_610CM, DRY_BULB_TEMP_715CM, DRY_BULB_TEMP_770CM, DRY_BULB_TEMP_1030CM, WET_BULB_CANOPY_160CM,

WET_BULB_TEMP_517CM, WET_BULB_TEMP_610CM, WET_BULB_TEMP_715CM, WET_BULB_TEMP_770CM, WET_BULB_TEMP_1030CM,

BIO_TEMP_SMALL_TREES, BIO_TEMP_MEDIUM_TREES,

BIO_TEMP_LARGE_TREES, VAPOUR_PRESSURE_CANOPY_160CM,

VAPOUR_PRESSURE_517CM, VAPOUR_PRESSURE_610CM,

VAPOUR_PRESSURE_715CM, VAPOUR_PRESSURE_770CM,

VAPOUR_PRESSURE_1030CM, WIND_SPEED_517CM, WIND_SPEED_610CM,

WIND_SPEED_715CM, WIND_SPEED_770CM, WIND_SPEED_1030CM,

WIND_DIR_1030CM, WIND_DIR_STDEV_1030CM and RAINFALL_250CM values are

missing on DOY 263 at 1530 through 264 at 600 due to the end of the 1994 field season.

- $\quad$ SOIL_HEAT_FLUX_NORTH_10CM,SOIL_HEAT_FLUX_WEST_10CM,

HEAT_STORAGE_NORTH_TOTAL,HEAT_STORĀGE_WEST_TŌTAL,

HEAT_STORAGE_NORTH_BIO,HEAT_STORAGE_WEST_BIO,

HEAT_STORAGE_SENSIBLE_AIR,HEAT_STORAḠE_LATENT_AIR,

HEAT_STORAGE_NORTH_10CM and HEAT_STORAGE_WEST_10CM values are missing on DOYs 262 and 263.

- $\quad$ SOIL_TEMP_WEST_5CM sensor unreliable on DOYs 256 from 630-1130, on DOY 256 at 1600 through 257 at 600 , on DOY 258 from 500-800, on DOY 258 at 1530 through 259 at 800 , on DOY 259 from 1230-1530, on DOY 259 from 1800-2200 due to wet conditions.

\section{Special Notes: 1996}

All data were averaged over thirty-minute intervals, starting on the hour or

half-hour, and ending thirty minutes later. Sampling was continous, and each day's data is from 0600 UTC to 0600 UTC the next day.

- $\quad$ LONGWAVE_IN_1138CM was calculated as a residual.

- Small nighttime values for SOLAR_RAD_IN_1182CM, SOLAR_RAD_OUT_1158CM, PPFD_IN_1154CM, and PPFD_OUTT_1136CM were set to zero to account for very slight zero depressions and elevations in the radiometers.

- $\quad$ BIO_TEMP_SMALL_TREES is an average value found from the temperatures of the small trees at both the north and west sites.

- $\quad$ R_NET_1170CM_CORRECTED was calculated from day and night time equations developed by Hodges and Smith (1997) (see documentation for details).

- When SOLAR_RAD_IN_1182CM is greater than zero, CO2_TOTAL_FLUX_900CM is the sum of CO2_EDDY_FLUX_900CM AND CO2_STORAGE_FLUX_900CM. If CO2_STORAGE_FLUX_900CM is missing, then CO2_EDDY_FLUX_900CM is used for CO2_TOTAL_FLUX_900CM.

- When SOLAR_RAD_IN_1182CM is equal to zero, CO2_TOTAL_FLUX_900CM is the sum of CO2_FLUX_NIGHT_MODEL_900CM and CO2_STORAGE_FLUX_900CM. If CO2_STORAGE_FLUX_900CM is missing, then CO2_FLUX_NIGHT_MODEL_900CM is used for CO2_TOTAL_FLUX_900CM.

\section{Data Period: May $8 \backslash 96$ - July $3 \backslash 96$ (DOY 129-185)}

- HEAT_STORAGE_NORTH_10CM and HEAT_STORAGE_WEST_10CM values are missing from DOY 129 to DOY 178 (inclusive) because soil moisture data were not available.

- HEAT_STORAGE_LATENT_AIR is missing DOY 129-133(2030), 137(1400)-141(1700), and $17 \overline{9}(1430-2130)$. HEAT_STORAGE_TOTAL_NORTH and

HEAT_STORAGE_TOTAL_WEST are therefore calculated from the remaining heat storage variables. 
Data Period: August 15 - August $28 \backslash 96$ (DOY 228-241)

- Values for SOIL_TEMP_NORTH_1CM,SOIL_TEMP_NORTH_5CM, SOIL_TEMP_NORTH_10CM, SOIL_TEMP_NORTH_25CM,

SOIL_TEMP_NORTH_50CM, SOIL_TEMP_NORTH_75CM, SOIL_TEMP_WEST_1CM, SOIL_TEMP_WEST_5CM, SOIL_TEMP_WEST_10CM, SOIL_TEMP_WEST_25CM, SOIL_TEMP_WEST_50CM, SOIL_TEMP_WEST_75CM, SOIL_TEMP_WEST_100CM, and

- $\quad$ RAINFALL_250CM were interpolated on DOY 232 at 1630.

Data Period: October 10 - October $23 \backslash 96$ (DOY 284-297)

- WIND_SPEED_517CM, WIND_SPEED_770CM, WIND_SPEED_1030CM, WIND_DIR_1030CM, and WIND_DIR_STDEV_1030CM values are missing on DOY $289(2000-0600), 290,291$, and $29 \overline{2}(06 \overline{3} 0-1800)$ because of freezing of the sensors.

Data Period: October 24 - November $6 \backslash 96$ (DOY 298-311)

- WIND_SPEED_517CM, WIND_SPEED_770CM, and WIND_SPEED_1030CM values are missing on DOY $300(0500-0600), 301,3 \overline{0} 2$, and $303(0630-20 \overline{3} 0)$ because of freezing of the anemometers.

\section{Data Description}

\subsection{Spatial Characteristics}

\subsubsection{Spatial Coverage}

All data were collected at the BOREAS NSA-YJP site. North American Datum of 1983 (NAD83) coordinates for the site are latitude $55.89575^{\circ} \mathrm{N}$, longitude $98.28706^{\circ} \mathrm{W}$, and elevation of $249.29 \mathrm{~m}$. The prevailing wind direction in the area is from the west. Therefore, the access path to the tower and all of the hard services (generator, fuel storage area, instrument hut, and storage tent) were located east of the tower.

Porometric data were collected at two locations on the YJP site in 1994. One location was designated as "dry" because it was located on the dry, sandy soil near the flux tower, and the other location was designated as "wet" because it was located on the wetter part of the site east of the flux tower. The wet site was $290 \mathrm{~m}$ from the tower at a bearing of 61 degrees, and the dry site was $150 \mathrm{~m}$ from the tower at a bearing of 56 degrees. The strategy of choosing two sample positions was to see whether the clearly different soil moisture status of the sites influenced the behavior of stomatal conductance. In 1996, one porometric sample zone was located approximately $40 \mathrm{~m}$ from the tower at a bearing of 250 degrees. This site was chosen in order to be close to the dense array of continuous soil moisture sample profiles run by HYD-01.

\subsubsection{Spatial Coverage Map}

Not applicable.

\subsubsection{Spatial Resolution}

The data collected from towers are usually thought of as point data. However, they actually represent an integrated response to the surface/atmosphere interaction, especially in terms of the eddy flux data, which are considered to represent an integrated upwind surface source region (Leclerc and Thurtell, 1990; Schmid and Oke, 1990). In general, at the YJP the fluxes apply to the surface between 20 to 400 meters upwind. At the fen, where fetch in certain wind directions is limited, data uncertainties may occur (see Section 10.1).

\subsubsection{Projection}

Not applicable. 


\subsubsection{Grid Description \\ Not applicable.}

\subsection{Temporal Characteristics}

\subsubsection{Temporal Coverage}

The start and stop times for the experiments were as follows:

15-Aug-1993 to 31-Aug-1993

25-May-1994 to 19-Sep-1994

30-Apr-1996 to 15-Nov-1996

\subsubsection{Temporal Coverage Map}

Not applicable.

\subsubsection{Temporal Resolution}

With one exception, the data values submitted to BORIS were integrations of the conditions for the 30 -minute reporting periods. The exception is the porometric data, and specifically the stomatal conductance of the jack pine, which is submitted as shorter-term averages.

Meteorological data were output at 15- and 30-minute intervals depending upon the variable. The 15-minute data included only absolute wet- and dry-bulb air temperatures and soil temperatures, which were used for heat storage calculations (described below). All signals, except temperature differences, were averaged over 30-minute periods. Only the 30-minute data were reported to BORIS. Eddy covariance data were output every 30 minutes.

Porometry data and other biophysical measurements were conducted at irregular sampling intervals as conditions and resources permitted. Dates and times are noted in the data submissions.

\subsection{Data Characteristics}

The data provided by the TF-10 team consist of both tower flux and porometry measurements. The details of these two data sets are contained in the following sections.

\subsubsection{Parameter/Variable}

The parameters contained in the flux data files on the CD-ROM are:

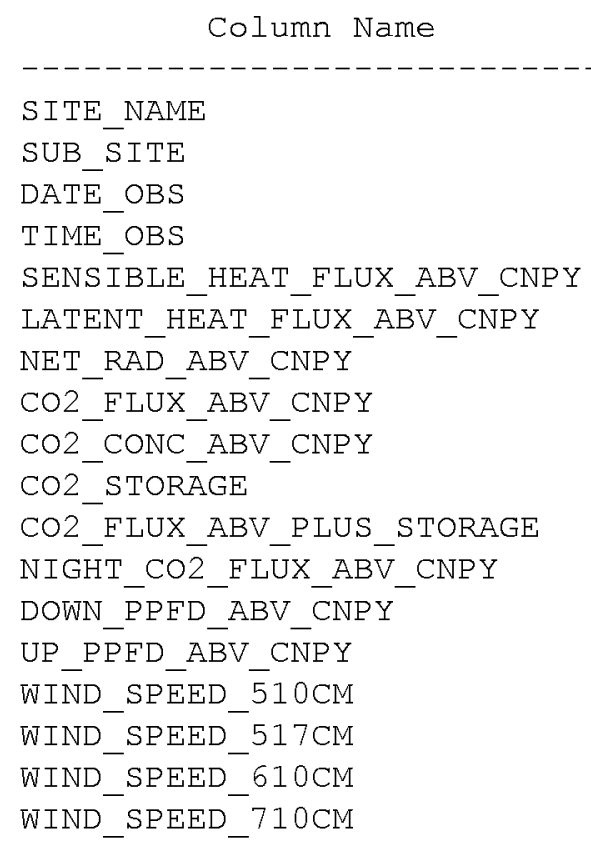




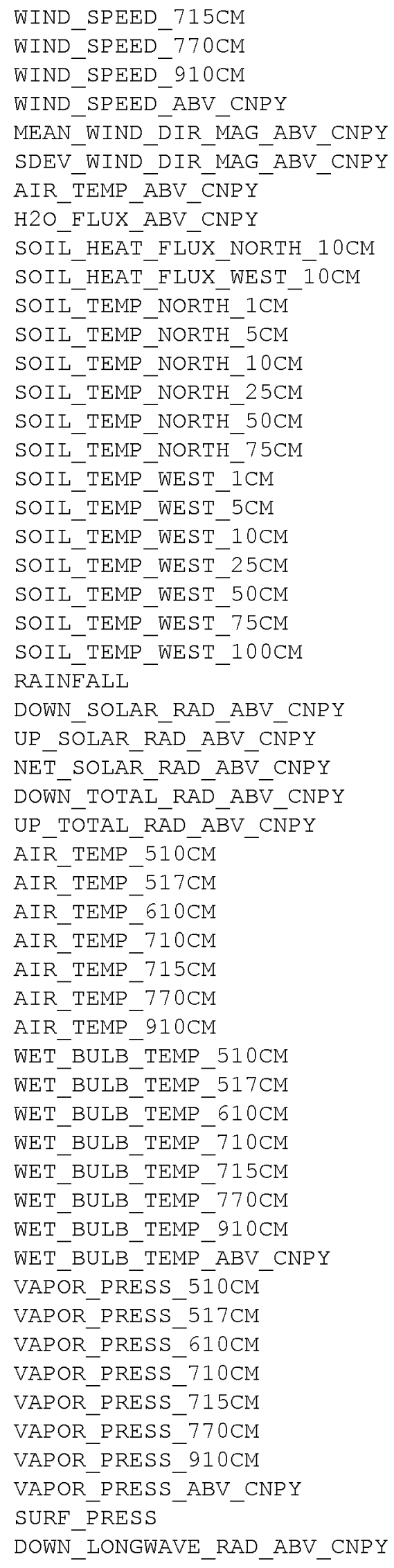




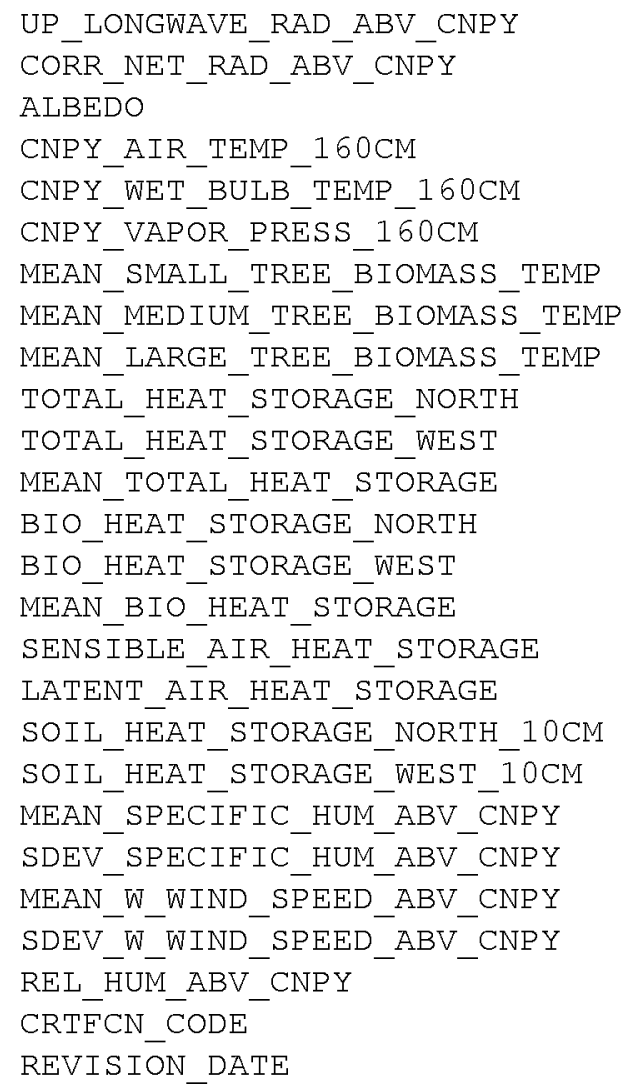

The parameters contained in the porometry data files on the CD-ROM are:

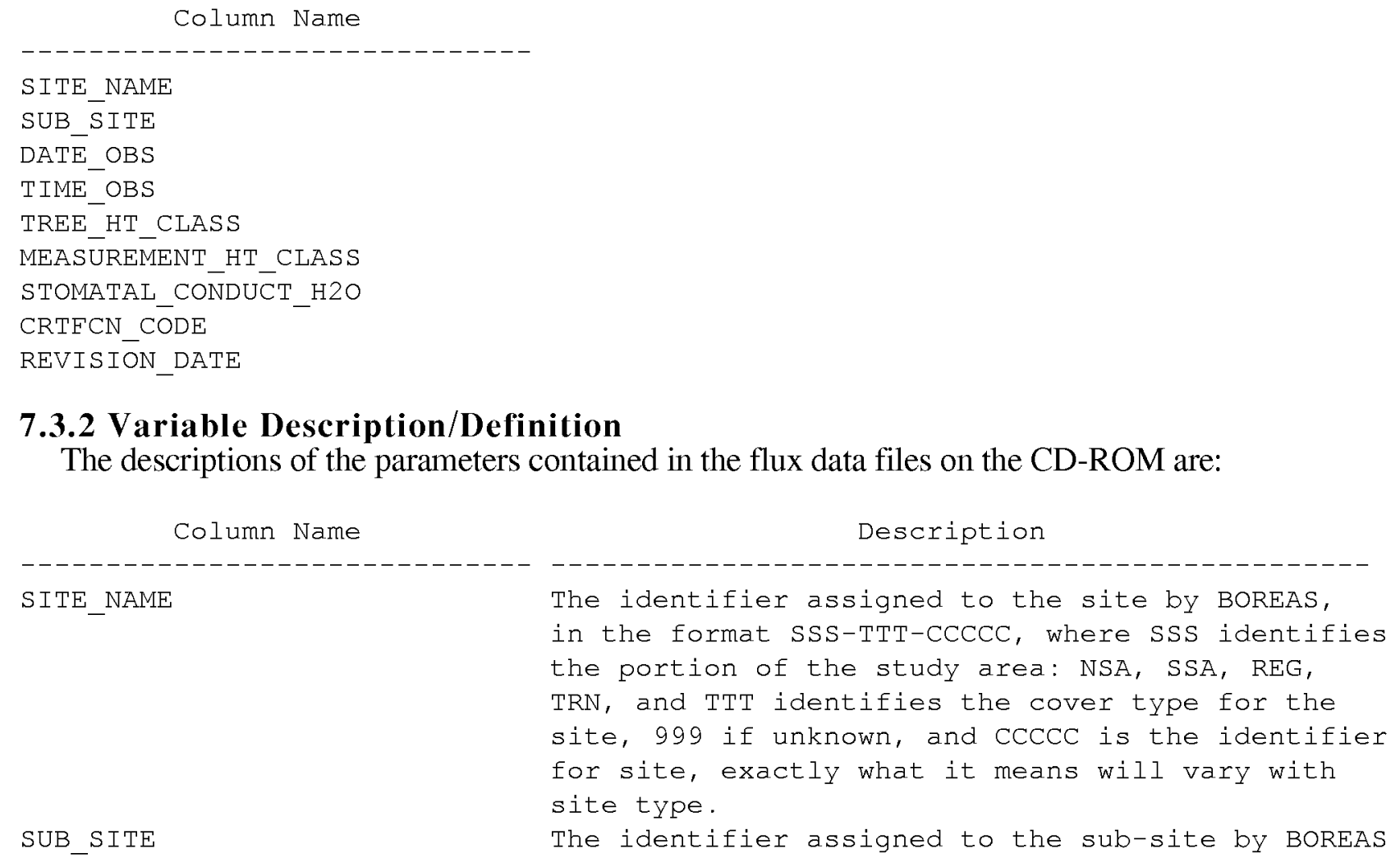

\subsubsection{Variable Description/Definition}

The descriptions of the parameters contained in the flux data files on the CD-ROM are:

$\begin{array}{ll}\text { Column Name } & \text { Description } \\ \text { SITE_NAME } & \text { The identifier assigned to the site by BOREAS, } \\ & \text { in the format SSS-TTT-CCCCC, where SSS identifies } \\ & \text { the portion of the study area: NSA, SSA, REG, } \\ & \text { TRN, and TTT identifies the cover type for the } \\ & \text { site, } 999 \text { if unknown, and CCCCC is the identifier } \\ & \text { for site, exactly what it means will vary with } \\ & \text { site type. } \\ \text { SUB_SITE } & \text { The identifier assigned to the sub-site by BOREAS }\end{array}$




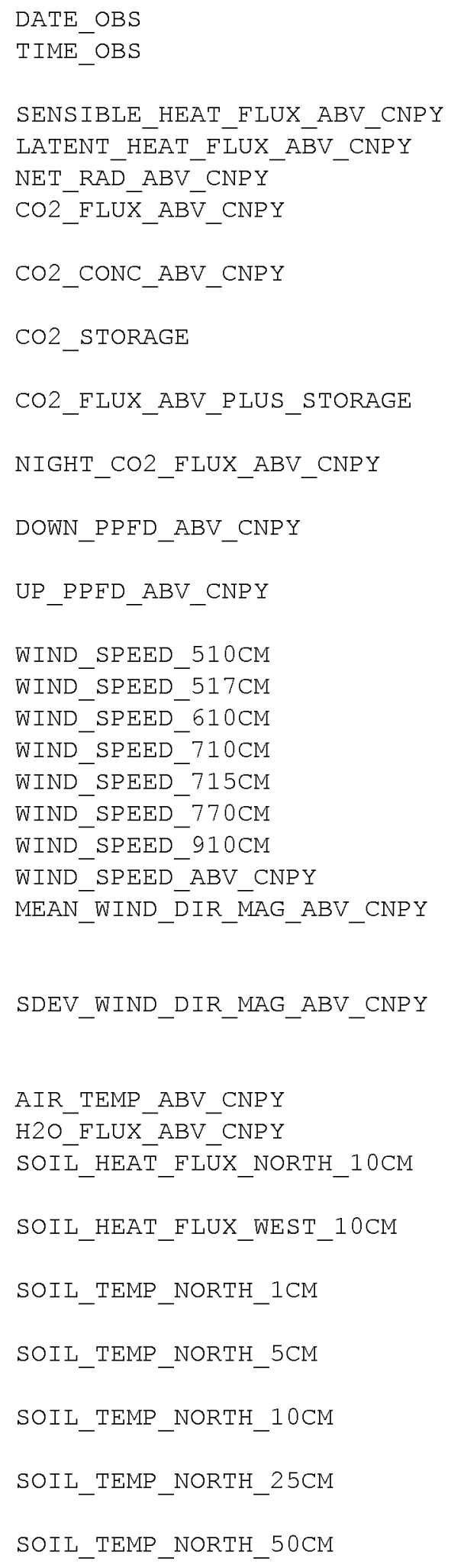

in the format GGGGG-IIIII, where GGGGG is the group associated with the sub-site instrument, e.g. HYD06 or STAFF, and IIIII is the identifier for sub-site, often this will refer to an instrument.

The date on which the data were collected.

The Greenwich Mean Time (GMT) of the start of the data collection.

The sensible heat flux measured above the canopy. The latent heat flux measured above the canopy. The net radiation measured above the canopy. The carbon dioxide flux measured above the canopy .

The carbon dioxide concentration measured above the canopy.

The storage term of carbon dioxide under the eddy flux system.

The sum of the above canopy carbon dioxide flux and the under flux instrument storage term.

The nighttime carbon dioxide flux estimated from a model based on temperature.

The downward (incoming) photosynthetic photon flux density measured above the canopy.

The reflected photosynthetic photon flux density measured above the canopy.

The wind speed measured $5.1 \mathrm{~m}$ above the ground. The wind speed measured $5.17 \mathrm{~m}$ above the ground. The wind speed measured $6.1 \mathrm{~m}$ above the ground. The wind speed measured $7.1 \mathrm{~m}$ above the ground. The wind speed measured $7.15 \mathrm{~m}$ above the ground. The wind speed measured $7.7 \mathrm{~m}$ above the ground. The wind speed measured $9.1 \mathrm{~m}$ above the ground. The wind speed measured above the canopy. The average wind direction in relation to magnetic north, over 30 minutes measured above the canopy.

The standard deviation of the wind direction in relation to magnetic north, over 30 minutes measured above the canopy.

The air temperature measured above the canopy. The water vapor flux measured above the canopy. The soil heat flux measured $10 \mathrm{~cm}$ below the soil surface at a location north of the flux tower. The soil heat flux measured $10 \mathrm{~cm}$ below the soil surface at a location west of the flux tower. Soil temperature $1 \mathrm{~cm}$ below the soil surface at a location north of the flux tower.

Soil temperature $5 \mathrm{~cm}$ below the soil surface at a location north of the flux tower.

Soil temperature $10 \mathrm{~cm}$ below the soil surface at a location north of the flux tower.

Soil temperature $25 \mathrm{~cm}$ below the soil surface at a location north of the flux tower.

Soil temperature $50 \mathrm{~cm}$ below the soil surface at 


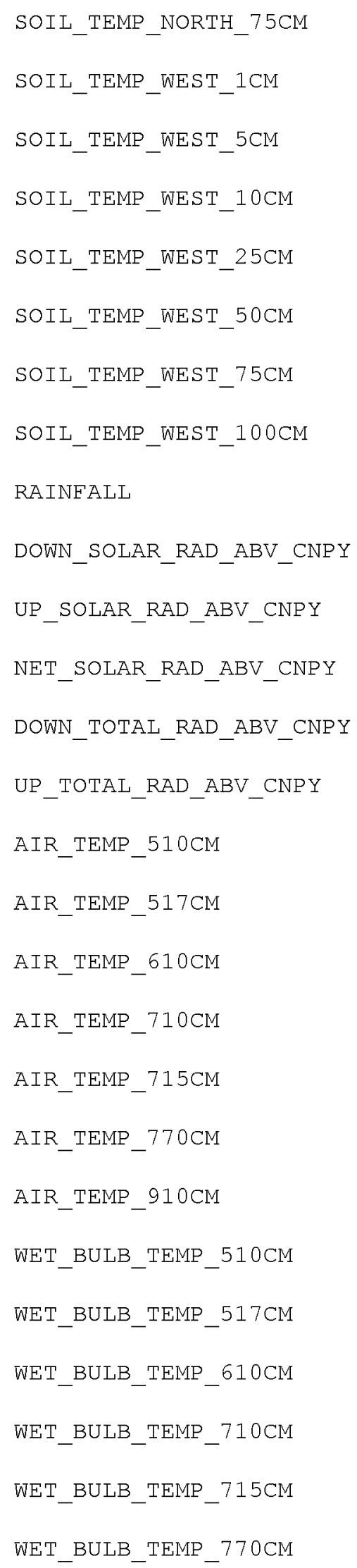

a location north of the flux tower.

soil temperature $75 \mathrm{~cm}$ below the soil surface at a location north of the flux tower.

Soil temperature $1 \mathrm{~cm}$ below the soil surface at a location west of the flux tower.

Soil temperature $5 \mathrm{~cm}$ below the soil surface at a location west of the flux tower.

Soil temperature $10 \mathrm{~cm}$ below the soil surface at a location west of the flux tower.

Soil temperature $25 \mathrm{~cm}$ below the soil surface at a location west of the flux tower.

Soil temperature $50 \mathrm{~cm}$ below the soil surface at a location west of the flux tower.

soil temperature $75 \mathrm{~cm}$ below the soil surface at a location west of the flux tower.

Soil temperature $1 \mathrm{~m}$ below the soil surface at a location west of the flux tower.

The amount of rainfall measured above the canopy in the 30 minute period following the given time. The downward (incoming) solar radiation measured above the canopy.

The reflected (outgoing) solar radiation measured above the canopy.

The net solar radiation measured above the canopy .

The total downward (incoming) radiation measured above the canopy.

The total upward (outgoing) radiation measured above the canopy.

The air temperature measured at 5.1 meters above the ground.

The air temperature measured at 5.17 meters above the ground.

The air temperature measured at 6.1 meters above the ground.

The air temperature measured at 7.1 meters above the ground.

The air temperature measured at 7.15 meters above the ground.

The air temperature measured at 7.7 meters above the ground.

The air temperature measured at 9.1 meters above the ground.

The wet bulb temperature measured at 5.1 meters above the ground.

The wet bulb temperature measured at 5.17 meters above the ground.

The wet bulb temperature measured at 6.1 meters above the ground.

The wet bulb temperature measured at 7.1 meters above the ground.

The wet bulb temperature measured at 7.15 meters above the ground.

The wet bulb temperature measured at 7.7 meters 


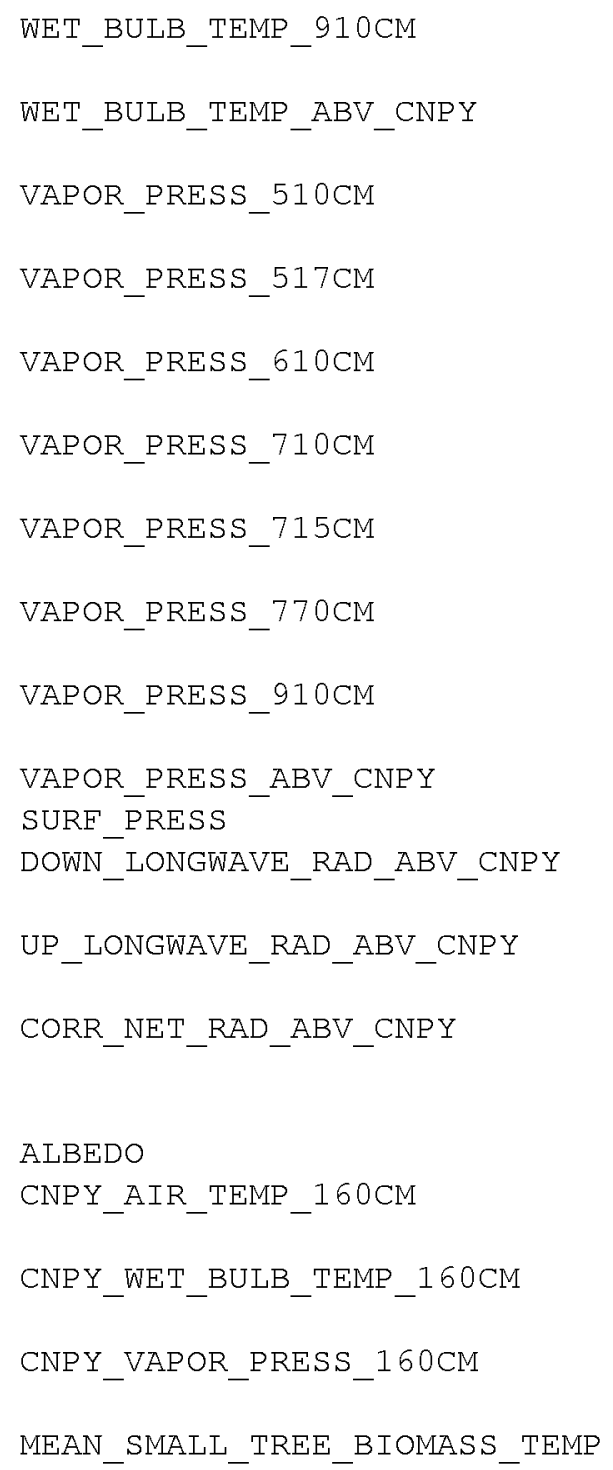

above the ground.

The wet bulb temperature measured at 9.1 meters above the ground.

The wet bulb temperature measured above the canopy.

The vapor pressure measured at 5.1 meters above the ground.

The vapor pressure measured at 5.17 meters above the ground.

The vapor pressure measured at 6.1 meters above the ground.

The vapor pressure measured at 7.1 meters above the ground.

The vapor pressure measured at 7.15 meters above the ground.

The vapor pressure measured at 7.7 meters above the ground.

The vapor pressure measured at 9.1 meters above the ground.

The vapor pressure measured above the canopy.

The atmospheric pressure measured at the station. The downward (incoming) longwave radiation measured above the canopy.

The upward (outgoing) longwave radiation measured above the canopy.

The corrected net radiation measured above the canopy, using equations developed by Hodges and Smith (1997).

Surface solar albedo.

The air temperature in the canopy measured at 1.6 meters above the ground.

The wet bulb temperature in the canopy measured at 1.6 meters above the ground.

The vapor pressure in the canopy measured at 1.6 meters above the ground.

The temperature of tree biomass in small trees. Measured using thermocouples embedded directly into the boles, $1 / 3$ of the way up the tree and $1 / 3$ of the radius into the boles. Three trees under $1.5 \mathrm{~m}$ height were measured.

The temperature of tree biomass in medium trees. Measured using thermocouples embedded directly into the boles, $1 / 3$ of the way up the tree and $1 / 3$ of the radius into the boles. Three trees over $2.5 \mathrm{~m}$ height were measured.

The temperature of tree biomass in large trees. Measured using thermocouples embedded directly into the boles, $1 / 3$ of the way up the tree and $1 / 3$ of the radius into the boles. Three trees over $5 \mathrm{~m}$ height were measured.

Total of minor heat storage terms including soil heat flux, storage in soil above flux plate, storage in biomass, and sensible and latent heat storage in the air at a location north of the 
TOTAL_HEAT_STORAGE_WEST

MEAN_TOTAL_HEAT_STORAGE

BIO_HEAT_STORAGE_NORTH

BIO_HEAT_STORAGE_WEST

MEAN_BIO_HEAT_STORAGE

SENSIBLE_AIR_HEAT_STORAGE

LATENT_AIR_HEAT_STORAGE

SOIL_HEAT_STORAGE_NORTH_10CM

SOIL_HEAT_STORAGE_WEST_10CM

MEAN_SPECIFIC_HUM_ABV_CNPY

SDEV_SPECIFIC_HUM_ABV_CNPY

MEAN_W_WIND_SPEED_ABV_CNPY

SDEV_W_WIND_SPEED_ABV_CNPY

REL HUM ABV CNPY

CRTFCN_EODE

REVISION_DATE flux tower.

Total of minor heat storage terms including soil heat flux, storage in soil above flux plate, storage in biomass, and sensible and latent heat storage in the air at a location west of the flux tower.

Average of the north and west site total heat storage values.

Biomass heat storage for a site north of the flux tower.

Biomass heat storage for a site west of the flux tower.

Average of the north and west site biomass heat storage values.

Sensible heat storage in air column between the surface and net pyrradiometer.

Latent heat storage in air column between the surface and net pyrradiometer.

Heat storage in the $10 \mathrm{~cm}$ of soil above the heat flux plate at a location north of the flux tower Heat storage in the $10 \mathrm{~cm}$ of soil above the heat flux plate at a location west of the flux tower The 30 minute mean specific humidity measured above the canopy.

The 30 minute standard deviation of specific humidity measured above the canopy.

The 30 minute mean of the vertical wind speed measured above the canopy.

The 30 minute standard deviation of the vertical wind speed measured above the canopy.

The relative humidity measured above the canopy. The BOREAS certification level of the data. Examples are CPI (Checked by PI), CGR (Certified by Group), PRE (Preliminary), and CPI-??? (CPI but questionable).

The most recent date when the information in the referenced data base table record was revised.

The descriptions of the parameters contained in the porometry data files on the CD-ROM are:

\begin{tabular}{|c|c|}
\hline Column Name & Description \\
\hline SITE_NAME & $\begin{array}{l}\text { The identifier assigned to the site by BOREAS, } \\
\text { in the format SSS-TTT-CCCCC, where SSS identifies } \\
\text { the portion of the study area: NSA, SSA, REG, } \\
\text { TRN, and TTT identifies the cover type for the } \\
\text { site, } 999 \text { if unknown, and CCCCC is the identifier } \\
\text { for site, exactly what it means will vary with } \\
\text { site type. }\end{array}$ \\
\hline SUB_SITE & $\begin{array}{l}\text { The identifier assigned to the sub-site by BOREAS } \\
\text { in the format GGGGG-IIIII, where GGGGG is the } \\
\text { group associated with the sub-site instrument, } \\
\text { e.g. HYD06 or STAFF, and IIIII is the identifier } \\
\text { for sub-site, often this will refer to an }\end{array}$ \\
\hline
\end{tabular}

Page 37 


\author{
DATE OBS \\ TIME_OBS \\ TREE HT CLASS \\ MEASUREMENT_HT_CLASS \\ STOMATAL_CONDUCT_H2O \\ CRTFCN_CODE
}

REVISION_DATE instrument.

The date on which the data were collected.

The Greenwich Mean Time (GMT) when the data were collected.

The height class of the tree being measured.

The height class in the tree where the

measurement was made.

Stomatal conductance of water vapor.

The BOREAs certification level of the data.

Examples are CPI (Checked by PI), CGR (Certified by Group), PRE (Preliminary), and CPI-??? (CPI but questionable).

The most recent date when the information in the referenced data base table record was revised.

\subsubsection{Unit of Measurement}

The measurement units for the parameters contained in the flux data files on the CD-ROM are:

\begin{tabular}{|c|c|}
\hline Column Name & Units \\
\hline SITE NAME & [none] \\
\hline SUB_SITE & [none] \\
\hline DATE_OBS & {$[D D-M O N-Y Y]$} \\
\hline TIME_OBS & [HHMM GMT] \\
\hline SENSIBLLE HEAT FLUX ABV CNPY & [Watts] [meter ${ }^{\wedge}-2$ ] \\
\hline LATENT_HEAT_FLUX_ABBV_CNPY & [Watts] [meter^-2] \\
\hline NET_RAD_ABV_CNPY & {$[$ Watts $]\left[\right.$ meter $\left.{ }^{\wedge}-2\right]$} \\
\hline CO2 ${ }^{-}$FLUX $A B \bar{V}$ CNPY & [micromoles] [meter $\left.{ }^{\wedge}-2\right]\left[\right.$ second $\left.{ }^{\wedge}-1\right]$ \\
\hline $\mathrm{CO}^{-}{ }^{-} \mathrm{CONC} \mathrm{ABV}^{-} \mathrm{CNPY}$ & [parts per million] \\
\hline CO2_STORĀGE & [micromoles] [meter $\left.{ }^{\wedge}-2\right]\left[\right.$ second $\left.{ }^{\wedge}-1\right]$ \\
\hline CO2-FLUX_ABV_PLUS STORAGE & [micromoles] [meter $\left.{ }^{\wedge}-2\right]\left[\right.$ second $\left.{ }^{\wedge}-1\right]$ \\
\hline 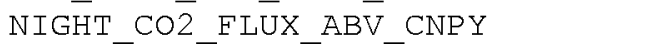 & [micromoles] [meter $\left.{ }^{\wedge}-2\right]\left[\right.$ second $\left.{ }^{\wedge}-1\right]$ \\
\hline DOWN_PPFD_ABV_C $\bar{C} N P Y-$ & [micromoles] [meter^^-2] [second^-1] \\
\hline $\mathrm{UP} P \overline{\mathrm{P}} \mathrm{FD} \_\mathrm{AB} V \_\overline{\mathrm{N}} \mathrm{P} Y$ & [micromoles] [meter $\left.r^{\wedge}-2\right]\left[\right.$ second $\left.d^{\wedge}-1\right]$ \\
\hline WIND_SPEED_ $\overline{5} 10 \mathrm{CM}$ & {$[$ meters $]\left[\operatorname{second}^{\wedge}-1\right]$} \\
\hline WIND_SPEED_517CM & {$[$ meters $][$ second^-1] } \\
\hline WIND_SPEED_610CM & [meters] [second^-1] \\
\hline WIND_SPEED_710CM & [meters] [ second^-1] \\
\hline WIND_SPEED_-715CM & [meters] [second^-1] \\
\hline WIND_SPEED_770CM & {$\left[\right.$ meters] [ second $\left.{ }^{\wedge}-1\right]$} \\
\hline WIND_SPEED_910CM & {$[$ meters ] [ second^-1] } \\
\hline WIND_SPEED_ABV_CNPY & {$[$ meters $][$ second^-1$]$} \\
\hline MEAN_WIND_DIR_MAG_ABV_CNPY & [degrees from magnetic north] \\
\hline SDEV_WIND_DIR_MAG_ABV_CNPY & [degrees from magnetic north] \\
\hline AIR_TEMP_ABV_CNPY & [degrees Celsius] \\
\hline H20_ELUX_ABV_CNPY & [millimoles] [meter $\left.{ }^{\wedge}-2\right]\left[\right.$ second $\left.{ }^{\wedge}-1\right]$ \\
\hline 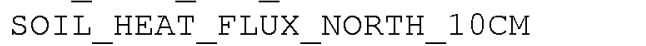 & {$[$ Watts $]\left[\right.$ meter^$\left.{ }^{\wedge}-2\right]$} \\
\hline SOIL_HEAT_FLUX_WEST_10CM & [Watts] [meter^-2] \\
\hline SOIL_TEMP_NORTH_1 ${ }^{-} \mathrm{CM}^{-}$ & [degrees Celsius] \\
\hline SOIL_TEMP_NORTH_5CM & [degrees Celsius] \\
\hline SOIL_TEMP_NORTH_10CM & [degrees Celsius] \\
\hline SOIL_TEMP_NORTH_25CM & [degrees Celsius] \\
\hline SOIL- TEMP NORTH $50{ }^{-}$CM & [degrees Celsius] \\
\hline SOIL_TEMP_NORTH_ $75 \mathrm{CM}$ & [degrees Celsius] \\
\hline
\end{tabular}




\begin{tabular}{|c|c|}
\hline SOIL_TEMP_WEST_1CM & [ degrees \\
\hline SOIL_TEMP_WEST_- $5 \mathrm{CM}$ & [degrees \\
\hline SOIL_TEMP_WEST_10CM & [degrees \\
\hline SOIL_TEMP_WEST_25CM & [ degrees \\
\hline SOIL ${ }^{-}$TEMP ${ }^{-}$WEST $50 \mathrm{CM}^{-}$ & [ degrees \\
\hline SOIL_TEMP_WEST_75CM & [degrees Celsius] \\
\hline SOIL_TEMP_WEST_100CM & [degrees Celsius] \\
\hline RAINFALL & [millimeters] \\
\hline DOWN SOLAR RAD ABV CNPY & [Watts] [meter ${ }^{\wedge}-2$ ] \\
\hline UP_SOLAR_RAD_ABBV_CNPY & [Watts] [meter^-2] \\
\hline 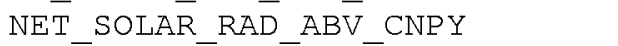 & [watts] [meter $\left.{ }^{\wedge}-2\right]$ \\
\hline 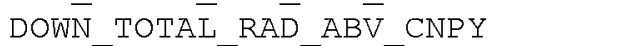 & [Watts] [meter^-2] \\
\hline 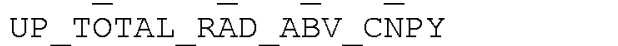 & [Watts] [meter^ ${ }^{\wedge} 2$ ] \\
\hline AIR_TEMP_510 $\overline{\mathrm{CM}}$ & [degrees Celsius] \\
\hline AIR_TEMP $517 \mathrm{CM}$ & [degrees Celsius] \\
\hline AIR_TEMP_ $610 \mathrm{CM}$ & [degrees \\
\hline AIR_TEMP_ $710 \mathrm{CM}$ & [degrees Celsius] \\
\hline AIR_TEMP $715 \mathrm{CM}$ & [degrees Celsius] \\
\hline AIR_TEMP_- $770 \mathrm{CM}$ & [degrees Celsius] \\
\hline AIR_TEMP_910CM & [degrees Celsius] \\
\hline WET_BULB_TEMP_510CM & [degrees Celsius] \\
\hline WET_BULB_TEMP_517CM & [degrees Celsius] \\
\hline WET_BULB_TEMP_ $610 \mathrm{CM}$ & [ degrees \\
\hline WET_BULB_TEMP_ $710 \mathrm{CM}^{-}$ & [degrees Celsius] \\
\hline WET_BULB_TEMP_ $715 \mathrm{cM}$ & [degrees Celsius] \\
\hline WET_BULB_TEMP_770 CM & [degrees Celsius] \\
\hline WET ${ }^{-}$BULB ${ }^{-}$TEMP ${ }^{-} 910 \mathrm{CM}$ & [degrees Celsius] \\
\hline WET_BULB_TEMP_ABV_CNPY & [degrees Celsius] \\
\hline VAPOR_PRESS_510 $\overline{10 M}$ & [kiloPascals] \\
\hline VAPOR_PRESS $517 \mathrm{CM}$ & [kilopascals] \\
\hline VAPOR PRESS ${ }^{-} 610 \mathrm{CM}$ & [kilopascals] \\
\hline VAPOR_PRESS_710CM & [kiloPascals] \\
\hline VAPOR_PRESS ${ }^{-} 715 \mathrm{CM}$ & [kiloPascals] \\
\hline VAPOR PRESS ${ }^{-} 770 \mathrm{CM}$ & [kilopascals] \\
\hline VAPOR_PRESS_910CM & [kiloPascals] \\
\hline VAPOR_PRESS_ABV_CNPY & [kilopascals] \\
\hline SURF $\bar{P} R E S S$ & [kilopascals] \\
\hline DOWN_LONGWAVE_RAD_ABV_CNPY & [Watts] [meter^-2] \\
\hline 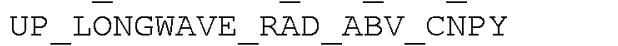 & [Watts] [meter^-2] \\
\hline 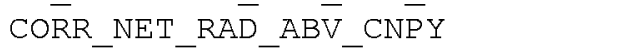 & [Watts] [meter $\left.{ }^{\wedge}-2\right]$ \\
\hline $\mathrm{ALBED}-\overline{-}-$ & [unitless] \\
\hline CNPY_AIR_TEMP_160CM & [degrees Celsius] \\
\hline CNPY WET_BULB_TEMP_160CM & [degrees Celsius] \\
\hline CNPY_VAPOTR_PRESS_1 $1 \overline{6} 0 \mathrm{CM}$ & [kilopascals] \\
\hline MEAN_SMALL_TREE_B'- BIOMASS_TEMP & [degrees Celsius] \\
\hline MEAN_MEDIUM_TREE_BIOMASS_TEMP & [degrees Celsius] \\
\hline MEAN_LARGE_TREE_BIOMASS_TEMP & [degrees Celsius] \\
\hline 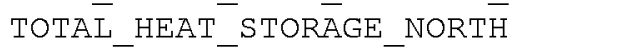 & [Watts] [meter $\left.{ }^{\wedge}-2\right]$ \\
\hline TOTAL_HEAT_STORAGE_WEST & [Watts] [meter $\left.{ }^{\wedge}-2\right]$ \\
\hline MEAN_TOTAL_HEAT_STORAGE & [Watts] [meter $\left.{ }^{\wedge}-2\right]$ \\
\hline BIO_E_EAT_STORAGE_NORTH & [Watts] [meter^-2] \\
\hline BIO־HEAT_ STORAGE WEST & [Watts] [meter $\left.{ }^{\wedge}-2\right]$ \\
\hline MEĀ̄ BIO-HEAT STÖRAGE & [Watts] [meter $\left.{ }^{\wedge}-2\right]$ \\
\hline SENSIBLE_AIR_HEAT_STORAGE & [Watts] [meter $\left.{ }^{\wedge}-2\right]$ \\
\hline
\end{tabular}

Page 39 


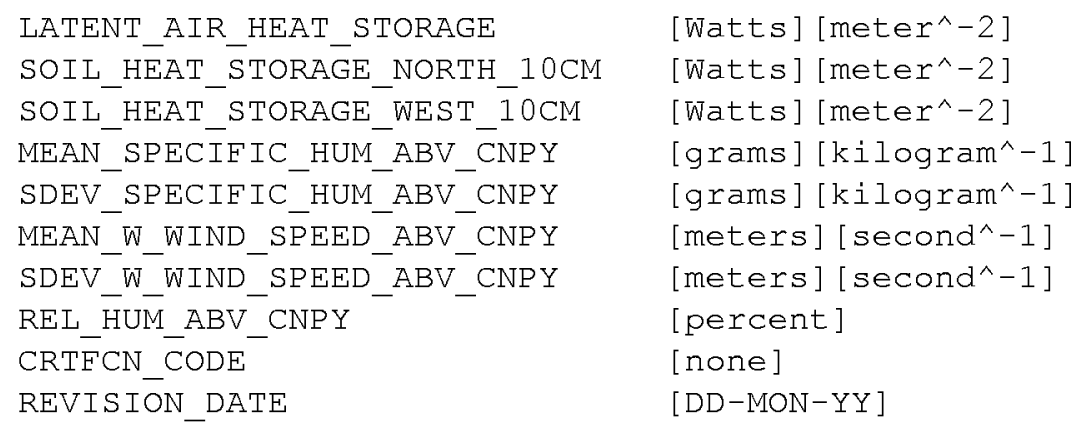

The measurement units for the parameters contained in the porometry data files on the CD-ROM are:

\begin{tabular}{|c|c|}
\hline Column Name & Units \\
\hline SITE_NAME & [none] \\
\hline SUB SITE & [none ] \\
\hline DATE OBS & [DD-MON-YY] \\
\hline TIME OBS & [ HHMM GMT] \\
\hline TREE HT CLASS & [meters] \\
\hline MEASUREEMENT HT CLASS & [meters] \\
\hline STOMATAL CONDDUCT H2O & [millimeters H2O][second $\left.{ }^{\wedge}-1\right]$ \\
\hline CRTFCN_CODE & [none ] \\
\hline REVISIONN DATE & {$[D D-M O N-Y Y]$} \\
\hline
\end{tabular}

\subsubsection{Data Source}

The sources of the parameter values contained in the flux data files on the CD-ROM are:

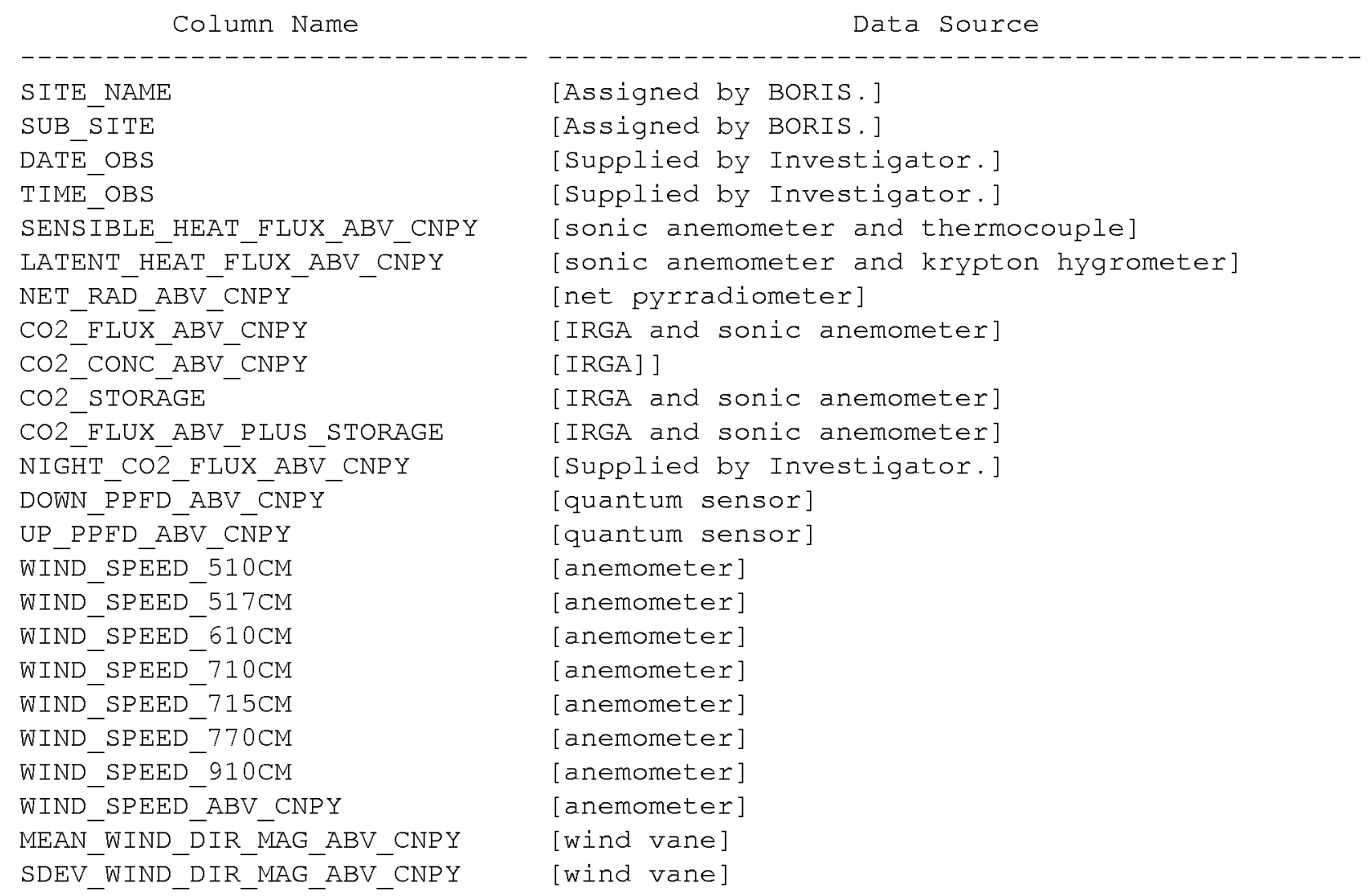




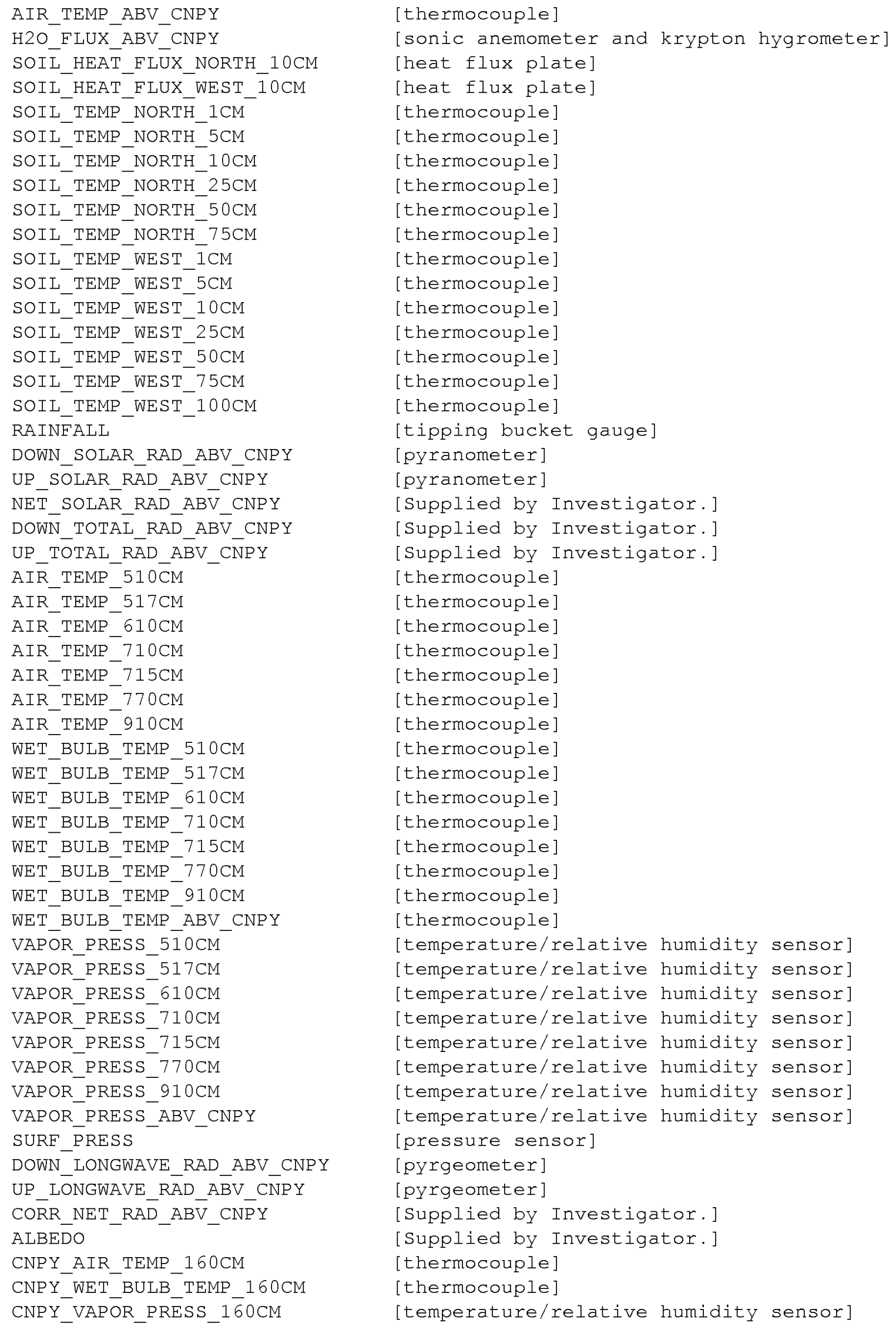

[thermocouple]

[sonic anemometer and krypton hygrometer]

[heat flux plate]

[heat flux plate]

[thermocouple]

[thermocouple]

[thermocouple]

[thermocouple]

[thermocouple]

[thermocouple]

[thermocouple]

[thermocouple]

[thermocouple]

[thermocouple]

[thermocouple]

[thermocouple]

[thermocouple]

[tipping bucket gauge]

[pyranometer]

[pyranometer]

[Supplied by Investigator.]

[Supplied by Investigator.]

[Supplied by Investigator.]

[thermocouple]

[thermocouple]

[thermocouple]

[thermocouple]

[thermocouple]

[thermocouple]

[thermocouple]

[thermocouple]

[thermocouple]

[thermocouple]

[thermocouple]

[thermocouple]

[thermocouple]

[thermocouple]

[thermocouple]

[temperature/relative humidity sensor]

[temperature/relative humidity sensor]

[temperature/relative humidity sensor]

[temperature/relative humidity sensor]

[temperature/relative humidity sensor]

[temperature/relative humidity sensor]

[temperature/relative humidity sensor]

[temperature/relative humidity sensor]

[pressure sensor]

[pyrgeometer]

[pyrgeometer]

[Supplied by Investigator.]

[Supplied by Investigator.]

[thermocouple]

[thermocouple]

[temperature/relative humidity sensor] 


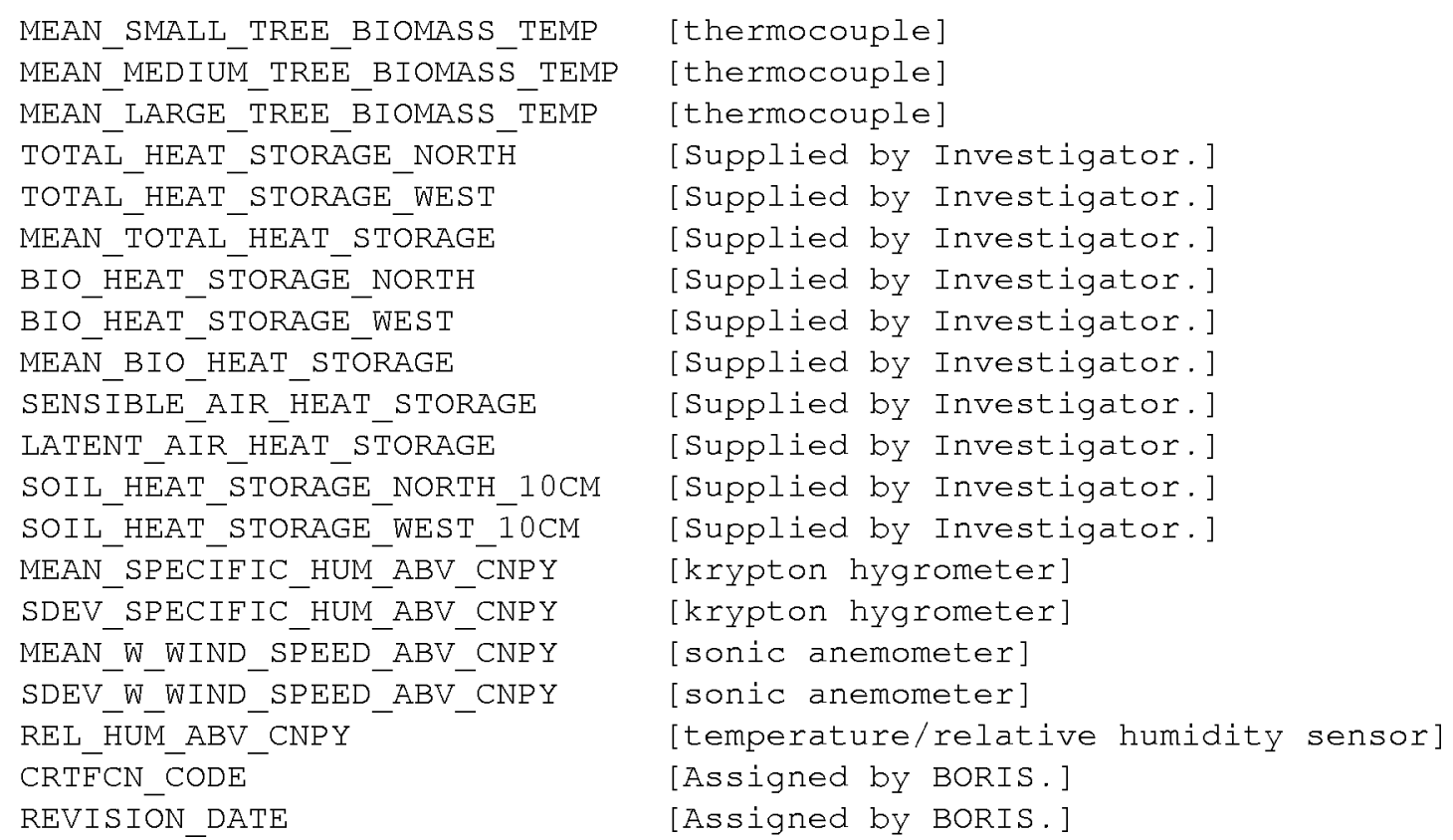

The sources of the parameter values contained in the porometry data files on the CD-ROM are:

\begin{tabular}{ll}
\multicolumn{1}{c}{ Column Name } & Data Source \\
---1 & \\
SITE_NAME & [Assigned by BORIS.] \\
SUB_SITE & [Assigned by BORIS.] \\
DATE_OBS & [Supplied by Investigator.] \\
TIME_OBS & [Supplied by Investigator.] \\
TREE_HT_CLASS & [Supplied by Investigator.] \\
MEASUREMENT_HT_CLASS & [Supplied by Investigator.] \\
STOMATAL_CONDUCT_H2O & [Porometer] \\
CRTFCN_CODE & [Assigned by BORIS.] \\
REVISION_DATE & [Assigned by BORIS.]
\end{tabular}

\subsubsection{Data Range}

The following table gives information about the parameter values found in the flux data files on the CD-ROM.

\begin{tabular}{|c|c|c|c|c|c|c|}
\hline Column Name & $\begin{array}{l}\text { Minimum } \\
\text { Data } \\
\text { Value }\end{array}$ & $\begin{array}{l}\text { Maximum } \\
\text { Data } \\
\text { Value }\end{array}$ & $\begin{array}{l}\text { Missng } \\
\text { Data } \\
\text { Value }\end{array}$ & $\begin{array}{l}\text { Unrel } \\
\text { Data } \\
\text { Value }\end{array}$ & $\begin{array}{l}\text { Below } \\
\text { Detect } \\
\text { Limit }\end{array}$ & $\begin{array}{l}\text { Data } \\
\text { Not } \\
\text { Cllctd }\end{array}$ \\
\hline-------------------- & --------------- & --------------- & ------ & ------ & ------- & ------- \\
\hline SITE_NAME & NSA-YJP-FLXTR & NSA-YJP-FLXTR & None & None & None & None \\
\hline SUB_SITE & 9TF10-FLX01 & $9 \mathrm{TF} 10-\mathrm{FLX01}$ & None & None & None & None \\
\hline DATE_OBS & $15-\mathrm{AUG}-93$ & $09-N O V-96$ & None & None & None & None \\
\hline TIME_OBS & 0 & 2330 & None & None & None & None \\
\hline $\begin{array}{l}\text { SENSIBLE_HEAT_FLUX_- } \\
\text { ABV_CNPY }\end{array}$ & -69.59 & 458.28 & -999 & None & None & None \\
\hline $\begin{array}{l}\text { LATENT_HEAT_FLUX_ABV } \\
\text { _CNPY }\end{array}$ & -68.9 & 428.3 & -999 & None & None & None \\
\hline 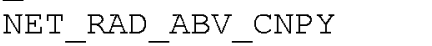 & -90.5 & 787 & -999 & None & None & None \\
\hline CO2_FLUX_ABV_CNPY & -16.1 & 32.757 & -999 & None & None & Blank \\
\hline $\mathrm{CO} 2$ CONC_ABV_CNPY & 288.4 & 435.3 & -999 & None & None & Blank \\
\hline CO2_STORAGE & -5.814 & 7.23 & -999 & None & None & Blank \\
\hline
\end{tabular}




\begin{tabular}{|c|c|c|c|c|c|c|}
\hline $\begin{array}{l}\text { CO2_ELUX_ABV_PLUS_ } \\
\text { STORAGE }\end{array}$ & -16.09 & 10.494 & -999 & None & None & Blank \\
\hline $\begin{array}{l}\text { NIGHT_CO2_FLUX_ABV } \\
\text { CNPY }\end{array}$ & -2.619 & 5.748 & -999 & None & None & Blank \\
\hline DOWN_PPED_ABV_CNPY & 0 & 2100 & -999 & None & None & None \\
\hline $\mathrm{UP} \_\mathrm{P} \overline{\mathrm{P}} \mathrm{FD} \_\mathrm{AB} \mathrm{B} V \_\overline{\mathrm{N}} \mathrm{PY}$ & 0 & 360 & -999 & None & None & None \\
\hline WIND_SPEED_5 $10 \mathrm{CM}$ & .199 & 5.168 & -999 & None & None & Blank \\
\hline WIND_SPEED_517CM & .199 & 6.223 & -999 & None & None & Blank \\
\hline WIND_SPEED_610CM & .199 & 6.848 & -999 & None & None & Blank \\
\hline WIND_SPEED_710CM & .199 & 6.022 & -999 & None & None & Blank \\
\hline WIND_SPEED_715CM & .199 & 7.3 & -999 & None & None & Blank \\
\hline WIND_SPEED_ $770 \mathrm{CM}$ & .199 & 7.59 & -999 & None & None & Blank \\
\hline WIND_SPEED_910CM & .199 & 6.547 & -999 & None & None & Blank \\
\hline WIND_SPEED_ABV_CNPY & .197 & 8.32 & -999 & None & None & None \\
\hline $\begin{array}{l}\text { MEAN_WIND_DIR_ }{ }^{-}{ }^{-} G_{-} \\
\text {ABV_CNPY }\end{array}$ & 0 & 359.9 & -999 & None & None & None \\
\hline $\begin{array}{l}\text { SDEV _WIND_DIR_MAG_ } \\
\text { ABV_CNPY }\end{array}$ & 0 & 78.1 & -999 & None & None & None \\
\hline AIR_TEMP_ABV_CNPY & -17.28 & 30.11 & -999 & None & None & None \\
\hline H20_ELUX_ABV_CNPY & -1.5283 & 7.8144 & -999 & None & None & None \\
\hline $\begin{array}{l}\text { SOIL_HEAT_FLUX_NORTH } \\
10 \mathrm{CM}\end{array}$ & -31.4 & 73 & -999 & None & None & None \\
\hline $\begin{array}{l}\text { SOIL_HEAT_FLUX_WEST_ } \\
10 \mathrm{CM}\end{array}$ & -45.2 & 93.1 & -999 & None & None & None \\
\hline SOIL_TEMP_NORTH_1CM & -1.86 & 31.61 & -999 & None & None & None \\
\hline SOIL_TEMP_NORTH_5CM & -.44 & 24.64 & -999 & None & None & None \\
\hline SOIL_TEMP_NORTH_10CM & -.65 & 20.99 & -999 & None & None & None \\
\hline SOIL_TEMP_NORTH_25CM & -.66 & 17.66 & -999 & None & None & Blank \\
\hline SOIL_TEMP_NORTH_50CM & -.7 & 15.1 & -999 & None & None & Blank \\
\hline SOIL_TEMP_NORTH_ $75 \mathrm{CM}$ & -.65 & 13.26 & -999 & None & None & Blank \\
\hline SOIL_TEMP_WEST_1 CM & -2.9 & 34.43 & -999 & None & None & None \\
\hline SOIL_TEMP_WEST_5CM & -.08 & 24.65 & -999 & None & None & None \\
\hline SOIL_TEMP WEST_ $10 \mathrm{CM}$ & -.15 & 19.55 & -999 & None & None & None \\
\hline SOIL_TEMP WEST $25 \mathrm{CM}$ & -.13 & 16.19 & -999 & None & None & None \\
\hline SOIL_TEMP_WEST_50CM & -.2 & 13.87 & -999 & None & None & None \\
\hline SOIL_TEMP_WEST_- $75 \mathrm{CM}$ & -.3 & 12.2 & -999 & None & None & None \\
\hline SOIL_TEMP WEST_100CM & -.24 & 10.89 & -999 & None & None & None \\
\hline RAINEALL & 0 & 6.35 & -999 & None & None & None \\
\hline $\begin{array}{l}\text { DOWN_SOLAR_RAD_ABV } \\
\text { CNPY }\end{array}$ & 0 & 1021 & -999 & None & None & None \\
\hline $\begin{array}{l}\text { UP_SOLAR_RAD_ABV }- \\
\text { CNPY }\end{array}$ & 0 & 188.2 & -999 & None & None & None \\
\hline $\begin{array}{l}\text { NET_SOLAR_RAD_ABV__ } \\
\text { CNPY }\end{array}$ & 0 & 891.4 & -999 & None & None & None \\
\hline $\begin{array}{l}\text { DOWN_TOTAL_RAD_ABV } \\
\text { CNPY }\end{array}$ & 179.45 & 1365.5 & -999 & None & None & None \\
\hline $\begin{array}{l}\text { UP_TOTAL_RAD_ABV_ } \\
\text { CNPY }\end{array}$ & 229.8 & 632.9 & -999 & None & None & None \\
\hline AIR_TEMP_510CM & .373 & 26.8 & -999 & None & None & Blank \\
\hline AIR_TEMP_517CM & -17.43 & 30.4 & -999 & None & None & Blank \\
\hline AIR_TEMP_610CM & -.013 & 30.18 & -999 & None & None & Blank \\
\hline AIR_TEMP_710CM & 2.581 & 26.57 & -999 & None & None & Blank \\
\hline $\mathrm{AIR}^{-} \mathrm{TEMP}_{-}^{-} 715 \mathrm{CM}$ & .156 & 29.45 & -999 & None & None & Blank \\
\hline AIR_TEMP_ $770 \mathrm{CM}$ & -17.36 & 30.14 & -999 & None & None & Blank \\
\hline
\end{tabular}




\begin{tabular}{|c|c|c|c|c|c|c|}
\hline AIR_TEMP_910CM & 3.752 & 26.37 & -999 & None & None & Blank \\
\hline WET_BULB_TEMP_510CM & .11 & 18.95 & -999 & None & None & Blank \\
\hline WET_BULB_TEMP_517CM & -.136 & 19 & -999 & None & None & Blank \\
\hline WET_BULB_TEMP_610CM & -.043 & 18.95 & -999 & None & None & Blank \\
\hline WET_BULB_TEMP_710CM & 3.641 & 18.78 & -999 & None & None & Blank \\
\hline WET_BULB_TEMP_715CM & .077 & 18.95 & -999 & None & None & Blank \\
\hline WET_BULB_TEMP_770CM & .132 & 18.94 & -999 & None & None & Blank \\
\hline WET_BULB_TEMP_910CM & 2.959 & 18.77 & -999 & None & None & Blank \\
\hline $\begin{array}{l}\text { WET_BULB_TEMP_ABV } \\
\text { CNPY }\end{array}$ & .156 & 18.92 & -999 & None & None & Blank \\
\hline VAPOR_PRESS_510CM & .5983 & 1.9357 & -999 & None & None & Blank \\
\hline VAPOR_PRESS_517CM & .4654 & 1.9731 & -999 & None & None & Blank \\
\hline VAPOR_PRESS_610CM & .4854 & 1.9724 & -999 & None & None & Blank \\
\hline VAPOR_PRESS_710CM & .5872 & 1.9041 & -999 & None & None & Blank \\
\hline VAPOR_PRESS $715 \mathrm{CM}$ & .4602 & 1.9717 & -999 & None & None & Blank \\
\hline VAPOR_PRESS_770CM & .4592 & 1.9731 & -999 & None & None & Blank \\
\hline VAPOR_PRESS_910CM & .6067 & 1.9161 & -999 & None & None & Blank \\
\hline VAPOR_PRESS_ABV_CNPY & .1338 & 2.3719 & -999 & None & None & None \\
\hline SURF_PRESS & 95.8 & 99.6 & -999 & None & None & Blank \\
\hline $\begin{array}{l}\text { DOWN_LONGWAVE_RAD_ } \\
\text { ABV_CNPY }\end{array}$ & 155.5 & 421.12 & -999 & None & None & None \\
\hline $\begin{array}{l}\text { UP_LONGWAVE_RAD_ABV } \\
\text { CNPY }\end{array}$ & 229.8 & 524.7 & -999 & None & None & None \\
\hline $\begin{array}{l}\text { CORR_NET_RAD_ABV } \\
\text { CNPY }\end{array}$ & -95.01 & 788.3 & -999 & None & None & Blank \\
\hline ALBEDO & 0 & .965 & -999 & None & None & None \\
\hline CNPY_AIR_TEMP_160CM & -4.114 & 31.87 & -999 & None & None & Blank \\
\hline $\begin{array}{l}\text { CNPY_WET_BULB_TEMP_ } \\
160 \mathrm{CM}\end{array}$ & -4.17 & 19.32 & -999 & None & None & Blank \\
\hline $\begin{array}{l}\text { CNPY_VAPOR_PRESS_- } \\
160 \mathrm{CM}\end{array}$ & .4415 & 2.0113 & -999 & None & None & Blank \\
\hline $\begin{array}{l}\text { MEAN_SMALL_TREE_- } \\
\text { BIOMASS_TEMP }\end{array}$ & -24.48 & 39.03 & -999 & None & None & None \\
\hline $\begin{array}{l}\text { MEAN_MEDIUM_TREE_ } \\
\text { BIOMASS_TEMP }\end{array}$ & -23.89 & 37 & -999 & None & None & None \\
\hline $\begin{array}{l}\text { MEAN_LARGE_TREE_- } \\
\text { BIOMASS TEMP }\end{array}$ & -21.88 & 35.56 & -999 & None & None & None \\
\hline $\begin{array}{l}\text { TOTAL_HEAT_STORAGE_ } \\
\text { NORTH }\end{array}$ & -146.1 & 102.7 & -999 & None & None & Blank \\
\hline $\begin{array}{l}\text { TOTAL_HEAT_STORAGE_ } \\
\text { WEST }\end{array}$ & -74.3 & 148.3 & -999 & None & None & Blank \\
\hline $\begin{array}{l}\text { MEAN_TOTAL_HEAT_ } \\
\text { STORAGE }\end{array}$ & -62.1 & 89.2 & -999 & None & None & Blank \\
\hline $\begin{array}{l}\text { BIO_HEAT_STORAGE_ } \\
\text { NORTH }\end{array}$ & -12 & 9.2 & -999 & None & None & Blank \\
\hline $\begin{array}{l}\text { BIO_HEAT_STORAGE_- } \\
\text { WEST }\end{array}$ & -25.3 & 15 & -999 & None & None & Blank \\
\hline $\begin{array}{l}\text { MEAN_BIO_HEAT_ } \\
\text { STORAGE }\end{array}$ & -10.5 & 6.2 & -999 & None & None & Blank \\
\hline $\begin{array}{l}\text { SENSIBLE_AIR_HEAT_ } \\
\text { STORAGE }\end{array}$ & -44 & 22.6 & -999 & None & None & None \\
\hline $\begin{array}{l}\text { LATENT_AIR_HEAT_- } \\
\text { STORAGE }\end{array}$ & -34.3 & 52.3 & -999 & None & None & None \\
\hline SOIL_HEAT_STORAGE_ & -66.7 & 46.8 & -999 & None & None & Blank \\
\hline
\end{tabular}




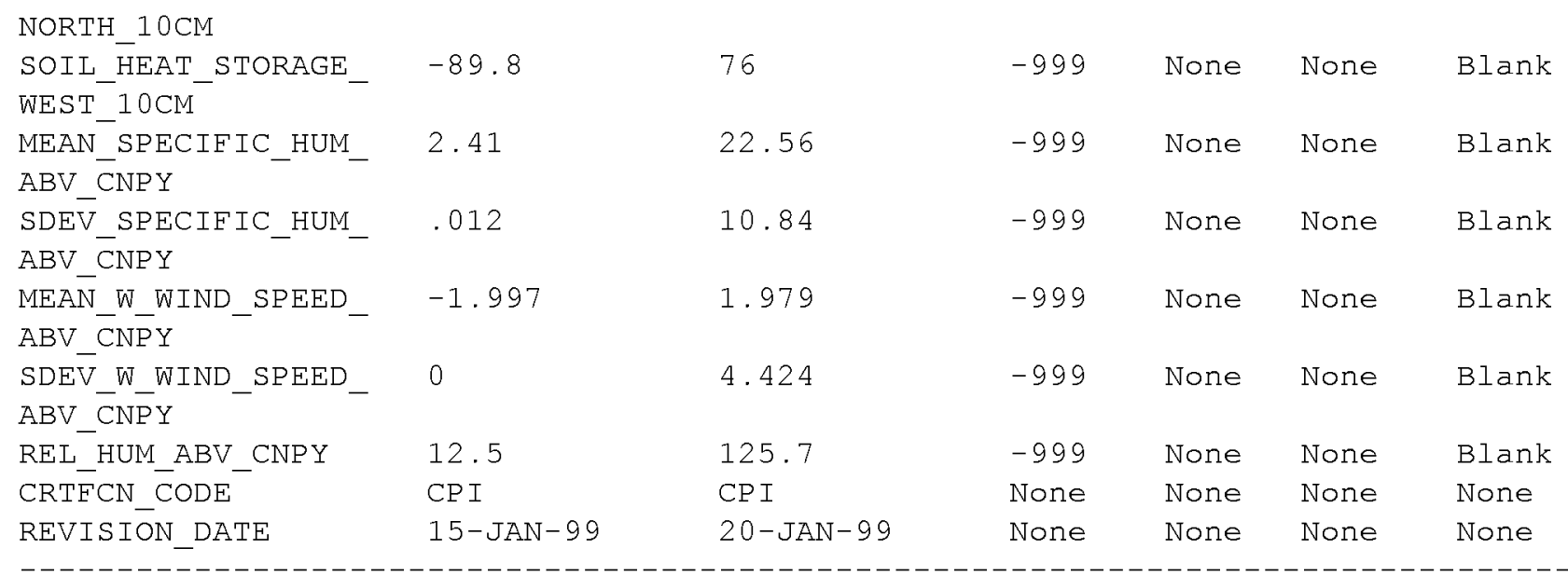

The following table gives information about the parameter values found in the porometry data files on the CD-ROM.

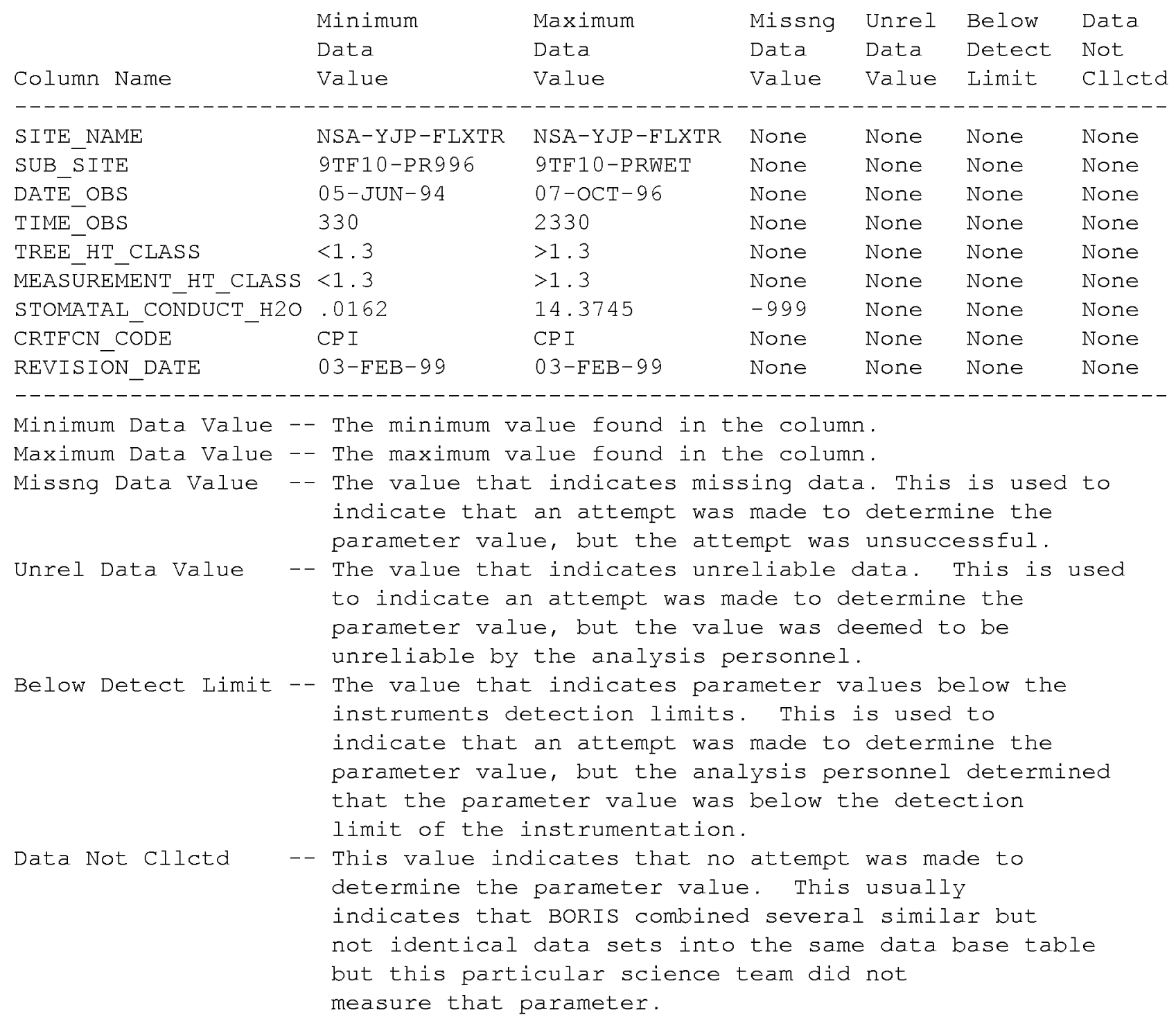


Blank -- Indicates that blank spaces are used to denote that type of value. N/A - - Indicates that the value is not applicable to the respective column. None -- Indicates that no values of that sort were found in the column.

\subsection{Sample Data Record}

The following are wrapped versions of flux data records from a sample data file on the CD-ROM.

SITE_NAME, SUB_SITE,DATE_OBS, TIME_OBS, SENSIBLE_HEAT_FLUX_ABV_CNPY, LATENTT HEAT FLUX ABV CNPY, NET RAD ABV CNPY, CO $\overline{2}$ FLUX ABV CNPY, CO2 CONC ABV CNPY, CO2_STORAGE, CO2_FLUX_ABV_PLUS_STORAGE, NIGHT_CO2_FLUX_ABV_CNPY, DOWN_PPFD_ABV_CNPY,

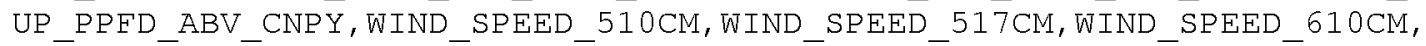
WINDD SPEED $710 \mathrm{CM}$, WIND ${ }^{-}$SPEED $715 \mathrm{CM}$, WIND SPEED $770 \mathrm{CM}$, WIND ${ }^{-}$SPEED $910 \mathrm{CM}$, WIND_SPEED_ABV_CNPY, MEAN_WIND_DIR_MAG_ABV_CNPY, SDEV_WIND_DIR_MAG_ABV_CNPY,

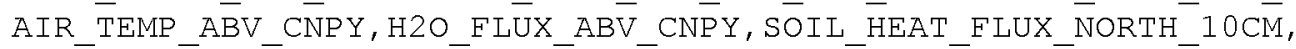
SOI $\bar{L}$ HEAT FLŪX WEST 1 $\overline{0} \mathrm{CM}$, SOIL TEMP NORTH_1CM, SOIL TEMP NORTH 5CM,

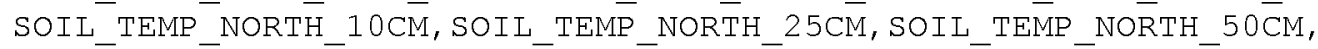
SOIL_TEMP_NORTH_75CM, SOIL_TEMP_WEST_1CM, SOIL_TEMP_WEST_5CM, SOIL_TEMP_WEST_10CM, SOIL_TEMP_WEST_- $5 \mathrm{CM}$, SOIL_TEMP_WEST_- $50 \mathrm{CM}$, SOIL_TEMP_WEST_$-75 \mathrm{CM}$, SOIL_TEMP_WEST_100CM, RAIN $\bar{N} F A L L, D O W N$ _SOLAR_RAD_ABV_CNPY, UP_SOLAR_RAD_ABV_CNPY, NET_SOLAR_RAD_ABV_CNPY,DOWN_TOTAL_RAD_ABV_CNPY, UP_TOTAL_RAD_ABV_CNPY,

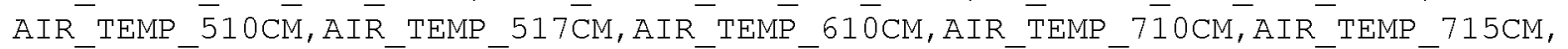
AIR_TEMP 7 70CM,AIR_TEMP_910CM,WET_BULB_TEMP_510CM, WET_BULB_TEMP_517CM, WET_BULB_TEMP_610 CM, WET_BULB_TEMP_710CM, WET_BULB_TEMP_715CM, WET_BULB_TEMP_770CM, WET_BULB_TEMP_910CM,WET_BULB_TEMP_ABV_CNPY, VAPOR_PRESS_510CM, VAPOR_PRESS_ $\overline{5} 17 \mathrm{CM}$,

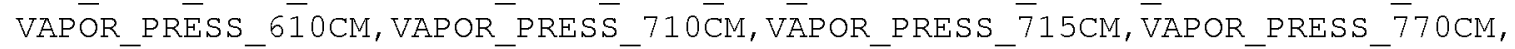
VAPOR_PRESS_910CM, VAPOR_PRESS_ABV_CNPY, SURF_PREST, DOWN_LONGWAVE_RAD_ABV_CNPY, UP_LONGWAVE_RAD_ABV_CNPY, CORR_NET_RAD_ABV_CNPY, ALBEDO, $\bar{C} N P Y \_A I R \_\overline{T E M P}-160 \overline{C M}$,

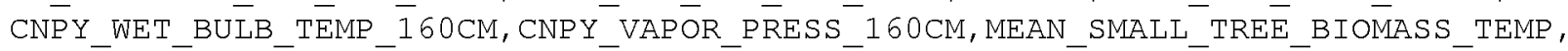
MEAN_MEDIUM_TREE_BIOMASS_TEMP, MEAN_LARGE_TREE_BIOMAS $\overline{\text { T }}$ TEMP, TOTAL_HEAT_STORAGE_NORTH, TOTAL_HEAT _STORAGE_WEST,MEAN_TOTAL_HEAT_STORAGE, BIO HEAT STORAGE NORTH, BIO HEAT STORAGE WEST, MEAN BIO HEAT STORAGE, SENSTIBLE_AIR_HEĀT_STORAGE, LATENT_AIR_HEĀT_STORAGE, SOIL_HEAT__STORAGE_NORTH_10CM, SOIL_HEAT_STORAGE_WEST_10CM, MEAN_SPECIFIC_HUM_ABV_CNPY,

SDEV_SPECIFIC_HUM_ABV_CNPY, MEAN_W WIND_SPEED_ABV_CNPY, SDEV_W_WIND_SPEED_ABV_CNPY, REL_HUM_ABV_CNPY, $\bar{C} R T E \bar{C} N \_C O D E, R E \bar{V} I \bar{S} I O N \_\overline{D A T E}$

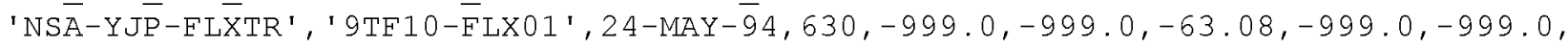
$-999.0,-999.0,-999.0,0.0,0.0,1.358,1.658,1.869,1.976,, 2.266,273.7,5.462,8.64$, $-999.0,1.1,-3.4,4.346,5.635,6.001,-999.0,-999.0,-999.0,3.906,5.162,5.327,4.298$, $2.119, .784, .178,0.0,0.0,0.0,0.0,-999.0,-999.0,7.03,7.61, .7 .98,8.17,1,5.496$, $-999.0,5.926,-999.0,6.332,1.8022,-999.0,, .7953,-999.0,1.8051,,-999.0,-999.0$, $-62.71,0.0,3.51,3.15, .7423, .05,1.225,5.068,-14.7,-20.5,,-.7,-1.6,-3.5,-.8,-10.8$, $-11.2,-999.0,-999.0,-999.0,-999.0,{ }^{\prime}{ }^{\prime} \mathrm{CPI}, 15-\mathrm{JAN}-99$

'NSA-YJP-FLXTR', ' 9TF10-FLX01', 24-MAY-94,700,-999.0,-999.0,-59.15,-999.0,-999.0, $-999.0,-999.0,-999.0,0.0,0.0,1.366,1.623,1.837,1.95,, 2.356,273.0,2.121,7.83$, $-999.0,-.1,-5.5,3.809,5.312,5.824,-999.0,-999.0,-999.0,3.354,4.826,5.144,4.274$, $2.154, .803, .188,0.0,0.0,0.0,0.0,-999.0,-999.0,6.054,6.557,6.92,7.14,1,4.949$, $-999.0,5.387,-999.0,5.962, .7966,-999.0,1.7955,-999.0,1.8099,,-999.0,-999.0$, $-58.08,0.0,3.276,2.959, .7348,-.84, .418,4.349,-15.4,-20.3,,-.5,-1.0,-3.3,-.8$, $-10.7,-9.7,-999.0,-999.0,-999.0,-999.0,{ }^{\prime}$ 'CPI', 15-JAN-99 
The following are wrapped versions of porometry data records from a sample data file on the CD-ROM.

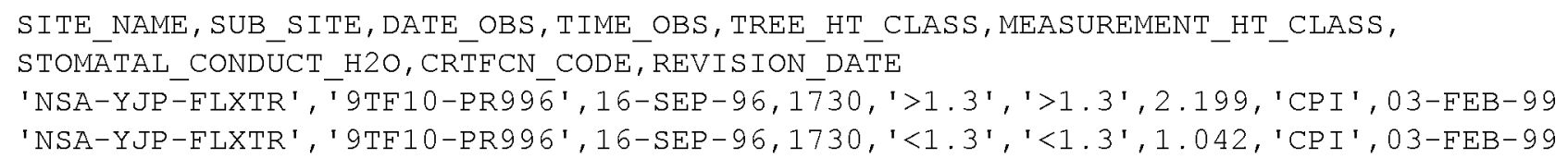

\section{Data Organization}

\subsection{Data Granularity}

The smallest unit of data tracked by BORIS was data collected at a given site on a given date.

\subsection{Data Format}

The Compact Disk-Read-Only Memory (CD-ROM) files contain American Standard Code for Information Interchange (ASCII) numerical and character fields of varying length separated by commas. The character fields are enclosed with single apostrophe marks. There are no spaces between the fields.

Each data file on the CD-ROM has four header lines of Hyper-Text Markup Language (HTML) code at the top. When viewed with a Web browser, this code displays header information (data set title, location, date, acknowledgments, etc.) and a series of HTML links to associated data files and related data sets. Line 5 of each data file is a list of the column names, and line 6 and following lines contain the actual data.

\section{Data Manipulations}

\subsection{Formulae}

Net Solar Radiation $\left(\mathrm{W} / \mathrm{m}^{2}\right)$

Net solar radiation $\left(\mathrm{K}^{*}\right)$ is the difference between incoming solar radiation $(\mathrm{Kd})$ and reflected solar radiation $(\mathrm{Ku})$ :

$$
\mathrm{K}^{*}=\mathrm{Kd}-\mathrm{Ku}
$$

\section{Incoming Longwave Radiation (W/m²)}

Incoming longwave radiation $(\mathrm{Ld})$ is calculated as a residual from the net radiation balance, where net radiation $\left(\mathrm{Q}^{*}\right)$ is the sum of net solar radiation $\left(\mathrm{K}^{*}\right.$, see e.g. 9.1) and net longwave radiation ( $\left.\mathrm{L}^{*}\right)$. $\mathrm{L}^{*}$ is the difference between incoming longwave radiation $(\mathrm{Ld})$ and outgoing longwave radiation (Lu).

$$
\mathrm{Q}^{*}=\mathrm{Kd}-\mathrm{Ku}+\mathrm{Ld}-\mathrm{Lu}
$$

\section{Total Incoming Radiation (W/m²)}

Total incoming radiation (Qd) is the sum of all incoming radiation:

$\mathrm{Qd}=\mathrm{Kd}+\mathrm{Ld}$

\section{Total Outgoing Radiation (W/m²)}

Total outgoing radiation $(\mathrm{Qu})$ is the sum of all outgoing radiation:

$$
\mathrm{Qu}=\mathrm{Ku}+\mathrm{Lu}
$$




\section{Net Radiation corrected $\left(\mathrm{W} / \mathrm{m}^{2}\right)$}

Measured net radiation $\left(\mathrm{Q}^{*}\right.$ ) was corrected using a set of site-specific day- and night-time equations developed by Hodges and Smith (1997). These equations (shown below) were used for all years of data, excluding data collected in 1993 at both fen and YJP. The use of the day or night equation is based on measured incoming solar radiation. When $\mathrm{Kd}>5.00 \mathrm{~W} / \mathrm{m}^{2}$, daytime equations are used. The relevant equations for the fen and YJP are:

$\begin{array}{llll}\text { Site } & \text { Time of day } & \text { Correction equation } & \\ \text { Fen } & \text { DAY } & Q^{*} \operatorname{corr}=0.957\left(Q^{*}\right)+3.2 & (9.5) \\ & \text { NIGHT } & Q^{*} \operatorname{corr}=1.079\left(Q^{*}\right)+11.1 & (9.6) \\ \text { YJP } & \text { DAY } & Q^{*} \operatorname{corr}=0.992\left(Q^{*}\right)+7.6 & (9.7) \\ & \text { NIGHT } & Q^{*} \operatorname{corr}=1.178\left(Q^{*}\right)+11.6 & (9.8)\end{array}$

Surface Albedo (dimensionless)

Surface albedo (a) is the ratio of the amount of radiation reflected by a body to the amount incident upon it:

$\mathrm{a}=\mathrm{Ku} / \mathrm{Kd}$

Total $\mathrm{CO}_{2}$ Flux $\left(\mathrm{umol} / \mathrm{m}^{2} / \mathrm{s}\right)$

The total $\mathrm{CO}_{2}$ flux $\left(\mathrm{FCO}_{2}\right)$ is the sum of the eddy flux $\left(\mathrm{Fe}_{\mathrm{CO} 2}\right)$ and the storage flux $\left(\mathrm{Fs}_{\mathrm{CO} 2}\right)$ :

$\mathrm{F}_{\mathrm{CO} 2}=\mathrm{Fe}_{\mathrm{CO} 2}+\mathrm{Fs}_{\mathrm{CO} 2} \quad(9.10)$

In 1994 and 1996 at the YJP site, a night model $\left(\mathrm{CO}_{2}\right.$ night $)$ was used in the calculation of the total $\mathrm{CO}_{2}$ flux (when $\mathrm{Kd}=0$ ), and

$$
\mathrm{CO}_{2} \text { night }=-2.4883+0.82337(\mathrm{Ts} 10 \mathrm{avg})-0.6777(\mathrm{Ts} 75 \mathrm{avg})
$$

where Ts10avg and Ts75avg are the average soil temperatures from the north and west zones from a depth of 10 and $75 \mathrm{~cm}$, respectively. Then,

$$
\mathrm{F}_{\mathrm{CO} 2}=\mathrm{CO}_{2} \text { night }+\mathrm{Fs}_{\mathrm{CO} 2}
$$

\section{Heat Storage $\left(\mathrm{W} / \mathrm{m}^{2}\right)$}

Total heat storage (G_total) is based on the sum of heat storage from several environmental compartments:

$$
\text { G_total }=\mathrm{G}+\mathrm{Ga}+\mathrm{Ge}+\mathrm{Gveg}
$$

where: $\mathrm{G}=$ soil heat flux

$\mathrm{Ga}=$ sensible heat storage in the air

$\mathrm{Ge}=$ latent heat storage in the air

Gveg $=$ heat storage in the vegetation

Only $\mathrm{G}$ is measured, and the remaining variables are calculated using the formulae given by Thom (1975):

$$
\begin{aligned}
& \mathrm{Ga}(\mathrm{T})=0.33 \mathrm{zrdTa}(\mathrm{t}) \\
& \mathrm{Ge}(\mathrm{T})=0.5 \mathrm{zrde}(\mathrm{t}) \\
& \operatorname{Gveg}(\mathrm{T})=0.8 \mathrm{Mv} \operatorname{dTb}(\mathrm{t})
\end{aligned}
$$


where $\mathrm{zr}$ is the reference height (in this case the height of the net pyrradiometer)(m); dTa, de, and dTb are the rates of change in air temperature $\left({ }^{\circ} \mathrm{C} / \mathrm{s}\right)$, vapor pressure $(\mathrm{kPa} / \mathrm{s})$, and biomass temperature $\left({ }^{\circ} \mathrm{C} / \mathrm{s}\right)$, respectively, for time step $\mathrm{t}$; and $\mathrm{Mv}$ is the standing green mass of vegetation over unit area $\left(\mathrm{kg} / \mathrm{m}^{2}\right)$. Theoretically, Ga and Ge are integrated over the height interval between the surface and $\mathrm{zr}$. In this study, the calculations were performed for discrete layers represented by the profile psychrometer heights and summed to get the totals. The calculation of all minor heat storage terms in the energy balance were calculated with the Fortran program called STORAG. An explanation of this program is given in Section 9.1.1, and a description of the command files used to process the data is given in Section 9.2.1.

Ground heat flux at the YJP site is computed in the usual sense, where the heat flux plate reading is summed with heat storage from the soil layer between the plate and soil surface.

The operational equations are:

$$
\begin{aligned}
& \mathrm{G}=\mathrm{G}(\mathrm{z})+\mathrm{S} \\
& \mathrm{S}=\mathrm{CdTs}(\mathrm{t}) \mathrm{z} / 1800 \\
& \mathrm{C}=\mathrm{CmXm}+\mathrm{Cw} \mathrm{Xw}_{\mathrm{w}}+\mathrm{Co} \mathrm{Xo}_{\mathrm{O}}
\end{aligned}
$$

where $\mathrm{G}$ is the ground heat flux at the soil surface integrated over a 30 -minute time interval $\left(\mathrm{W} / \mathrm{m}^{2}\right)$, $\mathrm{G}(\mathrm{z})$ is the soil heat flux measured at depth $\mathrm{z}\left(\mathrm{W} / \mathrm{m}^{2}\right)$, and $\mathrm{S}$ is the flux equivalent to the heat stored between the surface and the heat flux plates during the time interval $(t=1800 \mathrm{~s})\left(\mathrm{W} / \mathrm{m}^{2}\right)$. $\mathrm{C}$ is the volumetric heat capacity of the soil $\left(\mathrm{J} / \mathrm{m}^{3} /{ }^{\circ} \mathrm{C}\right), \mathrm{dTs}(\mathrm{t})$ is the temperature change in the soil layer above the heat flux plate over the time interval $\left({ }^{\circ} \mathrm{C} / \mathrm{s}\right)$, and $\mathrm{z}$ is the depth of the heat flux plates $(\mathrm{m})$. The volumetric heat capacity is obtained from measurements of the volume fractions (X) of the mineral, water, and organic soil components (subscript $\mathrm{m}$, w, and o, respectively) and their respective heat capacities ( $\mathrm{Cm}, \mathrm{Cw}$, and $\mathrm{Co})$.

Heat storage calculated for the YJP site was distinguished by zone in 1994 and 1996. Separate soil heat fluxes were measured for the north and west zones $(G(z) n$ and $G(z) w$, respectively). Calculated variables include sensible heat storage in the air $(\mathrm{Ga})$, latent heat storage in the air $(\mathrm{Ge})$, and heat storage in the vegetation at both the north and west sites (Gvegn and Gvegw, respectively). Heat storage in the soil volume above $10 \mathrm{~cm}$ depth (G10) is also a part of G_total in 1994 and 1996, resulting in the following equations:

$$
\begin{aligned}
& \text { G_totaln }=\mathrm{G}(\mathrm{z}) \mathrm{n}+\mathrm{Ga}+\mathrm{Ge}+\mathrm{Gvegn}+\mathrm{G} 10 \\
& \mathrm{G}_{\text {_totalw }}=\mathrm{G}(\mathrm{z}) \mathrm{w}+\mathrm{Ga}+\mathrm{Ge}+\mathrm{Gvegw}+\mathrm{G} 10
\end{aligned}
$$

In 1993, an average value of the north and west zones is presented for G_total and Gveg.

Ground heat flux at the fen in 1994 only (Gfen) was computed by adjusting the heat flux plate readings from the hollow (Ghol) with a correction factor determined from calorimetric methods. In the following explanation, Gpla is equal to Ghol. Hence,

$$
\begin{gathered}
\mathrm{G}=\mathrm{G}(\mathrm{z}) \mathrm{CF} \\
\text { where } \mathrm{CF}=\mathrm{Gcal} / \mathrm{Gpla}
\end{gathered}
$$

in which CF is a correction factor (3.04) determined from calorimetric calculations of heat storage in the soil profile (Gcal) and the time-integrated flux measured by the heat flux plates (Gpla). Gpla is calculated by summing the 30-minute average heat flux plate readings multiplied by 1800 seconds over a specified time interval (usually 10-14 days). Gcal is the total heat storage in the soil profile calculated from individual soil layers represented by the measured temperature profile(s), plus the heat flux out the bottom of the soil profile (GB).

Heat storage in the individual layers, $\mathrm{S}(\mathrm{i})$ is computed as:

$$
\mathrm{S}(\mathrm{i})=\mathrm{CdT}(\mathrm{t}) \mathrm{z}
$$


where symbols are defined as above. $\mathrm{C}$ varies between $3.48 \times 106 \mathrm{~J} / \mathrm{m}^{3} /{ }^{\circ} \mathrm{C}$ for saturated peat soil and $0.58 \times 10^{6} \mathrm{~J} / \mathrm{m}^{3} /{ }^{\circ} \mathrm{C}$ for dry peat soil. The flux out the base of the soil profile is calculated as:

$$
\mathrm{GB}=-\mathrm{Ks} \mathrm{dT} / \mathrm{dz}
$$

where $-\mathrm{Ks}$ is the thermal conductivity of saturated peat soil $\left(0.5 \mathrm{~W} / \mathrm{m} /{ }^{\circ} \mathrm{C}\right)$ and $\mathrm{dT} / \mathrm{dz}$ is the temperature gradient at the base of the soil profile.

In 1993, 1995, and 1996, no correction factor was applied to the fen's soil heat flux data (see Section 10.2.2). In these years, the soil heat flux from the hollow (Ghol) was used in the calculations of G_total.

\section{Stem Temperatures $\left({ }^{\circ} \mathrm{C}\right)$}

Stem temperatures were recorded at YJP in 1993, 1994, and 1996 from both the north and west sites at YJP. Stem temperatures from small (Tbsw), medium (Tbmw), and large trees (Tblw) were recorded at the west site, whereas only small trees were sampled at the north site (Tbsn). Stem temperatures recorded in the data files were taken from the west site, with the exception of stem temperatures from small trees. Tbs is an average of the stem temperatures from both the north and west sites:

$$
\mathrm{Tbs}=(\mathrm{Tbsn}+\mathrm{Tbsw}) / 2
$$

\section{Specific Iumidity (g/kg)}

Specific humidity $(\mathrm{SH})$ and the standard deviation of specific humidity $(\mathrm{sSH})$ were calculated using measured air temperature (T_air), vapor density (q), and the standard deviation of $\ln \mathrm{q}(\sin \mathrm{q})$.

Air density (rho) is found as a function of T_air, where:

$$
\begin{aligned}
& \text { if T_air>30 then tho }=1.149-0.0036(\text { T_air }-30.01) \quad(9.27) \\
& \text { if 25>T_air>30 then rho }=1.168-0.0038 \text { (T_air }-25.01) \quad(9.28) \\
& \text { if } 20>\bar{T} \text { _air>25 then rho }=1.188-0.0040 \text { (T_air }-20.01) \quad \text { (9.29) } \\
& \text { if 15>T_air>20 then rho }=1.209-0.0042(\text { T_air }-15.01) \quad(9.30) \\
& \text { if 10>T_air>15 then rho }=1.230-0.0042 \text { (T_air - 10.01) (9.31) } \\
& \text { if } \left.5>T_{-} \text {air }>10 \text { then rho }=1.252-0.0044 \text { (T_air }-5.01\right) \text { (9.32) } \\
& \text { if } 0>T_{-} \text {air }>5 \text { then rho }=1.275-0.0046(\text { T_air }-0.01) \text { (9.33) } \\
& \text { if } \left.-5>T_{-} \text {air }>0 \text { then rho }=1.229-0.0048 \text { (T_air }+4.99\right) \text { (9.34) } \\
& \text { if -10>T_air>-5 then rho }=1.324-0.0050 \text { (T_air }+9.99 \text { ) (9.35) } \\
& \text { if -15>T_air>-10 then rho }=1.350-0.0050 \text { (T_air }+14.99) \quad \text { (9.36) } \\
& \text { if }-20>T_{\text {T_air }}>-15 \text { then rho }=1.376-0.0054(\text { T_air }+19.99) \quad(9.37)
\end{aligned}
$$

The specific humidity is found from the vapor density $\left(\mathrm{g} / \mathrm{m}^{3}\right)$, measured by the krypton hygrometer at each site, and

$$
\mathrm{q}=(\ln \mathrm{s}-\ln \mathrm{v}) / \mathrm{kx} \quad(9.38)
$$

where $\mathrm{s}=$ the signal voltage from the hygrometer $(\mathrm{mv}), \mathrm{v}$ is the intercept of the hygrometer's calibration ( $4054 \mathrm{mv}$ for the fen and $4528 \mathrm{mv}$ for the YJP), $\mathrm{k}$ is absorption coefficient for water vapor $\left(-0.141 \mathrm{~m}^{3} / \mathrm{g} / \mathrm{cm}\right.$ for the fen and $-0.133 \mathrm{~m}^{3} / \mathrm{g} / \mathrm{cm}$ for the YJP), and $\mathrm{x}$ is the path length of the hygrometer $(1.542 \mathrm{~cm}$ for the fen and $1.400 \mathrm{~cm}$ for the YJP). Then,

$$
\begin{array}{ll}
\mathrm{SH}=\mathrm{q} / \text { rho } & (9.39) \text { and } \\
\mathrm{SSH}=(\mathrm{e} / \mathrm{l} \ln \mathrm{q}) / \mathrm{rho} & (9.40)
\end{array}
$$

where $s$ indicates the standard deviation. 


\section{Convective Heat Fluxes (II and LE)}

The sensible heat flux was found from equation 3.2 which states that

$$
\mathrm{H}=\text { rho } \mathrm{Cp}<\mathrm{w}^{\prime} \mathrm{T}^{\prime}>\quad(9.41)
$$

where the variables have their usual meanings. Webb (1982) showed that the air density and specific heat of air are functions of both the air's temperature and vapor pressure, and that air temperature had the largest control. Thus, in our calculations, the rho Cp term was corrected for changing temperature and air pressure as follows:

$$
\text { rho } \mathrm{Cp}=\mathrm{Cp}(\mathrm{d})(\mathrm{P} \mathrm{M} / \mathrm{R} \mathrm{T}) \quad(9.42)
$$

where $\mathrm{Cp}(\mathrm{d})$ is the specific heat of dry air, $\mathrm{P}$ is the atmospheric pressure, $\mathrm{M}$ is the molecular weight of dry air, $\mathrm{R}$ is the universal gas constant, and $\mathrm{T}$ is the air temperature. In the 1994 experiments, $\mathrm{P}$ was obtained from Thompson airport and read into the data logger once a day, usually about 1500 UTC, when the site was first visited. In 1996, analog pressure sensors at the YJP and fen were recorded P every half-hour. The air temperature that was used was the average value from the previous half-hour, which was updated on a continuous basis automatically by the data logger. The precision of this correction was improved in 1996 because we incorporated air pressure sensors into the measurement packages at each site, and this allowed the use of the previous half-hour's air pressure as well as temperature in equation 9.41.

The value of $\mathrm{L}$, the latent heat of vaporization, in the eddy covariance measurement of latent heat flux (equation 3.1) was found as a function of air temperature from the equation

$$
\mathrm{L}=2501+(-2.363) \mathrm{T}+(-0.00023) \mathrm{T}^{2}
$$

where $\mathrm{T}$ is the air temperature averaged over the previous half-hour. Equation 9.42 was part of the online calculations.

The krypton lamp in the hygrometer has two emission lines, a major line at $123.58 \mathrm{~nm}$, and a minor line at $116.49 \mathrm{~nm}$. Both lines are absorbed by both water vapor and oxygen. It is necessary to account for the effect of absorption by oxygen on the value of vapor density in order to correct the latent heat flux. The oxygen correction is a function of atmospheric pressure and temperature, and Tanner, et al. (1993) provide the appropriate equations to find the oxygen correction. At standard atmospheric pressure $(101.3 \mathrm{kP})$ and temperature $(305 \mathrm{~K})$, the pressure correction is small in comparison to that caused by temperature, and it is usual to correct for oxygen absorption based only on temperature. This procedure was followed in this experiment.

Webb et al. (1980) described the influence of sensible heat and vapor fluxes that cause changes in the density of atmospheric constituents, and the necessary corrections to the flux associated with these fluctuations. These corrections are usually termed the Webb, Pearman, and Leuning (WPL) corrections, and they were applied to the latent heat flux in this experiment (Joiner, 1994). The WPL correction due to the sensible heat flux is approximately five times larger than that due to the vapor flux itself (Tanner et al., 1993).

\section{Carbon Dioxide Flux}

Because we used a closed-path IRGA and the air sample was delivered to the instrument through a sample tube, there is a time delay, or lag, in the concentration of $\mathrm{CO}_{2}$, measured in the IRGA, and the measured vertical wind in the free atmosphere around the sonic. If the $\mathrm{CO}_{2}$ concentration data were not corrected for lag, we would not calculate the correct covariance, and the flux of $\mathrm{CO}_{2}$ would be incorrect. We found the lag for our $\mathrm{CO}_{2}$ systems at fen and YJP empirically. While continuously monitoring the output of $\mathrm{CO}_{2}$ and vertical wind, we introduced a bubble of nitrogen in the vicinity of the sample tube intake. The arrival of the nitrogen in the sample cell of the IRGA caused a discernable spike in the $\mathrm{CO}_{2}$ time series. We identified formally the time of occurrence of the spike by lag correlation analysis of $\mathrm{CO}_{2}$ concentration and vertical wind. The lag was where the correlation 
coefficient between $\mathrm{CO}_{2}$ and vertical wind was a maximum. Site-specific lag times were programmed into the data loggers at each site, and these lags allowed us to compute a covariance using the correct values of $\mathrm{CO}_{2}$ and vertical wind.

The concentration of $\mathrm{CO}_{2}$ measured by an IRGA is dependent on pressure. Changing pressure changes the calibration of the instrument (span/voltage difference) by changing the span. The span is the difference in concentration between the high and low span gases; in our case approximately 30 to 40 ppmv. The effect of changing pressure on the IRGA's calibration was corrected online.

Changes in the air's temperature and water vapor density, which in turn are related to the sensible and latent heat fluxes, affect the concentration of $\mathrm{CO}_{2}$ and hence the flux of $\mathrm{CO}_{2}$ (Webb et al., 1980). In postprocessing, the $\mathrm{CO}_{2}$ flux was corrected for changing density and vapor flux (Joiner, 1994). The correction includes a correction for the cross-sensitivity of the IRGA to water vapor and carbon dioxide (Leuning and Moncrieff, 1990; Leuning and King, 1992).

\subsubsection{Derivation Techniques and Algorithms}

STORAG is the general name for a Fortran program that calculates the minor heat storage terms in the energy balance. There are several operational versions of the program that differ depending upon the available data (see Section 9.2.1). Also, ENBAL, a Fortran program to solve for the terms of the radiation balance, was used in the analysis. Both STORAG and ENBAL work on the principle of GET commands that read input data into memory from various files, and when sufficient variables are read to solve the control equations, the calculations get done and are stored in output tables that can be delivered to spreadsheets or plotting packages for further processing and plotting. There is a worked example of the operation of STORAG in Section 9.2.1 that illustrates not only the specific features of STORAG but also the general nature of both programs.

\subsection{Data Processing Sequence}

\subsubsection{Processing Steps}

Two versions of STORAG were used in the calculations of heat storage depending on what data were available: STORY94.exe and STORY96.exe. STORY94.exe, used on 1993, 1994, and 1995 data, calculated heat storage variables from wet-bulb and dry-bulb temperatures, net radiation, soil heat flux, and soil temperatures. STORY96.exe was used on the 1996 data where relative humidity (RH) was an input measured variable, which replaced its calculation using wet-bulb temperatures.

A command file is used to run the STORAG program. It comprises a list of GET statements that will select variables from a specified column in a specified file. The last two numbers in the GET statement are the slope and intercept of the equation to be used with that data. This is useful if the input data are in the wrong units and a linear calibration can be applied. Other variables are set using SET statements. Variables used in the STORY94 program are:

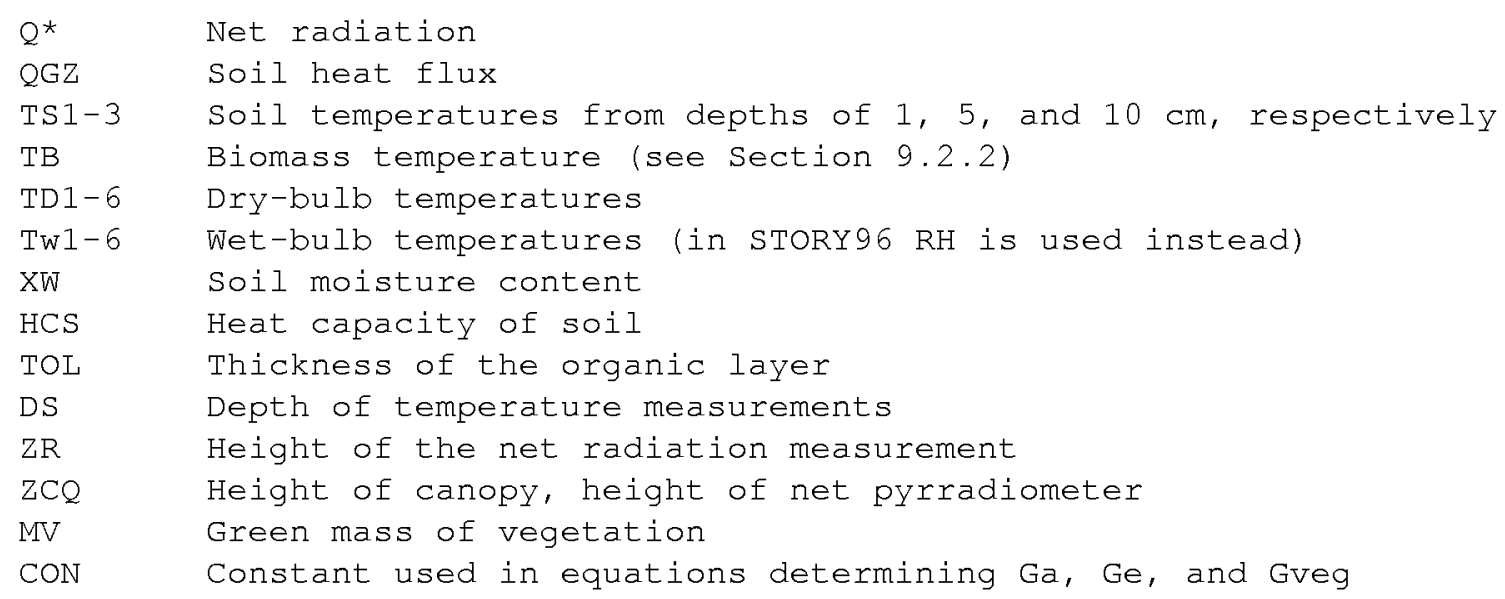


An example of the command file used to run STORAG is listed in Table 16 for one day of data. All commands must be in capital letters, Q* and QGZ data must be 30-minute averages, and the remaining temperatures are 15-minute averages.

Table 16. Example command file for STORAG, a program to find the minor heat storage terms in the surface energy balance.

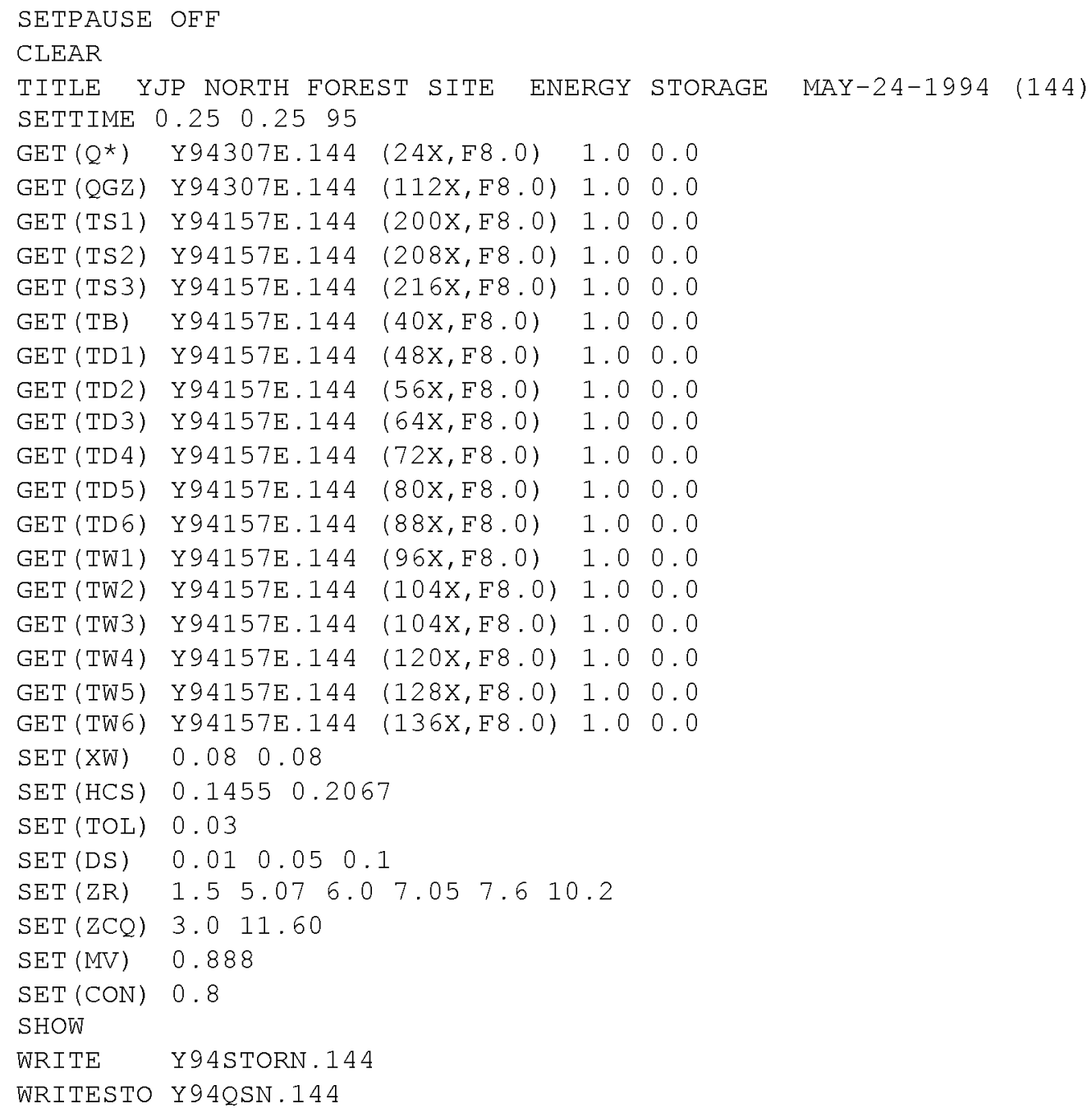

\subsubsection{Processing Changes}

Where one level of air temperature was missing from a file used in STORAG, the GET statement was changed to read the value from the nearest level. For example, if the third level of temperature is missing, the value from the fourth level could be used instead.

Mass of vegetation (MV) is zero in the fen calculations. For heat storage calculations at YJP in the west site, $M V=2.22$. Because there were only small trees in the north site, $M V=0.888$ for that site. Biomass temperature (TB) is zero in the fen calculations, whereas it is based on the stem temperatures at YJP. In the north site, TB = Tbsn. In the west site, the following weighted average, based on the percentage occurrence of small, medium, and large trees, was used to determine TB:

$$
\mathrm{TB}=0.4 \mathrm{Tbsw}+0.486 \mathrm{Tbmw}+0.114 \mathrm{Tblw} \quad(9.44)
$$

The STORAG program does not accept zero in the command file; therefore, the TB multiplier, the thickness of the organic layer (TOL), the height of the canopy, and the mass of vegetation (MV) were set to 0.000001 in the fen calculations, creating insignificant values in the calculated heat storage. 


\subsection{Calculations}

\subsubsection{Special Corrections/Adjustments}

The following rules were followed in preparing the data files:

- Any small negative values of $\mathrm{Kd}$ and $\mathrm{Ku}\left(<1 \mathrm{~W} / \mathrm{m}^{2}\right)$ were changed to zero and $\mathrm{Ld}, \mathrm{Qd}, \mathrm{Qu}$, and the albedo were recalculated accordingly; negative values occur as a result of zero depression on the instruments.

- All negative values of incoming and reflected photosynthetic photon flux density (PPFDd and PPFDu) were changed to zero; as is the case with pyranometers, small negative values result from zero depression.

- When $\mathrm{FsCO}_{2}$ was missing and $\mathrm{Kd}>0$, then $\mathrm{F}_{\mathrm{CO} 2}=\mathrm{Fe}_{\mathrm{CO} 2}$

- When $\mathrm{FsCO}_{2}$ was missing and $\mathrm{Kd}=0$, then $\mathrm{F}_{\mathrm{CO} 2}=\mathrm{CO}_{2}$ night.

- $\quad$ Latent heat flux (LE) was flagged (i.e., changed to -999) when $\mathrm{LE}<-50 \mathrm{~W} / \mathrm{m}^{2}$.

- $\quad$ Sensible heat flux $(\mathrm{H})$ was flagged when $\mathrm{H}<-70 \mathrm{~W} / \mathrm{m}^{2}$.

- $\quad$ All negative wind speeds were flagged.

- Where LE was flagged and vertical wind speed (w) was $>2$ or $<-2 \mathrm{~m} / \mathrm{s}$, w was flagged.

- Where between one and three half-hourly average values of a variable were missing, a linear interpolation was done, assuming that the meteorological conditions were steady and a clear temporal trend was present before and after the data gap.

\subsubsection{Calculated Variables}

Formulae for the following list of calculated variables can be found in Section 9.1: $\mathrm{K}^{*}, \mathrm{Ld}, \mathrm{Qd}$, $\mathrm{Qu}, \mathrm{Q}^{*}, \mathrm{Q}^{*}$ corr, a, $\mathrm{F}_{\mathrm{CO} 2}, \mathrm{CO}_{2}$ night, G_total, Ga, Ge, Gveg, G10, SH, and sSH.

\subsection{Graphs and Plots}

Day 260 in 1996 was chosen because it was a clear day and it shows many interesting contrasting features of the radiation, energy, and $\mathrm{CO}_{2}$ balances of the two sites (Figure 4). The time shown in the figure is UTC. The most notable differences in the radiation balances between the two sites (Figure 4A and $4 \mathrm{~B}$ ) occur in the net radiation $\left(\mathrm{Q}^{*}\right)$ and reflected solar radiation $(\mathrm{Ku})$ components: the latter is larger and the former is smaller at the fen as a result of $i)$ the larger albedo at the fen and ii) the higher surface temperatures on the jack pine; which increase the outgoing longwave radiation (Lu) from the drier surface; the greatest contrast in Lu occurs early in the day. The incoming solar radiation (Kd) and incoming longwave radiation (Ld) do not indicate substantial differences between the sites.

The fen had started to senesce by day 260; as a result, the majority of the available energy goes into sensible heat flux (average Bowen ratio 2.0) (Figure 4C). The YJP was still actively transpiring (average Bowen ratio 1.0), except for a short period in the middle of the day when the sensible heat flux exceeds the latent heat flux (Figure 4D). The value of the total heat storage (G_total) includes the soil heat storage and biomass storage from the north site.

The impact of senescence is very noticeable in the different net $\mathrm{CO}_{2}$ flux patterns. The fen is either effluxing or in a state of zero net exchange for the majority of the day (Figure 4E), but there is some very weak uptake in the late morning. The jack pine shows vigorous uptake for the whole daylight period and consistent efflux in the nighttime period at the start of the day (Figure 4F). The pattern of efflux breaks down late in the day under the very calm wind speed conditions (Figure 4H).

The pattern of wind at the fen is characterized by very low wind speed or complete calm during the night and maximum values of $5 \mathrm{~m} / \mathrm{s}$ during the daylight period (Figure $4 \mathrm{G}$ ). The increase of wind speed in the morning and the decrease in the evening are very sharp. The pattern at the YJP is quite different early in the day, when the wind speed increases gradually to a maximum of only $3 \mathrm{~m} / \mathrm{s}$ by the evening. The precipitous drop in wind speed at 0000 UTC is the same pattern as at the fen. The direction of the wind was steadier at the fen, where it blew from the southeast from 1200 UTC onwards. At the YJP, the direction was more easterly for the majority of the day. It is clear that the fen has its own particular wind climate, and on very calm nights such as the start of day 260 , it is much calmer than the more open YJP site (compare Figures $4 \mathrm{G}$ and $4 \mathrm{H}$ ). 
The slightly higher and more gradually declining air temperatures at the YJP in the early part of the day $($ Figure $4 \mathrm{H})$ are consistent with the presence of the higher wind speeds, which would have mixed the lower atmosphere more effectively. The increased mixing would hinder the development of a surface temperature inversion and raise the air temperature. It is important to note that the eddy covariance measurement of $\mathrm{CO}_{2}$ was very successful at this time of the day, when a constant efflux of $1 \mathrm{umole} / \mathrm{m}^{2} / \mathrm{s}$ was measured (Figure $4 \mathrm{~F}$ ). The same is not true for the fen, where the $\mathrm{CO}_{2}$ series is quite jagged (Figure 4E) as a result of measured negative fluxes that have been set to zero as part of the data management. Clearly, the measurement of the flux was breaking down at the fen under the totally calm wind speed conditions (Figure 4G).
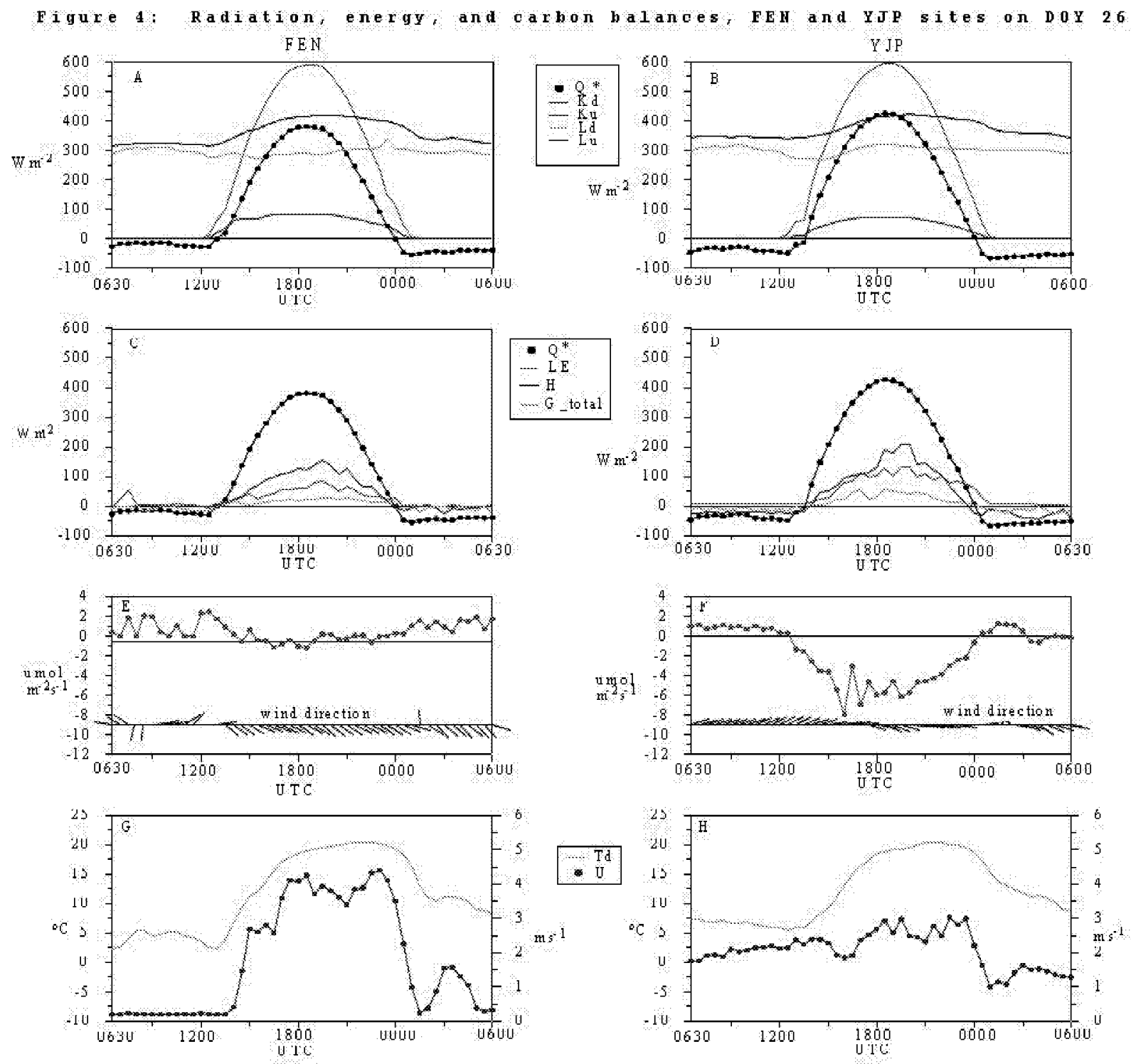

Figure 4: Contrasting Radiation, Energy, and $\mathrm{CO}_{2}$ Balances Between NSA-Fen and NSA-YJP 


\section{Errors}

\subsection{Sources of Error}

There are a number of sources of error in the data. In general, these sources can be identified as: i) instrument error, i.e., the error component from the transducer itself, ii) a component from the measurement device, and iii) a component dependent upon field placement. Not all of the components of error are easily evaluated, and the most difficult to evaluate through a formal analysis is that due to field placement. We believe that we minimized field placement error, but we do not have a formal way of verifying this claim. We do claim that all instruments were located according to normal field practice, and a close watch was kept by field staff for any apparent aberrant output from the instruments.

\subsection{Quality Assessment}

All aberrant data occurrences found in the field were noted in the field $\log$ and examined in detail during postprocessing. There are a number of reasons for the occurrence of aberrant values. In our particular case, the two most common reasons were i) shutdown of the $\mathrm{CO}_{2}$ system for calibration, which was done once a day and which resulted in the loss of one 30-minute average value, and ii) covering of the sonic anemometer to prevent its damage by heavy rain. There were various other occurrences of apparently aberrant values unrelated to these two causes. In order to try to identify aberrant behavior more formally, during postprocessing all raw time series were scanned for each day and the outliers from the series were identified and examined in detail. In addition, the calculated time series of fluxes were examined for outliers. Typically, when an outlier was found, the field notes were consulted to see if some action on the tower or in the vicinity of the instrument had been recorded that would have caused the outlier to occur. Irrespective of whether we could tie the outlier to a cause, a simple linear interpolation was applied if the outlier was judged aberrant, the period of bad data was short, and steady-state conditions applied. If it was clear that the data point was wrong and it could not be corrected or interpolated, it was flagged and a missing value place holder inserted. It is admitted that this process is not totally objective and it does involve some judgments based upon field experience. We do claim that the data acceptance criteria were conservative; i.e., it was normal to reject an apparently aberrant data point unless there was very strong evidence to the contrary.

\subsubsection{Data Validation by Source}

The overall best estimate of accuracy of the primary variables are as follows:

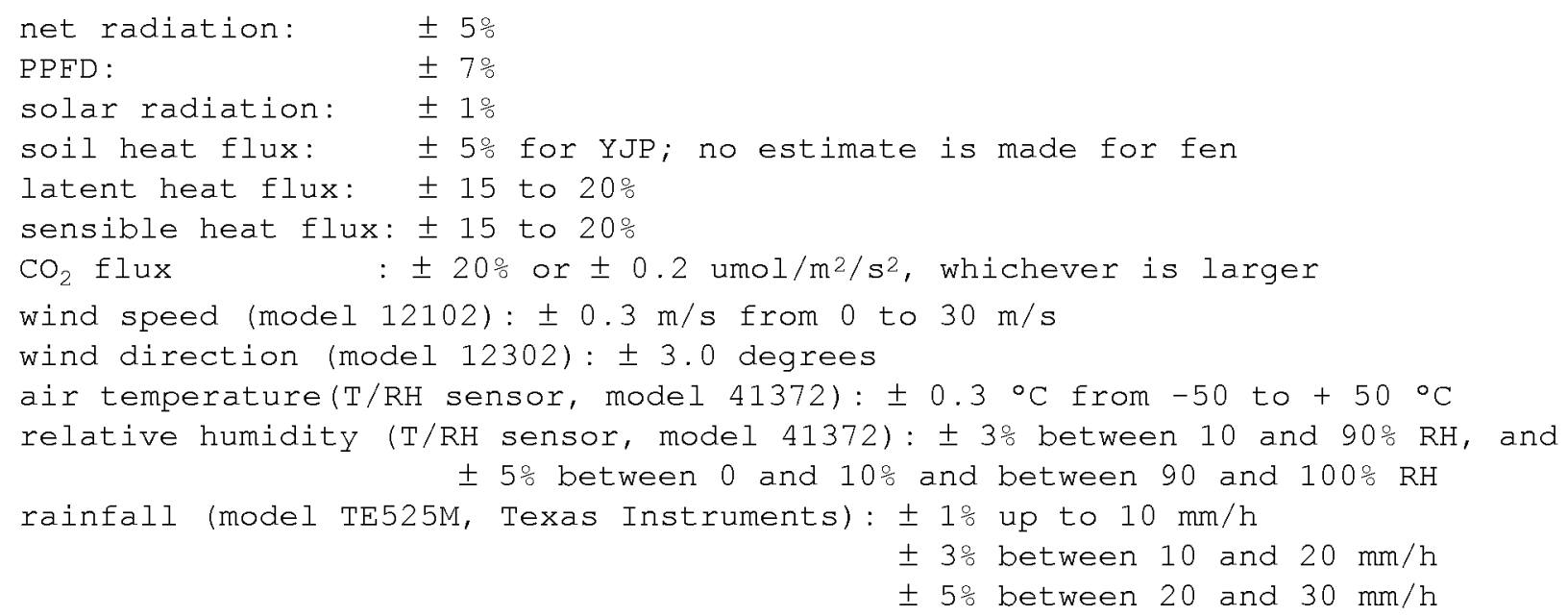

In 1993, 1995, and 1996, no correction factor was applied to the fen's soil heat flux data. Rather, we report the flux values measured by the plate(s). This is a puzzling result, but if the same correction value had been applied as in 1994, totally unreasonable values of flux would have resulted. In fact, the 
energy balance closures would have consistently been much greater than unity as a result. This points out the difficulty of measuring heat storage in the peat soil. We suggest that our application of different methodologies can be explained in the following way. In 1994, only the plate in the hollow exhibited any diurnal pattern, but the size and amplitude of the measured flux was tiny. The signal from the plate in the hummock showed zero amplitude, and was a flat line during the whole day, we believe as a result of poor thermal contact between the plate and the peat. Such patterns were not observed in the other sample years, when both plates exhibited similar and significant signal sizes and diurnal amplitudes. Furthermore, accepting the measured fluxes in these sample years results in reasonable energy balance closures. However, the measurement of soil heat flux on a fen remains a confounding problem, and it requires further careful assessment in terms of measurement methodology.

Another problem that caused serious questioning of our methodology was the measurement of the $\mathrm{CO}_{2}$ flux at night. This problem was most apparent at the YJP. After examination of the data, it was concluded that the measured fluxes should be replaced with modeled values in order to obtain reasonable diurnal patterns. The issue of how best to measure $\mathrm{CO}_{2}$ fluxes at night under low turbulent mixing conditions remains a priority. In addition, there are outstanding issues on the best way to model the nighttime $\mathrm{CO}_{2}$ flux.

\subsubsection{Confidence Level/Accuracy Judgment}

None given.

\subsubsection{Measurement Error for Parameters}

See Section 10.2.1.

\subsubsection{Additional Quality Assessments}

None given.

\subsubsection{Data Verification by Data Center}

Data were examined to check for spikes, values that were four standard deviations from the mean, long periods of constant values, and missing data.

\section{Notes}

\subsection{Limitations of the Data}

At this time (June 1998), the data series are not continuous. Where there were measurement problems, e.g., as a result of a sensor failure or a power failure, missing value place holders have been inserted. We are working toward providing robust methods for reconstruction of large data gaps. One method that has been fairly successful is to construct the diurnal patterns of fluxes using ensemble averaging. However, for users who require unbroken time series of 30-minute averages, these data will fall short. In most instances of a small gap, say one or two contiguous half-hours, in a period of steady-state atmospheric conditions, straight linear interpolation should work satisfactorily. If the atmospheric conditions are changing rapidly, or if the gap is large, say half a day, then a rigorous interpolation method will be required. Please consult the PI for progress on the development of interpolation routines for large data gaps.

At this time (June 1998), the eddy covariance flux data (sensible and latent heat and $\mathrm{CO}_{2}$ ) at the YJP site are from the Campbell Scientific single-axis sonic anemometer. A second sonic anemometer (Applied Technologies, Inc., (ATI), Boulder, CO, USA) was operational at the site in 1996, and both were located at the same height and orientation on the flux tower. The final calculation of the fluxes based on the ATI sonic data are not yet complete and are not included in this data set. 


\subsection{Known Problems with the Data}

Where tower flux sites do not have adequate upwind fetch, uncertainties are introduced into the interpretation of the flux data. We believe this may have been a problem at the fen. The eddy covariance instruments were located at a height of $4.5 \mathrm{~m}$ above the surface. Using the standard micrometeorological "rule-of-thumb" for fetch-to-height ratio of 100:1, a 4500-m fetch is required in all directions around the fen tower. The site did not meet this criterion. Fetch was limited along the northeast shore in the azimuth directions (from magnetic north) 350-0-125 degrees. Minimum fetch in this quadrant was approximately $150 \mathrm{~m}$ at a bearing 65 degrees. Similarly, fetch was limited along the south shore in the bearing 160-235 degrees. Minimum fetch in this quadrant was $220 \mathrm{~m}$ at the bearing 205 degrees. Fetch in all other directions exceeded $450 \mathrm{~m}$. Measurements for all wind directions were reported in the data set, and users are cautioned as to this possible source of uncertainty.

Fetch to height ratios at YJP were greater than 100:1 in all directions. However, the sector azimuth 45-140 degrees contains the access trail to the tower, the instrument and data processing hut, and the generator hut. Some contamination of fluxes measured from this direction may have occurred.

\subsection{Usage Guidance}

In 1994 at YJP, recording of the deep soil temperatures $(0.25,0.50$, and $0.75 \mathrm{~m})$ at the north soil heat flux site did not start until DOY 179 1994. This contrasts to the measurements at the west site, where recording began on DOY 144. As a result, lower minimum deep soil temperature values were observed at the west site. This phenomenon is reflected in the max/min summary in Section 7.3.5..

In the modeled nighttime carbon dioxide flux series, all negative values (uptake) were kept in the data set because there was no rationale for removing them. They occurred as a result of the nature of the empirical model (equation 9.11) used for the estimate.

\subsection{Other Relevant Information None.}

\section{Application of the Data Set}

These data can be used for various applications. For example, they will provide meteorological input variables for a wide range of models. Also, for those models that estimate fluxes, the data set provides flux data series for sensible and latent heat and $\mathrm{CO}_{2}$ for model verification.

\section{Future Modifications and Plans}

Once the data processing is complete, we will submit the convective and $\mathrm{CO}_{2}$ flux data for YJP in 1996 based on measurements from the ATI sonic. Secondly, we are working on a more objective method to fill data gaps. To date, we have used linear interpolation. This method applies only to short periods, a few half-hours at best, under steady-state conditions. If the meteorological conditions are changing, linear interpolation fails. It also fails if the data gap is longer than a few half-hours. When we encountered a long data gap, we have left the data field blank and assigned a "missing value" place holder. Given that we did have significant gaps in the flux series because of the difficulties of the Campbell sonic in rainy weather, we have used ensemble averaging to create complete average diurnal curves of fluxes for publications. We recognize that ensemble average data are not necessarily the ideal kind for modelers who prefer unbroken time series for each variable. 


\section{Software}

\subsection{Software Description}

The measurement of the raw data was principally on Campbell Scientific data loggers, and all of the specific control programs for these data loggers are available.

A variety of software was used in the data assessment and analysis. STORAG, a Fortran program to find the minor heat storage terms in the energy balance, calculated the surface soil heat flux, the biomass heat storage, and the latent and sensible heat storage in the air up to the level of measurement of net radiation, where the surface balance was closed. RADBAL, a Fortran program to solve the terms of the energy balance, was used in the analysis of the radiation balance data, including the calculation of shortwave and PPFD albedos, and the radiative surface temperatures. We developed a number of QuattroPro spreadsheets for the calculation of convective fluxes ( $\mathrm{H}$ and $\mathrm{LE}$ ) and the $\mathrm{CO}_{2}$ flux, including the correction of the fluxes for density effects and ensemble averaging to construct average daily flux patterns for the days included in the average. Ensemble averaging was used as a means to find the mean diurnal pattern from often incomplete flux data series on individual days. This methodology was successful and was favored over the development of other means for filling data gaps. However, active research on the issue of how best to fill data gaps continues.

\subsection{Software Access}

All software developed for the analysis of the data is available by contacting J.H. McCaughey (PI).

\section{Data Access}

The NSA-YJP tower flux, meteorological, and porometry data are available from the Earth Observing System Data and Information System (EOSDIS) Oak Ridge National Laboratory (ORNL) Distributed Active Archive Center (DAAC).

\subsection{Contact Information}

For BOREAS data and documentation please contact:

ORNL DAAC User Services

Oak Ridge National Laboratory

P.O. Box 2008 MS-6407

Oak Ridge, TN 37831-6407

Phone: (423) 241-3952

Fax: (423) 574-4665

E-mail: ornldaac@ornl.gov or ornl@eos.nasa.gov

\subsection{Data Center Identification}

Earth Observing System Data and Information System (EOSDIS) Oak Ridge National Laboratory (ORNL) Distributed Active Archive Center (DAAC) for Biogeochemical Dynamics http://www-eosdis.ornl.gov/.

\subsection{Procedures for Obtaining Data}

Users may obtain data directly through the ORNL DAAC online search and order system [http://www-eosdis.ornl.gov/] and the anonymous FTP site [ftp://www-eosdis.ornl.gov/data/] or by contacting User Services by electronic mail, telephone, fax, letter, or personal visit using the contact information in Section 15.1.

\subsection{Data Center Status/Plans}

The ORNL DAAC is the primary source for BOREAS field measurement, image, GIS, and hardcopy data products. The BOREAS CD-ROM and data referenced or listed in inventories on the CD-ROM are available from the ORNL DAAC. 


\section{Output Products and Availability}

\subsection{Tape Products}

None.

\subsection{Film Products}

None.

\subsection{Other Products}

These data are available on the BOREAS CD-ROM series.

\section{References}

\subsection{Platform/Sensor/Instrument/Data Processing Documentation}

All persons from Queen's University, Kingston, Ontario, who worked on the flux towers received training on tower climbing techniques, tower rescue methods, and the operation of a safe field site. The material is summarized in McCaughey (1993), and a summary of the training materials can be found in the tower safety document.

The data analysis to find the minor heat storage terms in the energy balance was accomplished with the software program titled STORAG, and details of this software are available in McCaughey (1991).

\subsection{Journal Articles and Study Reports}

Alemdag, I.S. 1983. Mass equations and merchantability factors for Ontario softwoods. Inf. Rep. PI-X-23, 27, Natl. For. Inst., Petawawa, Ontario, Canada.

Brand, D.G. 1987. Estimating the surface area of spruce and pine foliage from displaced volume and length. Can. J. For. Res. 17:1305-1308.

Campbell, G.S. and B.D. Tanner. 1985. A krypton hygrometer for measurement of atmospheric water vapor concentration. Moisture and Humidity 1985, Measurement and Control in Science and Industry, Proc. 1985 Intl. Symp. on Moisture and Humidity, Washington, DC, 609-612.

Campbell, G.S. and M.H. Unsworth. 1979. An inexpensive sonic anemometer for eddy correlation. J. Appl. Meteorol. 18:1072-1077.

Chen, J.M. and T.A. Black. 1992. Foliage area and architecture of plant canopies from sunfleck size distributions. Agric. For. Meteorol. 60:249-266.

Costello, A.M. 1995. Canopy Characteristics and Surface-Atmosphere Interactions of a Young Jack Pine Forest Near Thompson, Manitoba, M.Sc. Thesis, Queen's University, Kingston, Ontario, 125 pp.

Gower, S.T. and J.M. Norman. 1991. Rapid estimation of leaf area index in conifer and broad-leaf plantations. Ecology 72:1896-1900.

Halliwell, D.H. and W.R. Rouse. 1987. Soil heat flux in permafrost: Characteristics and accuracy of measurement. J. Climatol. 7:571-584.

Hodges, G.B. and E.A. Smith. 1997. Intercalibration, objective analysis, inter-comparison and synthesis of BOREAS surface net radiation measurements. Journal of Geophysical Research 102(D24): 28,885-28,900. 
Joiner, D.W. 1994. Corrections to TF-10 eddy covariance fluxes. Queen's University internal report, $23 \mathrm{pp}$.

Lafleur, P.M., J.H. McCaughey, D.W. Joiner, P.A. Bartlett, and D.E. Jelinski. 1997. Seasonal trends in energy, water, and carbon dioxide fluxes at a northern boreal wetland. Journal of Geophysical Research 102(D24): 29,009-29,020.

Leclerc, M.Y. and G.W. Thurtell. 1990. Footprint prediction of scalar fluxes using a Markovian analysis. Boundary-Layer Meteorol. 52:247-258.

Leuning, R. and J. Moncrieff. 1990. Eddy-covariance $\mathrm{CO}_{2}$ flux measurement using open- and closed-path $\mathrm{CO}_{2}$ analyzers: Corrections for analyzer water vapor sensitivity and damping of fluctuations in air sampling tubes. Boundary-Layer Meteorol. 53:63-76.

Leuning, R. and K.M. King. 1992. Comparison of eddy-covariance measurements of $\mathrm{CO}_{2}$ fluxes by open- and closed-path $\mathrm{CO}_{2}$ analyzers. Boundary-Layer Meteorol. 59:297-311.

McCaughey, J.H. 1991. Safety in Climatology: a Seminar on Tower Climbing. 7 pp., 1987, last revision in 1993.

McCaughey, J.H. RTDMS Program Manual, Second Edition, Delta T Documents, 50 pp.

McCaughey, J.H. and W.L. Saxton. 1988. Energy balance storage terms in a mixed forest. Agric. For. Meteorol. 44:1-18.

McCaughey, J.H., P.M. Lafleur, D.W. Joiner, P.A. Bartlett, A.M. Costello, D.E. Jelinski, and M.G. Ryan. 1997. Magnitudes and seasonal patterns of energy, water, and carbon exchanges at a boreal young jack pine forest in the BOREAS northern study area. Journal of Geophysical Research 102(D24): 28,997-29,007.

Mueller-Dombois, D. and H. Ellenberg. 1974. Aims and Methods of Vegetation Ecology. J. Wiley \& Sons, New York, 547 pp.

Newcomer, J., D. Landis, S. Conrad, S. Curd, K. Huemmrich, D. Knapp, A. Morrell, J. Nickeson, A. Papagno, D. Rinker, R. Strub, T. Twine, F. Hall, and P. Sellers, eds. 2000. Collected Data of The Boreal Ecosystem-Atmosphere Study. NASA. CD-ROM.

Saxton, W.L. and J.H. McCaughey. 1988. Measurement considerations and trends in biomass heat storage of a mixed forest. Can. J. For. Res. 18:143-149.

Schmid, H.P. and T.R. Oke. 1990. A model to estimate the source area contributing to turbulent exchange in the surface layer over patchy terrain. Quart. J. Roy. Meteorol. Soc. 116:965-988.

Sellers, P. and F. Hall. 1994. Boreal Ecosystem-Atmosphere Study: Experiment Plan. Version 1994-3.0, NASA BOREAS Report (EXPLAN 94).

Sellers, P. and F. Hall. 1996. Boreal Ecosystem-Atmosphere Study: Experiment Plan. Version 1996-2.0, NASA BOREAS Report (EXPLAN 96).

Sellers, P., F. Hall, and K.F. Huemmrich. 1996. Boreal Ecosystem-Atmosphere Study: 1994 Operations. NASA BOREAS Report (OPS DOC 94).

Sellers, P., F. Hall, and K.F. Huemmrich. 1997. Boreal Ecosystem-Atmosphere Study: 1996 Operations. NASA BOREAS Report (OPS DOC 96). 
Sellers, P., F. Hall, H. Margolis, B. Kelly, D. Baldocchi, G. den Hartog, J. Cihlar, M.G. Ryan, B. Goodison, P. Crill, K.J. Ranson, D. Lettenmaier, and D.E. Wickland. 1995. The boreal ecosystem-atmosphere study (BOREAS): an overview and early results from the 1994 field year. Bulletin of the American Meteorological Society. 76(9):1549-1577.

Sellers, P.J., F.G. Hall, R.D. Kelly, A. Black, D. Baldocchi, J. Berry, M. Ryan, K.J. Ranson, P.M. Crill, D.P. Lettenmaier, H. Margolis, J. Cihlar, J. Newcomer, D. Fitzjarrald, P.G. Jarvis, S.T. Gower, D. Halliwell, D. Williams, B. Goodison, D.E. Wickland, and F.E. Guertin. 1997. BOREAS in 1997: Experiment Overview, Scientific Results and Future Directions. Journal of Geophysical Research 102(D24): 28,731-28,770.

Smith, E.A., G.B. Hodges, M. Bacrania, H.J. Cooper, M.A. Owens, R. Chappell, and W. Kincannon. 1997. Final Report NASA Grant NAG5-2447, BOREAS Net Radiometer Engineering Study. Goddard Space Flight Center, Greenbelt, Maryland. 51 pp.

Smith, N.J., J.M. Chen, and T.A. Black. 1993. Effects of clumping on estimates of stand leaf area index using the LI-COR LAI 2000. Can. J. For. Res. 23:1940-1943.

Tanner, B.T., E. Swiatek, and J.P. Greene. 1993. Density fluctuations and use of the krypton hygrometer in surface flux measurements. Proceedings of the 1993 National Conference on Irrigation and Drainage Engineering, American Society of Civil Engineers, Park City, Utah.

Thom, A.S. 1975. Momentum, mass and heat exchange of plant communities. In: Vegetation and the Atmosphere, Vol. 1 (Ed. J. L. Monteith), Academic Press, London. pp. 57-109.

Webb, E.K. 1982. On the correction of flux measurements for effects of heat and water vapor transfer. Boundary-Layer Meteorol. 23:251-254.

Webb, E.K., G.I. Pearman, and R. Leuning. 1980. Correction of flux measurements for density effects due to heat and water vapor transfer. Quart. J. Roy. Meteorol. Soc. 106:85-100.

\subsection{Archive/DBMS Usage Documentation}

None.

\section{Glossary of Terms}

$\begin{array}{lll}\text { Symbol } & \text { Quantity } & \text { Units } \\ \text { a } & \text { Albedo } & \mathrm{dim} . \\ \mathrm{AT} & \text { Total needle area } & \mathrm{cm} 2 \\ \mathrm{C} & \text { Volumetric heat capacity of soil } & \mathrm{J} / \mathrm{m} 3 /{ }^{\circ} \mathrm{C} \\ \mathrm{C} & \text { Co2 concentration per volume fluctuation } & \mathrm{ppmv} \\ \mathrm{CF} & \text { Correction factor } & \mathrm{dim} . \\ \mathrm{Cm} & \text { Heat capacity of mineral fraction } & \mathrm{J} / \mathrm{m} 3 /{ }^{\circ} \mathrm{C} \\ \text { Co } & \text { Heat capacity of organic soil } & \mathrm{J} / \mathrm{m} 3 /{ }^{\circ} \mathrm{C} \\ \text { Co2night } & \text { Net co2 flux from model when Kd } 5 \mathrm{~W} / \mathrm{m} 2 & \mu \mathrm{mol} / \mathrm{m} 2 / \mathrm{s} \\ \text { CoN } & \text { Constant used in SToRAG to find heat storage in } & \mathrm{J} / \mathrm{m} 3 /{ }^{\circ} \mathrm{C} / \mathrm{s} \\ \text { Cp } & \text { air, soil, and vegetation } & \mathrm{J} / \mathrm{kg} /{ }^{\circ} \mathrm{C} \\ \text { CW } & \text { Specific heat of air at constant pressure } & \mathrm{J} / \mathrm{m} 3 /{ }^{\circ} \mathrm{C} \\ \text { dbh } & \text { Heat capacity of water } & \mathrm{cm} \\ \text { de } & \text { Diameter at breast height } & \mathrm{kPa} / \mathrm{s} \\ \text { dim. } & \text { Rate of change in vapor pressure } & \mathrm{dim} .\end{array}$

Page 62 
DS

dTa

$\mathrm{dTb}$

dTs

FeCO2

FsCO2

FCO2

G

$G(z)$

G10

$\mathrm{Ga}$

$\mathrm{GB}$

Gcal

$\mathrm{Ge}$

Gfen

Ghol

$G(z) n$

Gpla

$G(z) w$

G_total

G_totaln

G_totalw

Gveg

Gvegn

Gvegw

$\mathrm{h}$

$\mathrm{H}$

HCS

$\mathrm{Kd}$

$\mathrm{Ku}$

Ks

$\mathrm{k}$

$\mathrm{K}^{\star}$

$\mathrm{L}$

LE

Ld

Lu

$\mathrm{L} *$

M

mis.

$\mathrm{Mv}$

$\mathrm{P}$

PA

$\mathrm{PA}(\mathrm{S})$

PPFDd

PPFDu

Qd

QGZ

Qu

$Q^{*}$

$Q^{*} \operatorname{corr}$
Depth of temperature measurements

Rate of change in air temperature

Rate of change in biomass temperature

Rate of change in soil temperature

Eddy flux of $\mathrm{CO} 2$ (equivalent to net flux at height of measurement)

Storage flux of $\mathrm{CO} 2$

Total CO2 flux

Soil heat flux at surface

Soil heat flux measured at depth $z$

Heat storage in the soil volume above $10-\mathrm{cm}$ depth

Sensible heat storage in air

Heat flux out the bottom of the soil profile at the fen

Total heat storage in the soil profile at fen

Latent heat storage in air

Ground heat flux at the fen in 1994

Ground heat flux in hollow at the fen

Soil heat flux at YJP (north site)

Time-integrated soil flux from plate at fen

Soil heat flux at YJP (west site)

Total heat storage

Total heat storage at YJP (north site)

Total heat storage at YJP (west site)

Heat storage in biomass at YJP

Heat storage in biomass at YJP (north site)

Heat storage in biomass at YJP (west site)

Tree height

Sensible heat flux

Heat capacity of soil in STORAG

Incoming solar radiation

Reflected solar radiation

Thermal conductivity of saturated peat soil

Instrument H2O vapor absorption coefficient

Total shortwave radiation

Latent heat of vaporization of water

Latent heat flux

Incoming longwave radiation

outgoing longwave radiation

Net longwave radiation

Molecular weight of dry air

Missing value

Standing green biomass

Atmospheric pressure

Total projected needle area

shoot projected area

Incoming PPED

Reflected PPFD

Total incoming radiation

soil heat flux from flux plate (for STORAG only)

Total outgoing radiation

Net radiation

Corrected net radiation (following Hodges and

Smith (1997)) m

${ }^{\circ} \mathrm{C} / \mathrm{s}$

${ }^{\circ} \mathrm{C} / \mathrm{s}$

${ }^{\circ} \mathrm{C} / \mathrm{s}$

$\mu \mathrm{mol} / \mathrm{m} 2 / \mathrm{s}$ or

$\mathrm{mg} / \mathrm{m} 2 / \mathrm{s}$

$\mu \mathrm{mol} / \mathrm{m} 2 / \mathrm{s}$

$\mu \mathrm{mol} / \mathrm{m} 2 / \mathrm{s}$

$\mathrm{W} / \mathrm{m} 2$

$\mathrm{W} / \mathrm{m} 2$

$\mathrm{W} / \mathrm{m} 2$

$\mathrm{W} / \mathrm{m} 2$

$\mathrm{W} / \mathrm{m} 2$

$\mathrm{W} / \mathrm{m} 2$

$\mathrm{W} / \mathrm{m} 2$

$\mathrm{W} / \mathrm{m} 2$

$\mathrm{W} / \mathrm{m} 2$

$\mathrm{W} / \mathrm{m} 2$

$\mathrm{W} / \mathrm{m} 2$

$\mathrm{W} / \mathrm{m} 2$

$\mathrm{W} / \mathrm{m} 2$

$\mathrm{W} / \mathrm{m} 2$

$\mathrm{w} / \mathrm{m} 2$

$\mathrm{W} / \mathrm{m} 2$

$\mathrm{W} / \mathrm{m} 2$

$\mathrm{W} / \mathrm{m} 2$

$\mathrm{m}$

$\mathrm{W} / \mathrm{m} 2$

$\mathrm{J} / \mathrm{m} 3 /{ }^{\circ} \mathrm{C}$

$\mathrm{W} / \mathrm{m} 2$

$\mathrm{W} / \mathrm{m} 2$

$\mathrm{W} / \mathrm{m} / \mathrm{K}$

$\mathrm{m} 3 / \mathrm{kg} / \mathrm{cm}$

$\mathrm{w} / \mathrm{m} 2$

$\mathrm{J} / \mathrm{kg}$

$\mathrm{W} / \mathrm{m} 2$

$\mathrm{W} / \mathrm{m} 2$

$\mathrm{W} / \mathrm{m} 2$

$\mathrm{W} / \mathrm{m} 2$

Mole

dim.

$\mathrm{kg} / \mathrm{m} 2$

$\mathrm{kPa}$

cm2

$\mathrm{cm} 2$

Mmol /m2/s

$\mu \mathrm{mol} / \mathrm{m} 2 / \mathrm{s}$

$\mathrm{W} / \mathrm{m} 2$

$\mathrm{W} / \mathrm{m} 2$

$\mathrm{W} / \mathrm{m} 2$

$\mathrm{W} / \mathrm{m} 2$

$\mathrm{W} / \mathrm{m} 2$

\section{Page 63}




\begin{tabular}{|c|c|c|}
\hline$q$ & Water vapor density & $\mathrm{g} / \mathrm{m} 3$ \\
\hline$q^{\prime}$ & Water vapor density fluctuation & $\mathrm{g} / \mathrm{m} 3$ \\
\hline $\mathrm{R}$ & Universal gas constant & $\mathrm{J} / \mathrm{mol} / \mathrm{K}$ \\
\hline$R^{\prime}$ & Conifer correction factor & dim. \\
\hline rho & Density of air & $\mathrm{kg} / \mathrm{m} 3$ \\
\hline rho (c) & Density of $\mathrm{CO} 2$ & $\mathrm{~kg} / \mathrm{m} 3$ \\
\hline s & Signal voltage from hygrometer & $\mathrm{mv}$ \\
\hline S & $\begin{array}{l}\text { Flux equivalent to the heat stored between } \\
\text { individual soil layers }\end{array}$ & $\mathrm{W} / \mathrm{m} 2$ \\
\hline $\mathrm{SH}$ & Specific humidity & $\mathrm{g} / \mathrm{kg}$ \\
\hline sSH & Standard deviation of specific humidity & $\mathrm{g} / \mathrm{kg}$ \\
\hline $\mathrm{T}^{\prime}$ & Temperature fluctuation & ${ }^{\circ} \mathrm{C}$ \\
\hline T_air & Air temperature & ${ }^{\circ} \mathrm{C}$ \\
\hline $\mathrm{TB}$ & Biomass temperature in STORAG & ${ }^{\circ} \mathrm{C}$ \\
\hline Tblw & Stem temperature of large trees (west site) & ${ }^{\circ} \mathrm{C}$ \\
\hline Tbmw & Stem temperature of medium trees (west site) & ${ }^{\circ} \mathrm{C}$ \\
\hline Tbsn & Stem temperature of small trees (north site) & ${ }^{\circ} \mathrm{C}$ \\
\hline Tbsw & Stem temperature of small trees (west site) & ${ }^{\circ} \mathrm{C}$ \\
\hline $\mathrm{TD}$ & Dry bulb temperature in STORAG & ${ }^{\circ} \mathrm{C}$ \\
\hline TOL & Thickness of organic layer in STORAG & $\mathrm{m}$ \\
\hline Ts & Soil temperature & ${ }^{\circ} \mathrm{C}$ \\
\hline Ts10avg & Average soil temperature at $10-\mathrm{cm}$ depth & ${ }^{\circ} \mathrm{C}$ \\
\hline Ts 75 avg & Average soil temperature at $75-\mathrm{cm}$ depth & ${ }^{\circ} \mathrm{C}$ \\
\hline $\mathrm{TW}$ & Wet-bulb temperature & ${ }^{\circ} \mathrm{C}$ \\
\hline $\mathrm{U}$ & Wind speed & $\mathrm{m} / \mathrm{s}$ \\
\hline $\mathrm{v}$ & Intercept of the krypton hygrometer calibration & $\mathrm{mv}$ \\
\hline$w^{\prime}$ & Vertical wind velocity & $\mathrm{m} / \mathrm{s}$ \\
\hline $\mathrm{x}$ & Path length of the hygrometer & $\mathrm{cm}$ \\
\hline $\mathrm{Xm}$ & Soil volumetric mineral fraction & fraction \\
\hline Xo & Soil volumetric organic soil fraction & fraction \\
\hline $\mathrm{Xw}$ & Soil volumetric water fraction & fraction \\
\hline$X W$ & Soil moisture content in STORAG & fraction \\
\hline $\mathrm{z}$ & Depth to soil heat flux plate & $\mathrm{m}$ \\
\hline $\mathrm{ZCQ}$ & $\begin{array}{l}\text { Control variable in STORAG; used to read two } \\
\text { variables: height of canopy and heightof net } \\
\text { pyrradiometer }\end{array}$ & $\mathrm{m}, \mathrm{m}$ \\
\hline zr & Reference height & $\mathrm{m}$ \\
\hline $\mathrm{ZR}$ & $\begin{array}{l}\text { Height of net radiation measurement in early } \\
\text { version of STORAG }\end{array}$ & $\mathrm{m}$ \\
\hline
\end{tabular}

\section{List of Acronyms}

$\begin{array}{ll}\text { AES } & \text { Atmospheric Environment Services } \\ \text { AFM } & \text { Airborne Fluxes and Meteorology } \\ \text { ASCII } & \text { American Standard Code for Information Interchange } \\ \text { ATI } & \text { Applied Technologies, Inc. } \\ \text { BOREAS } & \text { BOReal Ecosystem-Atmosphere Study } \\ \text { BORIS } & \text { BOREAS Information System } \\ \text { CCRS } & \text { Canada Centre for Remote Sensing } \\ \text { CD-ROM } & \text { Compact Disk-Read-Only Memory } \\ \text { CGR } & \text { Certified by Group } \\ \text { CO2 } & \text { Carbon dioxide } \\ \text { CPI } & \text { Certified by PI }\end{array}$




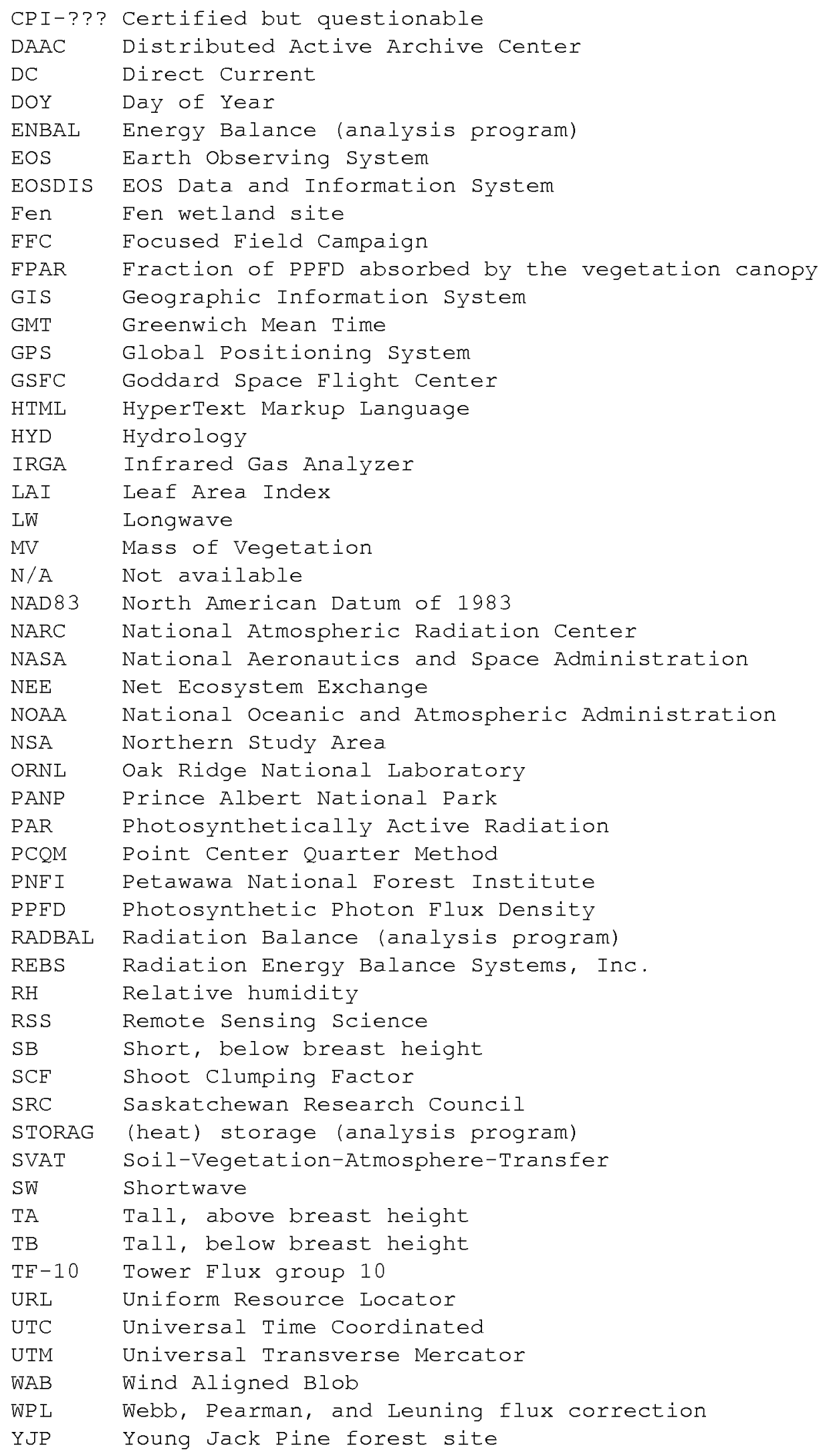

\section{Page 65}




\section{Document Information}

20.1 Document Revision Date

Written: 06-Jun-1998

Revised: 28-Sep-1999

20.2 Document Review Date(s)

BORIS Review: 25-Apr-1999

Science Review:

\subsection{Document ID}

\subsection{Citation}

When using these data, please include the following acknowledgment as well as citations of relevant papers in Section 17.2:

These data were provided by BOREAS Team TF-10; the primary consultants include:

Flux and meteorological data (YJP and Fen):

Dr. J. Harry McCaughey, Department of Geography, Queen's University, Kingston, ON, CANADA, K7L 3N6 (PI) and Dr. Peter M. Lafleur, Department of Geography, Trent University, Peterborough, ON, CANADA, K9J 7B8. Both investigators should be acknowledged in all future publications.

Fen biophysical data:

Dr. D.E. Jelinski, Department of Geography, Queen's University, Kingston, ON, CANADA, K7L 3N6 (PI).

YJP biophysical data:

Dr. J. Harry McCaughey, Department of Geography, Queen's University, Kingston, ON, CANADA, K7L 3N6 (PI).

If using data from the BOREAS CD-ROM series, also reference the data as:

McCaughey, J.H. and D.E. Jelinski, "Surface Energy and Water Balances of Forest and Wetland Subsystems in the Boreal Forest - Surface Atmosphere Links and Ecological Controls." In Collected Data of The Boreal Ecosystem-Atmosphere Study. Eds. J. Newcomer, D. Landis, S. Conrad, S. Curd, K. Huemmrich, D. Knapp, A. Morrell, J. Nickeson, A. Papagno, D. Rinker, R. Strub, T. Twine, F. Hall, and P. Sellers. CD-ROM. NASA, 2000.

Also, cite the BOREAS CD-ROM set as:

Newcomer, J., D. Landis, S. Conrad, S. Curd, K. Huemmrich, D. Knapp, A. Morrell, J. Nickeson, A. Papagno, D. Rinker, R. Strub, T. Twine, F. Hall, and P. Sellers, eds. Collected Data of The Boreal Ecosystem-Atmosphere Study. NASA. CD-ROM. NASA, 2000.

\subsection{Document Curator}

\subsection{Document URL}



gathering and maintaining the data needed and completing and reviewing the collection of information. Send comments regarding this burden estimate or any other aspect of this collection of information including suggestions for reducing this burden to Washington Headguarters Services, Directorate for Information Operations and Reports 1215 Jefferson

Davis Highway, Suite 1204, Arlington, VA 22202-4302, and to the Office of Management and Budget, Paperwork Reduction Project (0704-0188), Washington, DC 20503.

\begin{tabular}{|l|l|l|}
\hline 1. AGENCY USE ONLY (Leave blank) & 2. REPORT DATE & 3. REPORT TYPE AND DATES COVERED
\end{tabular}

4. TITLE AND SUBTITLE

November 2000

Technical Memorandum

Technical Report Series on the Boreal Ecosystem-Atmosphere Study (BOREAS) BOREAS TF-10 NSA-YJP Tower Flux, Meteorological, and Porometry Data

6. AUTHOR(S)

J. Harry McCaughey and Laura Liblik

Forrest G. Hall and Karl Huemmrich, Editors

7. PERFORMING ORGANIZATION NAME(S) AND ADDRESS (ES)

Goddard Space Flight Center

Greenbelt, Maryland 20771

5. FUNDING NUMBERS

923

RTOP: 923-462-33-01

9. SPONSORING / MONITORING AGENCY NAME(S) AND ADDRESS (ES)

10. SPONSORING / MONITORING AGENCY REPORT NUMBER

National Aeronautics and Space Administration

Washington, DC 20546-0001

TM-2000-209891

Vol. 208

\section{SUPPLEMENTARY NOTES}

J.H. McCaughey and L. Liblik: Queen's University, Kingston, Ontario;

K. Huemmrich: University of Maryland, NASA Goddard Space Flight Center, Greenbelt, Maryland

\begin{tabular}{l|l}
\hline 12a. DISTRIBUTION / AVAILABILITY STATEMENT & 12b. DISTRIBUTION CODE \\
Unclassified-Unlimited & \\
Subject Category: 43 & \\
Report available from the NASA Center for AeroSpace Information, \\
7121 Standard Drive, Hanover, MD 21076-1320. (301) $621-0390$.
\end{tabular}

13. ABSTRACT (Maximum 200 words)

The BOREAS TF-10 team collected tower flux and meteorological data at two sites, a fen and a young jack pine forest, near Thompson, Manitoba, Canada, as part of BOREAS. A preliminary data set was assembled in August 1993 while field testing the instrument packages, and at both sites data were collected from 15-Aug to 31-Aug. The main experimental period was in 1994, when continuous data were collected from the young jack pine site from 23-May to 20-Sep. Upon examination of the 1994 data set, it became clear that the behavior of the heat, water, and carbon dioxide fluxes throughout the whole growing season was an important scientific question, and that the 1994 data record was not sufficiently long to capture the character of the seasonal behavior of the fluxes. Thus, the young jack pine site was operated from 08-May to 07-Nov in 1996 in order to collect data from spring melt to autumn freeze-up. All variables are presented as 30-minute averages. Supporting data were also collected to describe the surface's state and to provide the information, in association with the flux data, to build SVAT models. For the young jack pine site, these supporting data included stomatal conductance measurements. The data are stored in tabular ASCII files.

14. SUBJECT TERMS

BOREAS, tower flux, meteorological data, porometry data.

15. NUMBER OF PAGES 66

16. PRICE CODE

\begin{tabular}{l|c|c} 
17. SECURITY CLASSIFICATION & 18. SECURITY CLASSIFICATION & 19. SECURITY CLASSIFICATION \\
OF REPORT & OFIS PAGE \\
Onclassified & Unclassified & Unclassified
\end{tabular}

20. LIMITATION OF ABSTRACT

UL


